\title{
Precio del carbón y dinámica laboral en Valledupar*
}

\author{
Recibido: diciembre, 18 de 2018 - Aprobado: abril, 19 de 2019
}

Doi: http:/ /dx.doi.org/10.12804/revistas.urosario.edu.co/economia/a.8146

\author{
Luis E. Arango ${ }^{\dagger}$ \\ Luz A. Flórez $\ddagger$ \\ María A. Olarte-Delgado§
}

\section{Resumen}

En esta investigación se realiza un análisis del mercado laboral en Valledupar en el periodo 2007-2017 encontrando que, a partir de la caída de los precios del carbón en 2014, este se deterioró de manera significativa; así, durante este periodo creció la tasa de desempleo, especialmente entre los más educados, las mujeres y los jóvenes. Los resultados econométricos confirman que los cambios en los precios del carbón tienen un efecto positivo en la participación laboral y en los salarios reales; adicionalmente, se encuentra que los retornos a la educación superior en Valledupar son menores en comparación con otras ciudades del país.

Palabras clave: Valledupar, desempleo, ocupación, participación laboral, retornos a la educación.

Clasificación JEL: J21, J23, J24, J30, R11.

* Las opiniones contenidas en el presente artículo no representan al Banco de la República ni a su Junta Directiva. Se agradecen los comentarios y sugerencias de Jaime Bonet, Leonardo Bonilla y Luis Armando Galvis.

† Investigador principal del Banco de la República. Correo electrónico: laranth@banrep.gov.co. ORCID: 0000-0003-0260-5997.

‡ Investigadora del Banco de la República. Correo electrónico: lflorefl@banrep.gov.co ORCID: 0000-0001-9813-6720.

$\S$ Profesional especializado del Banco de la República. Correo electrónico: mariale. olarte@gmail.com. ORCID: 0000-0003-2680-6523.

Para citar este artículo: Arango, L.E., Flórez, L.A., \& Olarte-Delgado, M.A. (2019). Precio del carbón y dinámica laboral en Valledupar. Revista de Economía del Rosario 22(2), 313-370. Doi: http://dx.doi.org/10.12804/revistas.urosario.edu.co/economia/a.8146 


\title{
The Price of Coal and Labour Dynamics in Valledupar
}

\begin{abstract}
In this paper, we present a description of the labour market in Valledupar for the period 2007-2017. We find that after the fall of coal prices, the labour market has presented a significant deterioration, reflected in the increase of unemployment rate, especially for the most educated, women and youth. The econometric results confirm that changes in coal prices have a positive and significant effect in labour participation and real wages. Moreover, we find that the return of higher education in Valledupar is lower, compared to the rest of cities in Colombia.
\end{abstract}

Keywords: Valledupar, unemployment, occupation, labour participation, returns to education. JEL Classification: J21, J23, J24, J30, R11.

\section{Preço do carvão e dinâmica do mercado de trabalho em Valledupar}

\begin{abstract}
Resumo
Se realiza uma descrição do mercado laboral em Valledupar no período 2007-2017 encontrando que, a partir da caída dos preços do carvão desde 2014, este se deteriorou de maneira significativa, refletindo-se em uma maior taxa de desemprego especialmente dos mais educados, as mulheres e os jovens. Os resultados econométricos confirmam que as mudanças nos preços do carvão têm um efeito positivo na participação laboral e nos salários reais. Adicionalmente, encontra-se que os retornos à educação superior em Valledupar são menores respeito de outras cidades do país, especialmente para os universitários.

Palavras-chave: Valledupar, desemprego, ocupação, participação laboral, retornos à educação. Classificação JEL: J21, J23, J24, J30, R11.
\end{abstract}




\section{Introducción}

A juzgar por el comportamiento de su tasa de desempleo (TD), el mercado laboral de Valledupar en los últimos años ha sufrido un deterioro importante, como se observa en la figura 1. Dicho deterioro tiene explicaciones tanto por el lado de la oferta como de la demanda de trabajo, en un período en el que las cotizaciones internacionales del carbón, bien primario producido mayormente en el departamento del Cesar, tuvieron una caída importante. Es muy probable que la asociación entre precios de bienes primarios y desempeño del mercado laboral sea un argumento recurrente entre los analistas, los diseñadores y ejecutores de la política económica y los propios actores del mercado de trabajo, pero, hasta donde sabemos, este artículo es el primero en explorar dichos efectos en la oferta y la demanda de trabajo de una ciudad o grupo de ciudades tratando de entender los mecanismos en que se produce dicha asociación.

La figura 1 presenta también las tasas de desempleo (TD) de Riohacha, de las otras capitales de la costa (Caribe, Barranquilla, Cartagena, Santa Marta, Montería y Sincelejo), y del resto de 16 ciudades $^{1}$ entre 2008 y 2017. Se observa que la TD de Riohacha es más volátil que la de Valledupar, la cual registraba una dinámica muy similar a la de las 16 capitales restantes, excepto en los últimos tres años. Contrario a lo observado en Valledupar y Riohacha, la TD de las otras cinco ciudades del Caribe se mantuvo relativamente estable, con una leve reducción a finales de 2017, mientras que la de las 16 ciudades restantes mostró un deterioro moderado, principalmente desde el segundo semestre de 2016.

La dinámica de menor crecimiento de la producción observada en la economía colombiana durante los últimos años está vinculada con el choque adverso sufrido por el precio de los bienes primarios (petróleo y carbón, fundamentalmente). Las economías de Valledupar y Riohacha no fueron la excepción y también resultaron afectadas por la caída en los precios del carbón. Sin embargo, dado que La Guajira es un departamento con características

1 El Departamento Administrativo Nacional de Estadística (DANE) utiliza las 23 principales ciudades del país como referencia urbana de los indicadores del mercado laboral. Las ciudades capitales de la costa Caribe, excluyendo Valledupar y Riohacha son: Barranquilla, Cartagena, Santa Marta, Montería y Sincelejo. La isla de San Andrés no se incluye en el análisis por las particularidades de la legislación y por la disponibilidad de información. Por su parte, el resto de ciudades son: Bogotá, Medellín, Cali, Bucaramanga, Tunja, Pasto, Florencia, Neiva, Ibagué, Quibdó, Cúcuta, Armenia, Pereira, Manizales, Villavicencio y Popayán, con sus respectivas áreas metropolitanas, cuando es el caso, de acuerdo con la metodología del DANE. 
muy específicas (Meisel, 2007) que hacen el análisis del mercado laboral en Riohacha mucho más complejo, este documento enfoca su análisis en Valledupar, aunque utiliza como referente a Riohacha, al conjunto del resto de ciudades capitales de la costa Caribe (sin la isla de San Andrés) y a las 16 ciudades restantes que forman parte del total de 23 ciudades pertenecientes a las áreas urbanas reportadas por el Departamento Administrativo Nacional de Estadística (DANE).

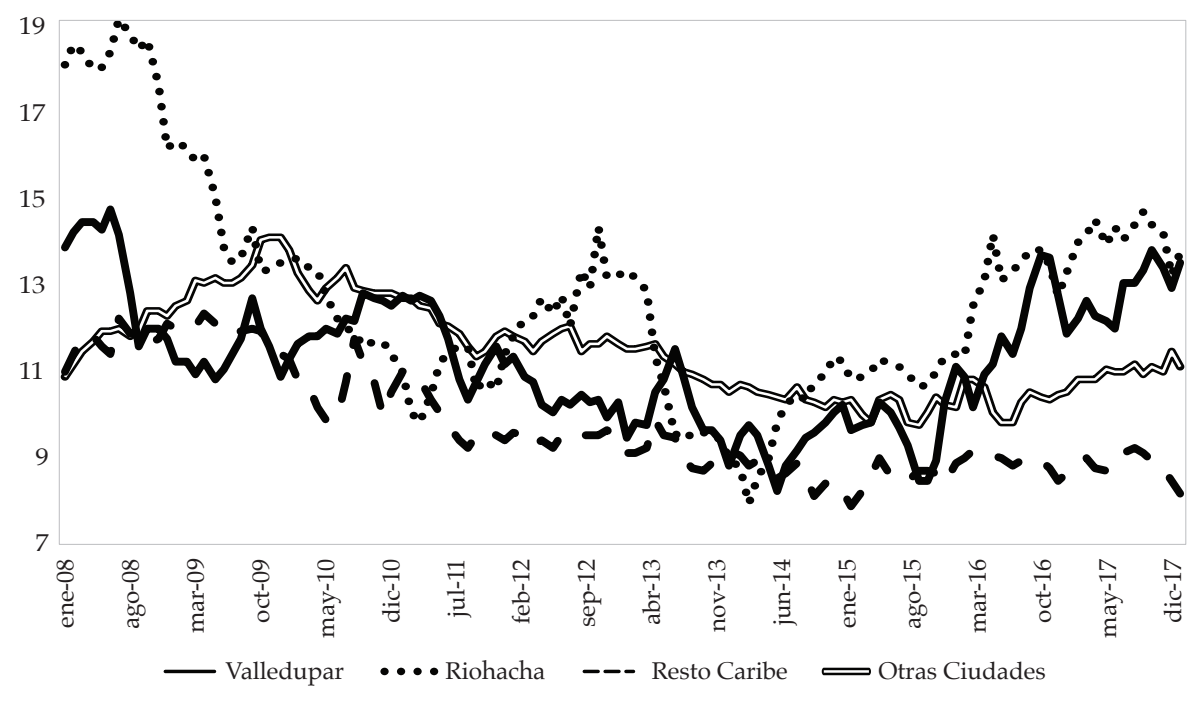

Figura 1. Tasa de desempleo

Fuente: Departamento Administrativo Nacional de Estadística (DANE), Gran Encuesta Integrada de Hogares (GEIH). Cálculos de los autores.

Desde 2015 existe una diferencia significativa de participación laboral entre Valledupar y el resto de ciudades del país, superior a la observada en Riohacha y en otras ciudades de la costa Caribe. Sin embargo, la brecha frente a estas últimas parece haberse reducido en el último año. En relación con la demanda de trabajo, las diferencias entre ciudades son mucho más marcadas; si bien durante 2009 y 2010, Valledupar y Riohacha tuvieron un crecimiento importante, en línea con la dinámica de crecimiento de los precios del carbón, esta tendencia cambió a partir de mediados de 2015. El deterioro de la demanda laboral se ha observado claramente en Valledupar y, recientemente, en Riohacha, de ahí que la diferencia en las tasas de ocupación (TO) de estas dos ciudades se esté ampliando, no sólo con respecto a 16 ciudades sino, también, con las cinco capitales de la costa Caribe. Esta caída en la demanda laboral se ha presentado con mayor énfasis en las personas más educadas y es particularmente más pronunciada en el mercado laboral de Valledupar. 
A pesar de la caída de la participación laboral, el mayor deterioro de la demanda de trabajo en casi todas las ciudades se ha traducido en un aumento importante de la tasa de desempleo, principalmente en Valledupar y Riohacha. Si bien el aumento en la TD en estas dos capitales ha sido generalizado en todos los niveles de escolaridad, se destaca el aumento en el desempleo de las personas más educadas de ambas ciudades frente al promedio de 16 ciudades, e incluso al promedio de las capitales de la costa Caribe.

Este documento tiene dos objetivos. En primer término, busca describir el comportamiento del mercado laboral en Valledupar ${ }^{2}$ durante el periodo 2007-2017; 3 en tal sentido, se busca entender por qué la TD de Valledupar ha aumentado, especialmente para las personas con al menos un año de educación superior. Esto es distinto de lo sucedido en 16 ciudades donde estos dos grupos han tenido TD relativamente similares. Lo anterior, se ha reflejado en menores ingresos de los más educados en Valledupar en comparación con el promedio de las 16 ciudades restantes. Además, estas divergencias en los salarios, especialmente de este grupo poblacional, podrían deberse a diferencias de productividad de la mano de obra o de la vocación productiva de las ciudades.

Considerando que el incremento de la TD de Valledupar ha sido notable en los últimos dos años, se explora el efecto de los cambios recientes de los precios del carbón. Por ello, el segundo objetivo es ahondar en los determinantes de la oferta y la demanda de mano de obra, analizada - esta última- mediante ecuaciones de ingresos. En tal sentido, se presenta evidencia del efecto de los precios del carbón en estas dos dimensiones del mercado laboral. El análisis se efectúa utilizando la información mensual de la Gran Encuesta Integrada de Hogares (GEIH) del DANE entre enero de 2007 y diciembre de $2016 .{ }^{4}$

No son muchos los estudios sobre el mercado laboral de las ciudades, lo cual oculta la amplia heterogeneidad regional observada en el país. Arango (2013) explora la heterogeneidad en la participación, la ocupación y el desempleo entre ciudades, construyendo rangos para estas variables como la

2 Según las proyecciones de población del DANE para 2017, la población de Valledupar es de, aproximadamente, 473.251 habitantes. Si tenemos en cuenta que las ciudades intermedias tienen entre 50 mil y 1 millón de habitantes (Cepal, 1998), Valledupar puede ser catalogada como tal.

3 Este artículo deja de lado temas fundamentales como la informalidad laboral, la duración del desempleo y el efecto de la migración de venezolanos, tan sensible en el área geográfica analizada.

4 Las regresiones utilizan información del periodo 2009-2016 para el cual los datos de ingresos imputados e IPC para cada una de las 23 ciudades estaban disponibles en la página del DANE. 
diferencia entre el valor más alto correspondiente a una ciudad y el valor más bajo correspondiente a otra en el mismo momento. El autor encuentra que los rangos promedio de cada una de estas variables pueden superar 13 puntos porcentuales (pp), confirmando la existencia de la dispersión regional. Además, concluye que esta dispersión se puede explicar por las diferencias en las preferencias de las personas en las distintas regiones y en las estructuras productivas de las ciudades, más que por las normas y rigideces del mercado laboral, que son las mismas para todo el país. Lo anterior hace que las respuestas a choques de los mercados laborales regionales sean heterogéneas. Según el autor, hay ciudades donde el análisis se debe enfocar en la oferta laboral, como en Ibagué, Bucaramanga y Montería; otras ciudades, como Quibdó, Popayán, Cartagena, Manizales, y Valledupar, requieren un análisis más detallado de la demanda de trabajo. Cárdenas et al. (2015) analiza la heterogeneidad de las tasas de desempleo en las 23 principales ciudades de Colombia, utilizando una metodología de análisis factorial múltiple. Según los autores, dentro de los elementos que explican esta heterogeneidad se encuentran la calificación de la mano de obra, la estructura etaria y los incentivos a la participación laboral. Trabajos enfocados directamente en Valledupar han resaltado la importancia del sector de lácteos como el principal generador de empleo en la ciudad (Guzmán, 2013), mientras que otros, como Bonet y Ayala (2017), han estudiado las dificultades en el cumplimiento del saneamiento fiscal, luego del Acuerdo de Restructuración de Pasivos firmado en 2014.

Un análisis del mercado laboral por ciudades en Colombia fue realizado por Arango y Flórez (2017). ${ }^{5}$ Estos autores realizan un estudio sobre el impacto del salario mínimo para las 23 ciudades principales y dan cuenta de los efectos heterogéneos de esta política nacional. Los autores no encontraron efectos significativos del salario mínimo sobre la informalidad para el caso de Valledupar; sin embargo, encuentran que la actividad económica, la tasa de interés y los costos laborales no salariales sí tienen efectos importantes.

El Boletín Económico Regional (BER) del Banco de la República (2017), examina el mercado laboral por regiones. Así, por ejemplo, para el segundo trimestre de 2017 mostró una tasa de desempleo de la región Caribe de 9,7\%, superior en $0,7 \mathrm{pp}$ a la del total nacional. Si bien estos informes examinan la coyuntura reciente del mercado laboral regional, no alcanzan a explorar

5 De manera similar, Arango y Flórez (2016) realizan estimaciones de los principales determinantes de la tasa de desempleo estructural para las 4 principales ciudades: Bogotá, Barranquilla, Medellín y Cali, en los cuales encuentran una amplia heterogeneidad en la magnitud de los determinantes, como el salario mínimo, la tasa de vacantes, los costos laborales no salariales y algunas variables demográficas, entre otras. 
los determinantes de la oferta y demanda laboral por ciudades, de ahí la importancia del presente trabajo, el cual constituye un elemento adicional al entendimiento de la heterogeneidad del mercado de trabajo en Colombia.

El artículo está compuesto por cinco secciones. La primera sección presenta de manera breve la evolución reciente de la actividad económica del departamento del Cesar, señalando los principales renglones de la producción del departamento y de su capital. La segunda describe el comportamiento de la oferta laboral de distintos grupos poblacionales (edad, nivel educativo y género); en esta sección se estima una ecuación de participación para cada una de las áreas geográficas analizadas. La tercera sección describe el comportamiento de la demanda laboral, mientras que la cuarta sección analiza el comportamiento del desempleo y los salarios, y estima la ecuación de Mincer que permite entender las diferencias salariales entre Valledupar y el resto de dominios geográficos. Finalmente, la sección 6 concluye y deriva algunas implicaciones de política.

\section{La producción del Cesar}

En 2016 el Producto Interno Bruto (PIB) del Cesar y de La Guajira representó, respectivamente, 1,9\% y 1,0 \% del PIB nacional y $12,7 \%$ y $6,8 \%$ del PIB de la región Caribe. ${ }^{6}$ En términos de población, estos departamentos, representan $2,2 \%$ y $2,1 \%$ de la población nacional, y, $10 \%$ y 9,4\% de la población de la región Caribe, respectivamente (DANE, 2016).

Al comienzo del presente siglo, la economía del Cesar tuvo un crecimiento del PIB levemente superior al promedio nacional, aunque en los últimos años se ha moderado bastante al pasar de un promedio de 7,8\% entre 2001 y 2007 a uno de 4,1\% entre 2008 y 2017. En 2013 registró un crecimiento negativo de $0,8 \%$, seguido de una ligera recuperación durante 2015 y 2016 (figura 2). Este comportamiento no se observó en el agregado de la región Caribe que, por el contrario, tuvo un crecimiento de $5,1 \%$ anual en 2013, muy cercano al promedio nacional.

6 En esta región los datos de la GEIH solo incluyen los departamentos de Atlántico, Bolívar, Córdoba, La Guajira, Magdalena, Sucre y Cesar. No se incluye la parte insular correspondiente al archipiélago de San Andrés, Providencia y Santa Catalina, debido a la disponibilidad de información y a la legislación especial sobre el mercado laboral en las islas. 

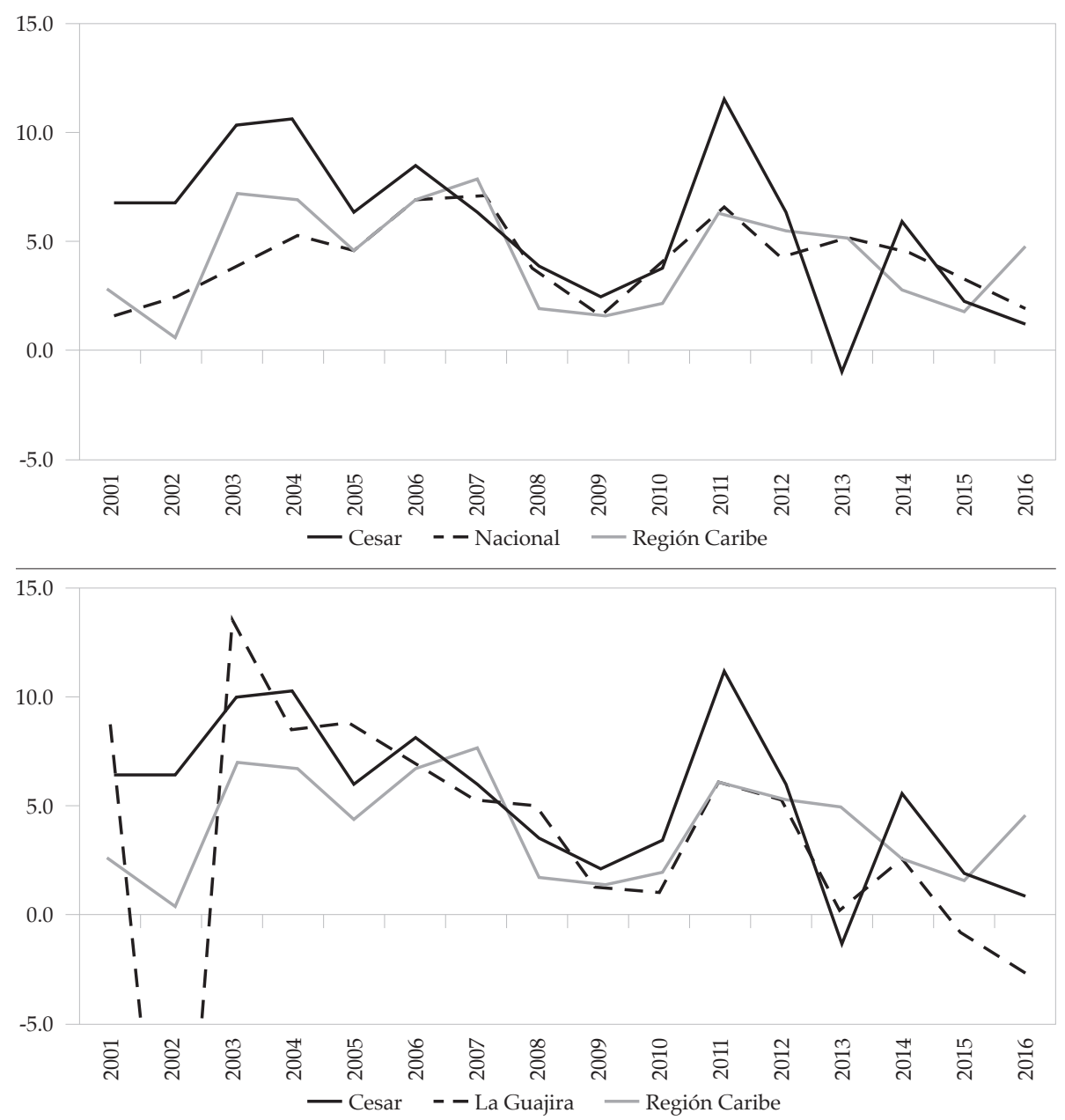

Figura 2. Variación porcentual anual del PIB nacional, la región Caribe y los departamentos del Cesar y La Guajira.

Fuente: elaboración propia con datos del Departamento Administrativo Nacional de Estadística (DANE).

La menor dinámica reciente del Cesar y La Guajira está relacionada, en buena medida, con la evolución de los precios del carbón en los mercados internacionales dada su dependencia de la explotación de este recurso natural, a diferencia de Bolívar y Atlántico, cuyas actividades principales son la industria y los servicios financieros. Las economías de los departamentos de Córdoba, Magdalena y Sucre, por su parte combinan una serie de actividades entre las que se destacan los servicios sociales y comunales, el comercio y la agricultura. 
Pese a la perdida de importancia del sector agrícola, la ganadería sigue siendo fundamental en el departamento del Cesar. Según el inventario pecuario nacional de 2016 realizado por el Instituto Colombiano Agropecuario, este es el sexto departamento con el mayor número de cabezas de ganado bovino (1.357.512 cabezas) y es, además, el quinto productor de leche del país (después de Antioquia, Cundinamarca, Boyacá y Córdoba, según el censo agropecuario de 2014). Igualmente, el Cesar es el segundo departamento, después del Meta, con el mayor número de hectáreas sembradas de palma de aceite (76.122 ha) las cuales representaron alrededor de $38 \%$ del total del área cultivada del departamento, seguido del maíz tradicional (33.500 ha), el café (30.282 ha) y el arroz mecanizado (14.453 ha). Este último se produce principalmente en la capital ( $21 \%$ del total del departamento).

Valledupar es una ciudad de vocación agropecuaria ubicada en medio de las zonas de explotación carbonífera más importantes del país: el Cerrejón, en el departamento de La Guajira, y la Jagua de Ibirico-La Loma al sur del departamento del Cesar. La empresa Drummond emplea en el proyecto carbonífero La Loma más de 6.000 personas de manera directa y más de 3.500 contratistas (Drummond, 2018); el grupo Prodeco emplea más de 4.600 trabajadores en la mina La Jagua (El Heraldo, 2017) y el Cerrejón cuenta con más de 5.000 personas (La República, 2018). Si bien la actividad carbonífera no emplea directamente la mayoría de la mano de obra de la región, su relación indirecta con otras actividades económicas sí explica en buena medida la dinámica del mercado laboral en dichas zonas.

Para tener una noción de la importancia de los efectos del choque de los precios de los bienes primarios observado desde 2013, en los departamentos del Cesar y La Guajira, debe tenerse en cuenta que el primero tiene una participación de 60,1\% en la explotación de carbón nacional, seguida por el departamento de La Guajira cuya contribución es del 34,1\% según el Boletín Económico Regional (BER) de la costa Caribe publicado por el Banco de la República (2017). Esto indica que, en suma, estos dos departamentos aportan el 94,2\% de la explotación de carbón en el país.

La figura 3 muestra la producción de carbón de la Región Caribe y los precios internacionales desde 2012. Como se puede observar, luego de los altos precios del carbón observados en 2012, estos cayeron drásticamente hasta principios de 2016. Comparando el precio promedio del carbón en 2012 frente al precio mínimo que alcanzó en el primer semestre de 2016, se registra una caída de los precios del carbón de $48 \%$. La producción también disminuyó, aunque para finales de 2017 tanto los precios como la producción parecían recuperarse. Así las cosas, el choque observado hasta finales de 2015 de los 
precios del carbón tuvo un efecto negativo en el crecimiento tanto del departamento del Cesar como de La Guajira (figura 3). De igual manera, afectó negativamente el comportamiento del mercado laboral de ambos departamentos y sus capitales, especialmente desde 2015.

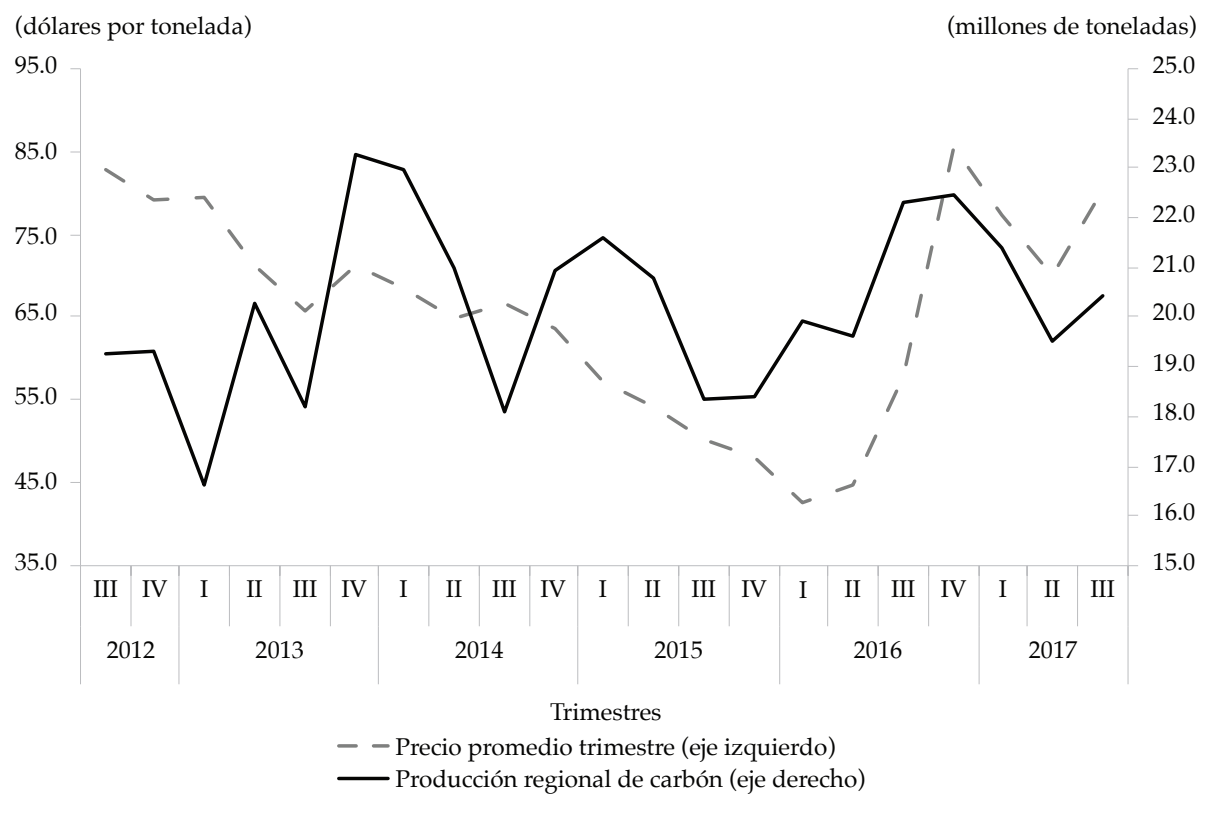

Figura 3. Carbón: Producción en la región Caribe y precio promedio

Fuente: Banco de la República, Boletín Económico Regional (BER), tercer trimestre de 2017.

\section{Participación laboral}

En esta sección, se presenta una caracterización de la oferta laboral en la ciudad de Valledupar para el periodo 2007-2017, utilizando la Gran Encuesta Integrada de Hogares (GEIH), comparando los datos de esta ciudad con los de los otros tres grupos de ciudades señalados. Como medida de oferta, utilizamos la tasa global de participación (TGP), definida como el porcentaje de la población en edad de trabajar (PET) que participa activamente del mercado laboral, ya sea como ocupada o desempleada, es decir, que busca una ocupación. El análisis se realiza para distintos grupos poblacionales dependiendo de los años de educación aprobados, la edad y el género.

Como se observa en la figura 4, desde 2008 y hasta mediados de 2014, la participación laboral de la ciudad de Valledupar era muy similar a la de las demás ciudades de la costa Caribe (resto Caribe), pero bastante inferior 
a la de Riohacha y a la de las otras 16 ciudades del país (otras ciudades). A partir de entonces y hasta mediados de 2016, periodo en el cual se observa una caída marcada en los precios del carbón, la participación laboral de Valledupar empezó a caer, ampliando la brecha frente al resto de ciudades de la costa. Sin embargo, en el último año y medio, la participación se ha venido recuperando hasta alcanzar niveles similares a los del resto del Caribe, excluyendo a Riohacha. A pesar de lo anterior, durante el periodo analizado, la brecha en participación de Valledupar frente al resto de 16 ciudades del país es bastante significativa, incluso superior a la observada en Riohacha o las ciudades de la costa Caribe.

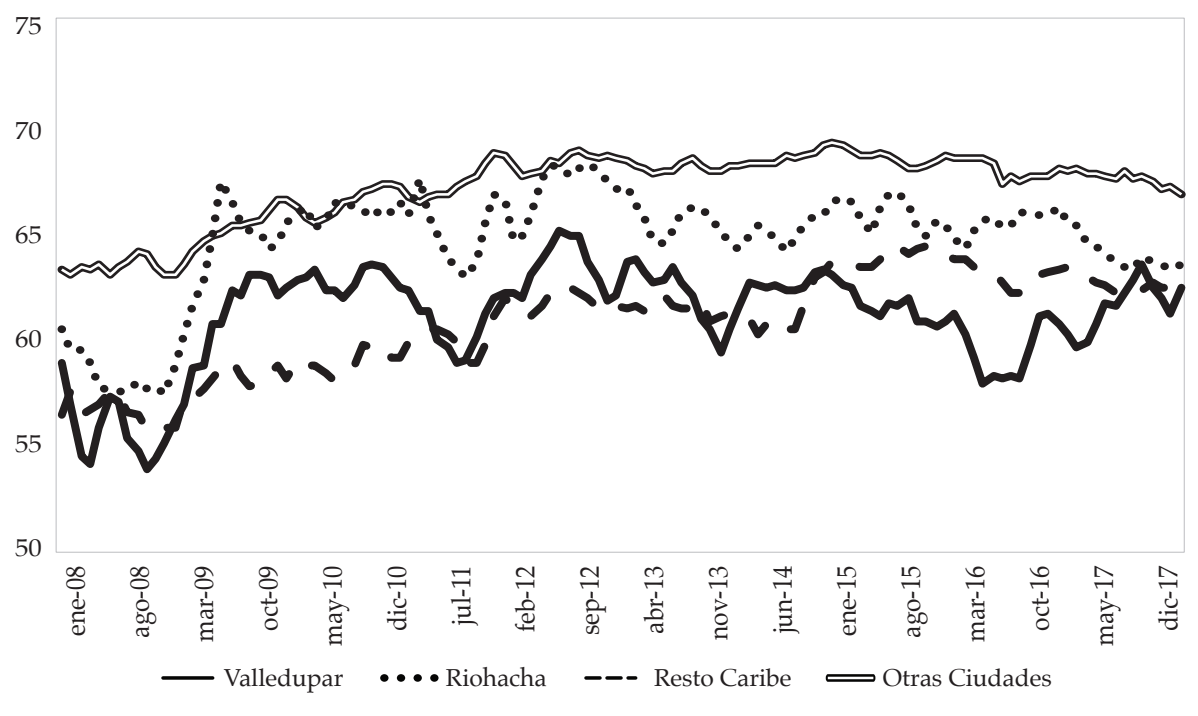

Figura 4. Tasa global de participación

Fuente: elaboración propia con datos del Departamento Administrativo Nacional de Estadística (DANE), Gran Encuesta Integrada de Hogares (GEIH).

Antes de analizar la participación laboral según el nivel de educación es importante observar el cambio que ha tenido la composición educativa de la PET. La figura 5 presenta la proporción de personas sin educación superior, es decir, que como máximo finalizaron la educación media. Como se observa, el proceso de transformación de la fuerza laboral ha sido similar en los cuatro grupos de ciudades analizados. Prácticamente, desde 2009 la proporción de personas sin educación superior ha venido cayendo, aunque a un ritmo menor desde 2014. Por ejemplo, entre enero de 2009 y junio de 2014 la caída en la proporción de personas sin educación superior fue bastante marcada 
en Valledupar y Riohacha (1,3 pp y 1,5 pp, respectivamente), pero a partir de julio de 2014, esta caída ha sido más moderada ( 0,5 pp y 1,1 pp respectivamente) como se observa en la tabla 1.

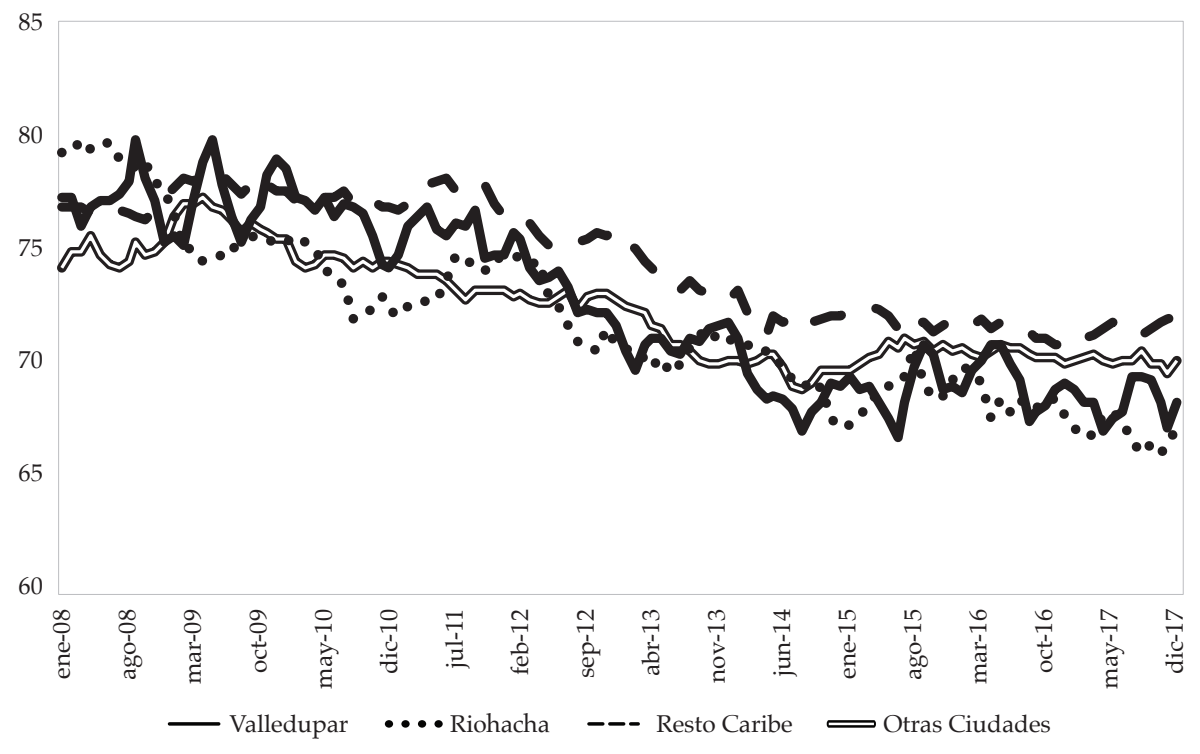

Figura 5. Personas sin educación superior como proporción de la PET

Fuente: elaboración propia con datos del Departamento Administrativo Nacional de Estadística (DANE), Gran Encuesta Integrada de Hogares (GEIH).

Tabla 1. Variación de personas sin educación superior como proporción de la PET (pp)

\begin{tabular}{ccccc}
\hline Periodo & Valledupar & Riohacha & Resto Caribe & Otras ciudades \\
\hline 2009:1-2017:12 & $-1,0$ & $-1,3$ & $-0,6$ & $-0,5$ \\
2009:1-2014:6 & $-1,3$ & $-1,5$ & $-0,7$ & $-0,8$ \\
2014:7-2017:12 & $-0,5$ & $-1,1$ & $-0,3$ & 0,0 \\
\hline
\end{tabular}

Fuente: elaboración propia con datos del Departamento Administrativo Nacional de Estadística (DANE), Gran Encuesta Integrada de Hogares (GEIH).

A pesar de esta transformación paralela de la mano de obra entre ciudades, las diferencias en participación son significativas. La figura 6 (paneles A y B) presenta la TGP de las personas con y sin educación superior. Como es de esperarse, la participación laboral de las personas más educadas es mayor que la de las menos educadas. No obstante, desde 2014 sobresale la 
caída en la participación laboral de las personas sin educación superior en Valledupar frente a las de otras ciudades de la costa Caribe e incluso frente al resto de 16 ciudades (panel C).
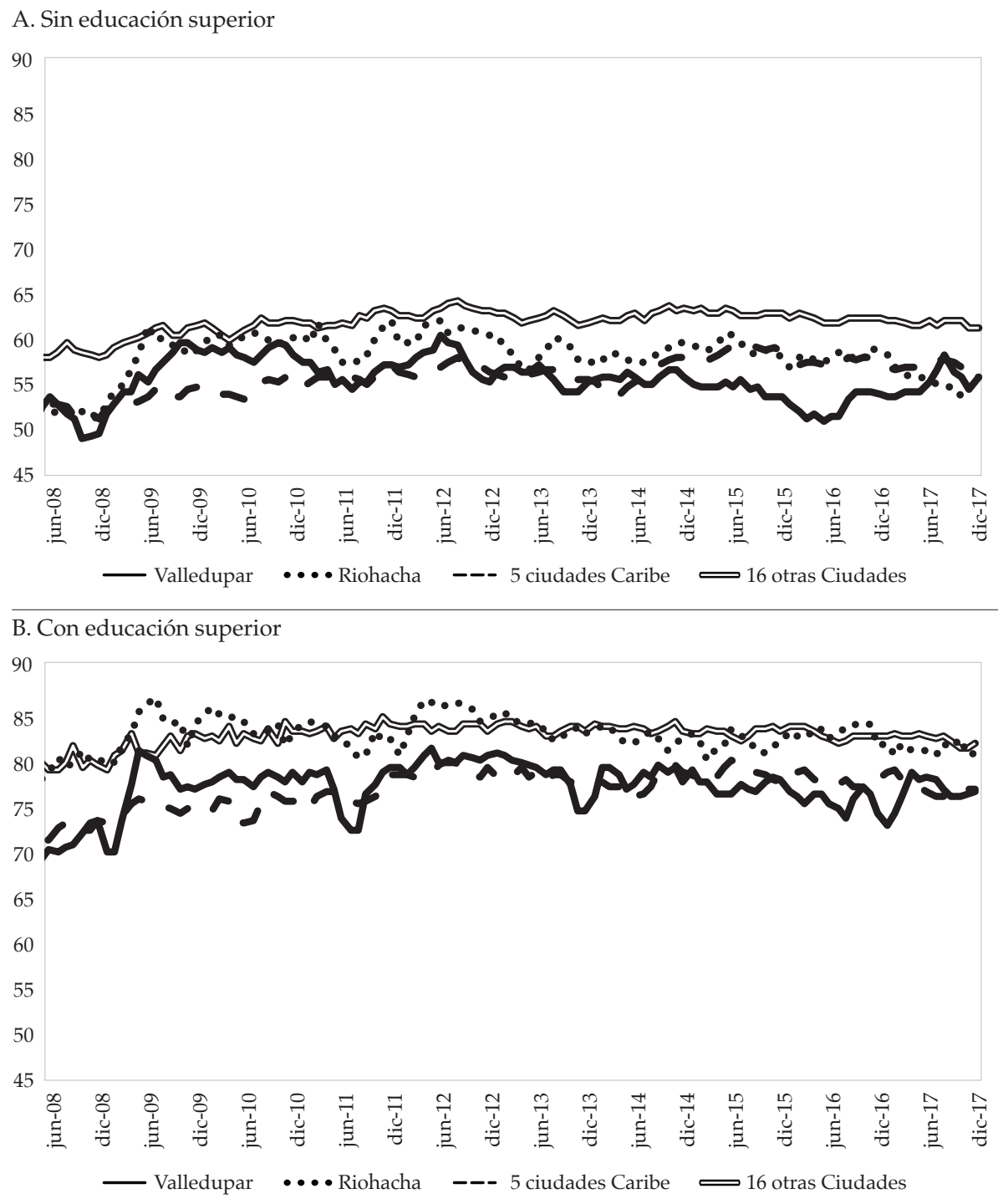


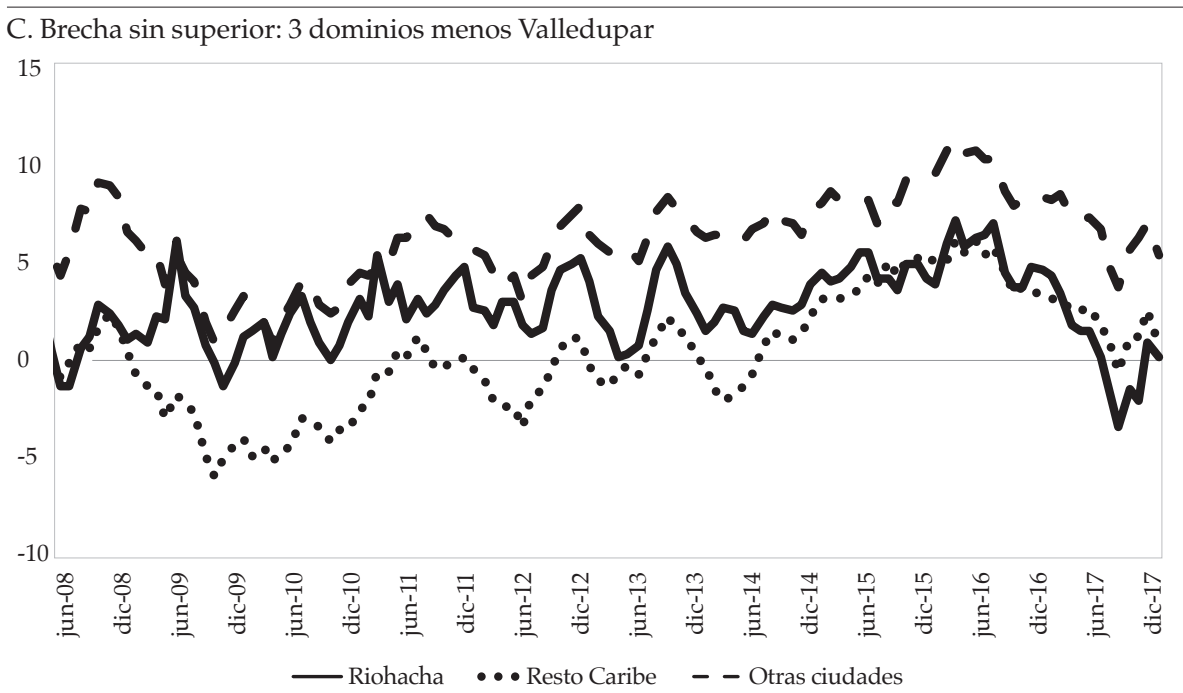

D. Brecha con superior: 3 dominios menos Valledupar

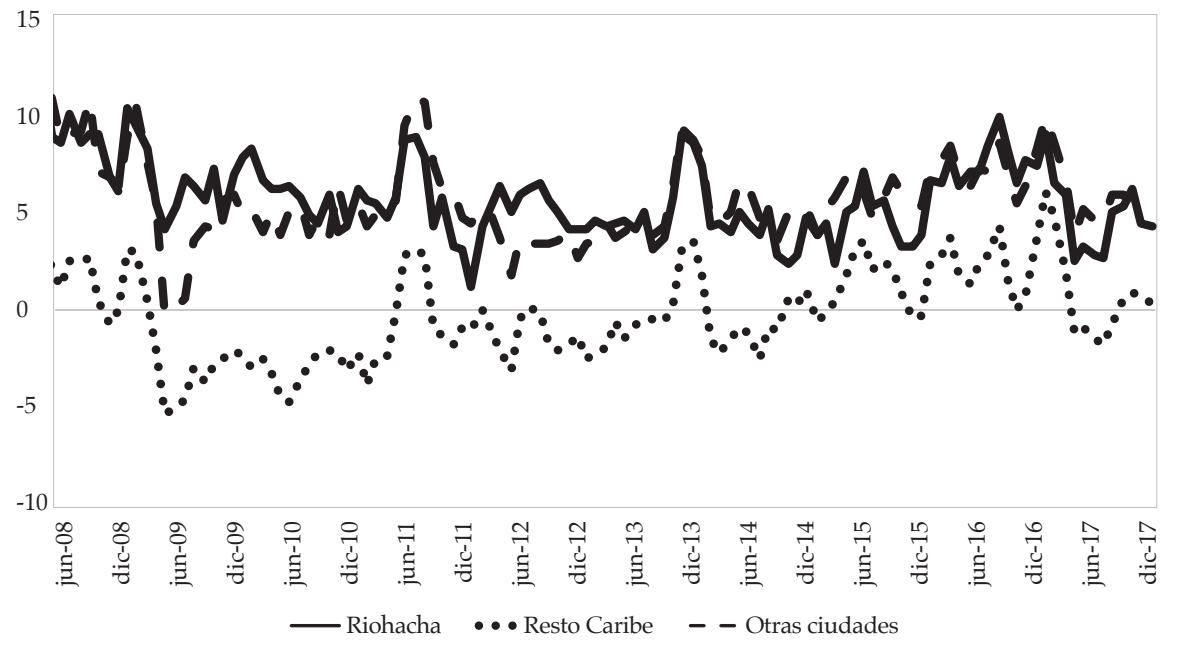

Figura 6. Participación laboral por nivel educativo

Fuente: elaboración propia con datos del Departamento Administrativo Nacional de Estadística (DANE), Gran Encuesta Integrada de Hogares (GEIH).

Si bien durante 2017 se produjo una corrección importante de este comportamiento, aún sigue existiendo una brecha de participación considerable en Valledupar frente al resto de las 16 ciudades. En el caso de las personas con educación superior, la trayectoria de participación en Valledupar es similar a la observada en las ciudades de la región Caribe, excluyendo a Riohacha. No obstante, frente al promedio de 16 ciudades y Riohacha, la brecha en participación de Valledupar es significativa (Panel D, figura 6). 
Por género se observa que, en general, la participación laboral de las mujeres es inferior a la de los hombres. Arango, Castellani y Lora (2017) explican la menor participación femenina en el mercado laboral colombiano mediante el esquema de incentivos, el bajo acceso a servicios de cuidado infantil y la vocación productiva de los vecindarios, etc. En el panel A de la figura 7, se observa la baja participación laboral de las mujeres en Valledupar y en las cinco ciudades restantes de la costa Caribe; por ello, la brecha de participación de Riohacha y el promedio de las 16 ciudades con respecto a Valledupar es

\section{A. Mujeres}

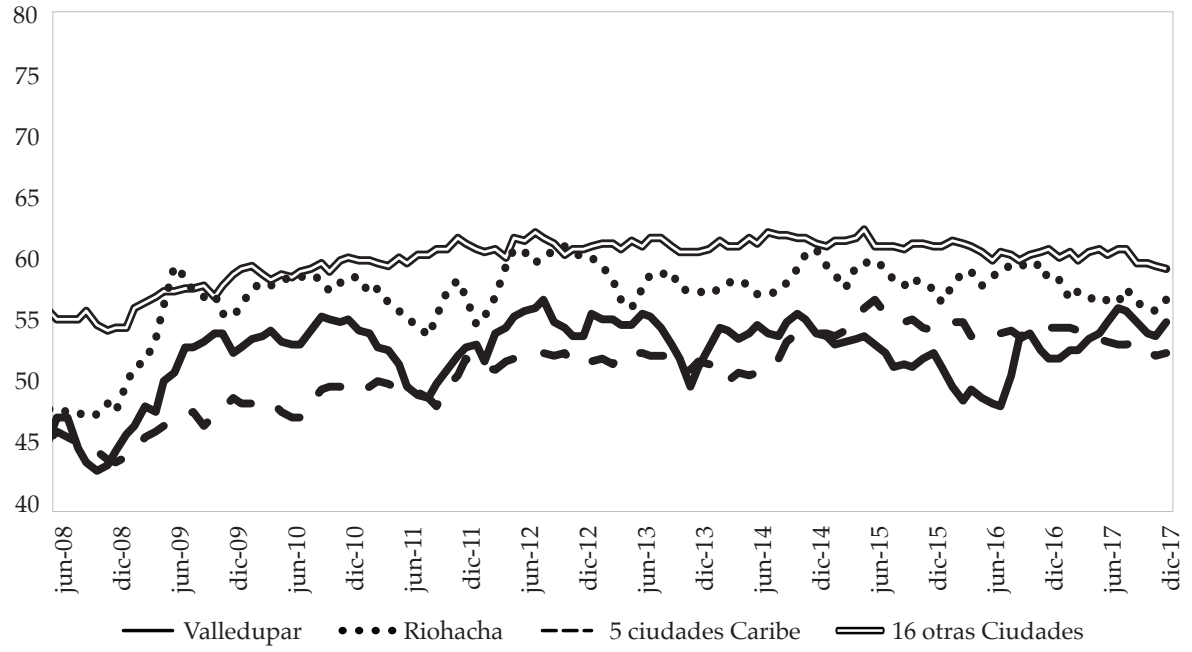

\section{B. Hombres}

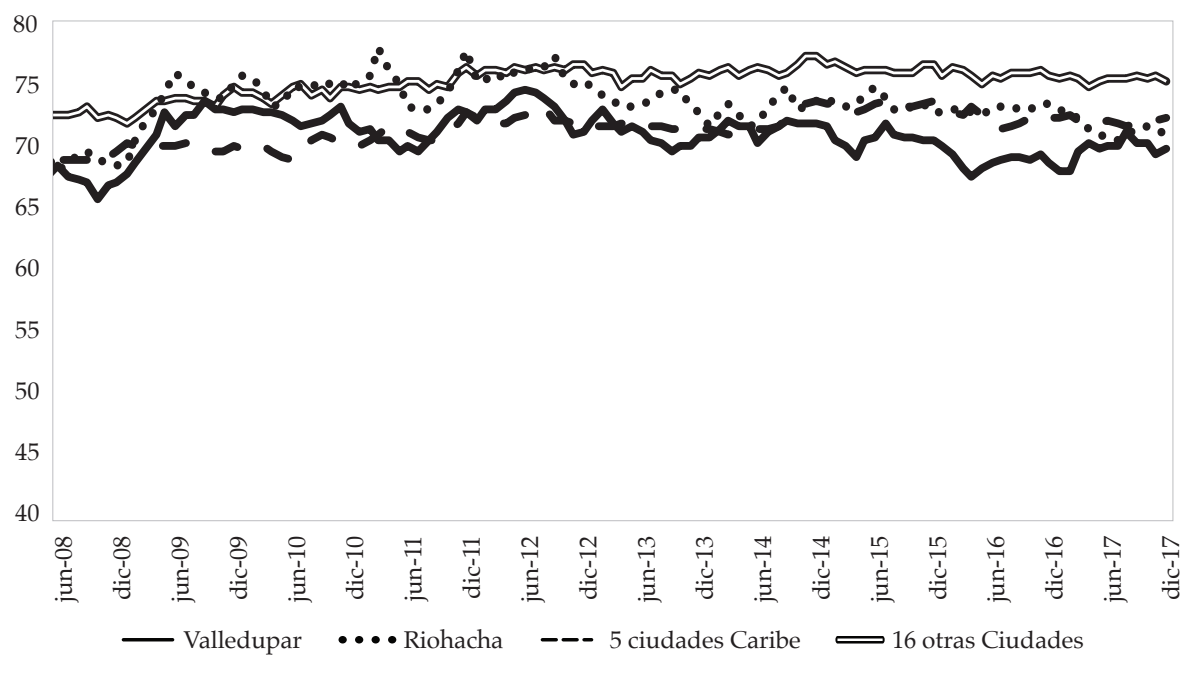




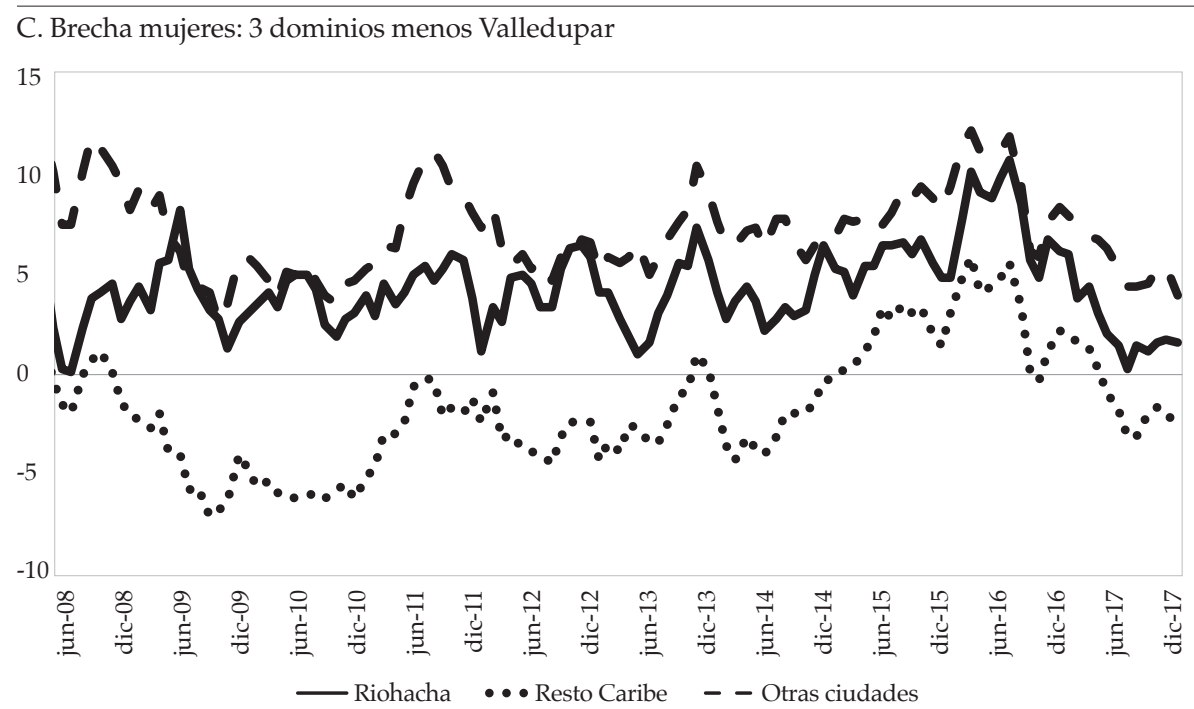

D. Brecha hombres: 3 dominios menos Valledupar

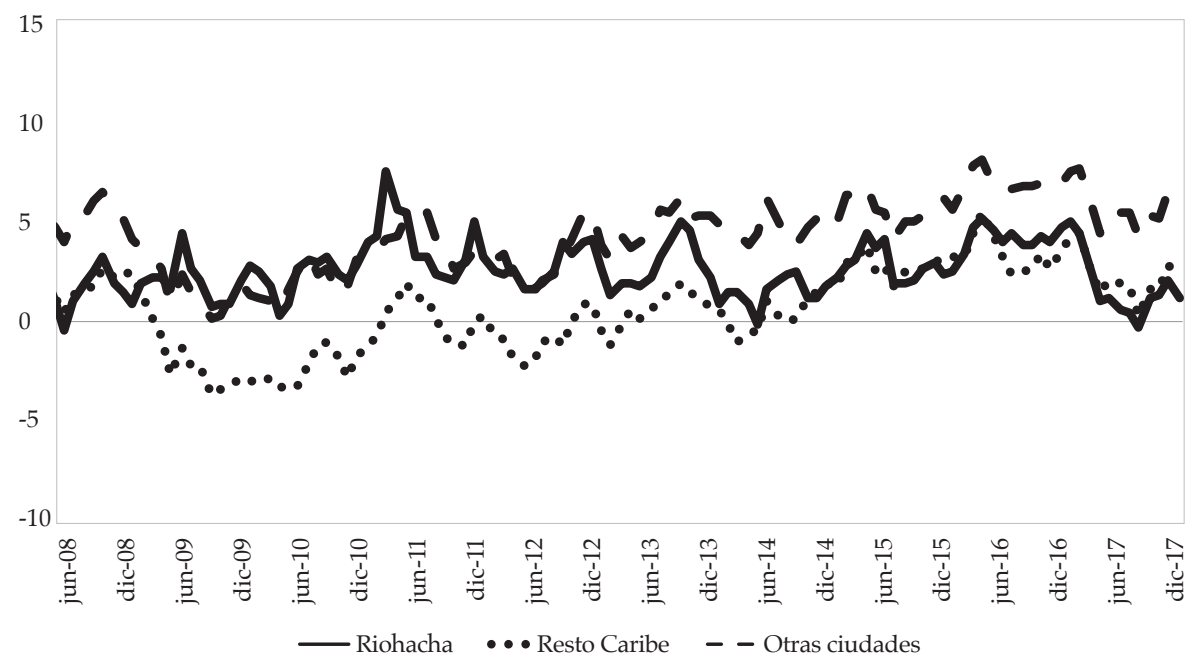

Figura 7. Participación laboral por género

Fuente: Departamento Administrativo Nacional de Estadística (DANE), Gran Encuesta Integrada de Hogares (GEIH). Cálculos de los autores.

positiva (panel C). En Riohacha, la participación femenina es superior a la de la región Caribe, aunque está por debajo del promedio de 16 ciudades. En el caso de los hombres (panel B), sobresale la caída en la participación laboral en Valledupar desde 2014, que, si bien se ha venido corrigiendo durante 2017, mantiene una brecha, especialmente con el promedio de 16 ciudades (panel D). 


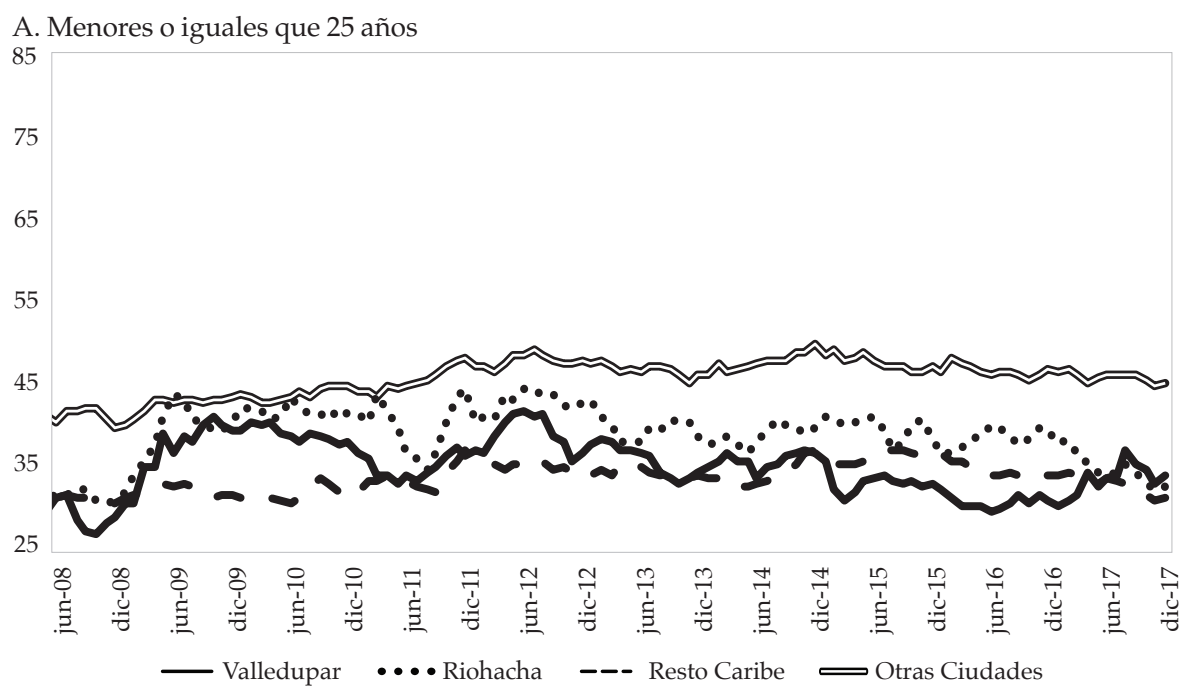

B. Mayores que 25 años

85

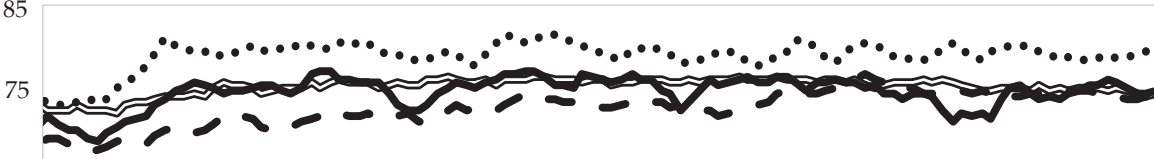

65

55

45

35

25

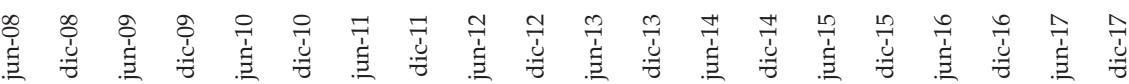

$$
\begin{aligned}
& \text { - Valledupar } \quad . . \text { Riohacha --- Resto Caribe } \rightleftharpoons \text { Otras Ciudades }
\end{aligned}
$$



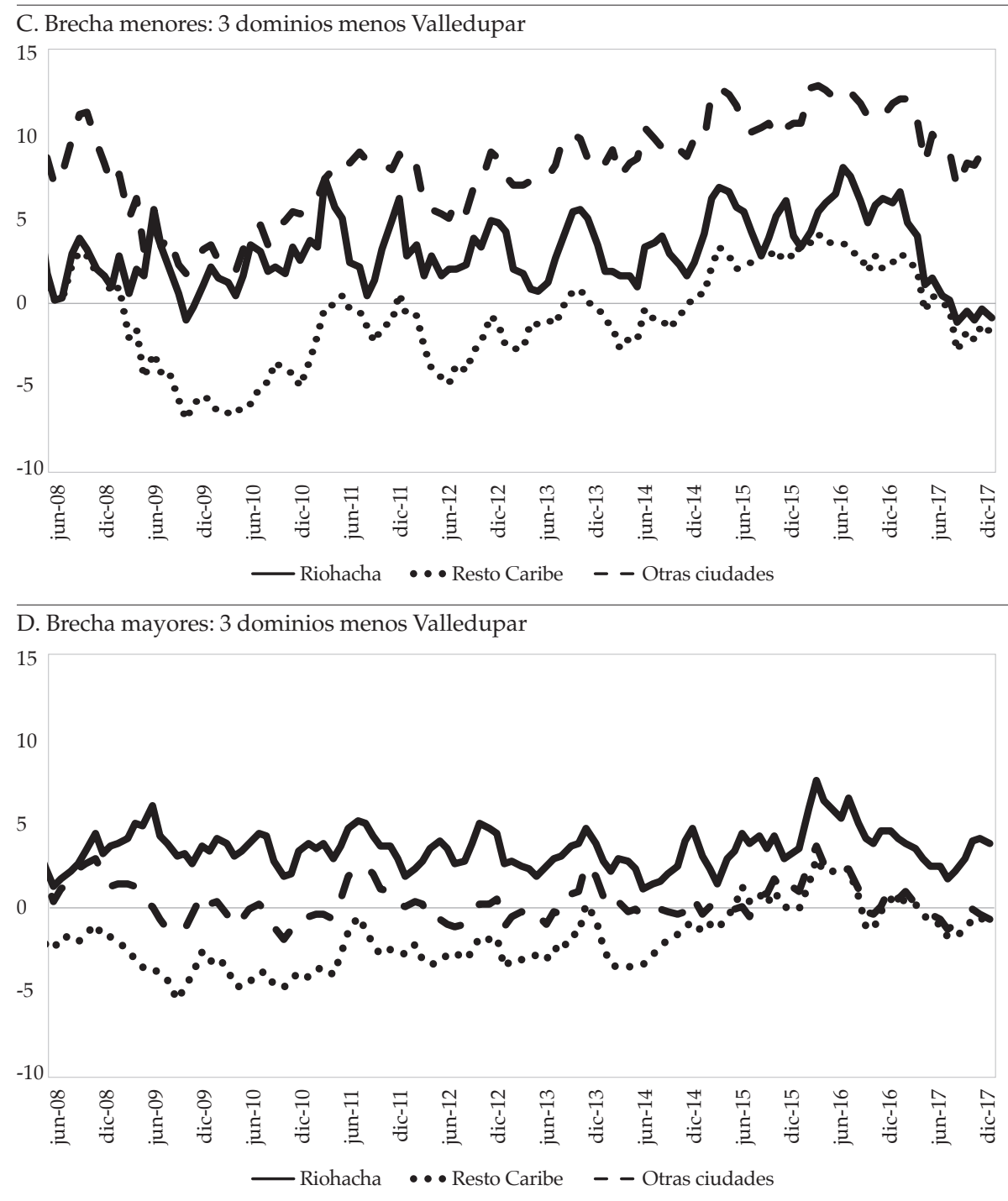

Figura 8. Participación laboral por edades

Fuente: elaboración propia con base en datos del Departamento Administrativo Nacional de Estadística (DANE), Gran Encuesta Integrada de Hogares (GEIH).

Las diferencias en participación laboral se explican, en parte, por la composición de la población en edad de trabajar (PET) por edades (figura 9). El Panel A muestra cómo en las ciudades de la región Caribe la proporción de personas de 25 años o menos es superior a la observada en el resto de 16 ciudades (Panel A, figura 9), mientras que la proporción de personas mayores de 40 años es mucho más baja (Panel C, figura 9). 


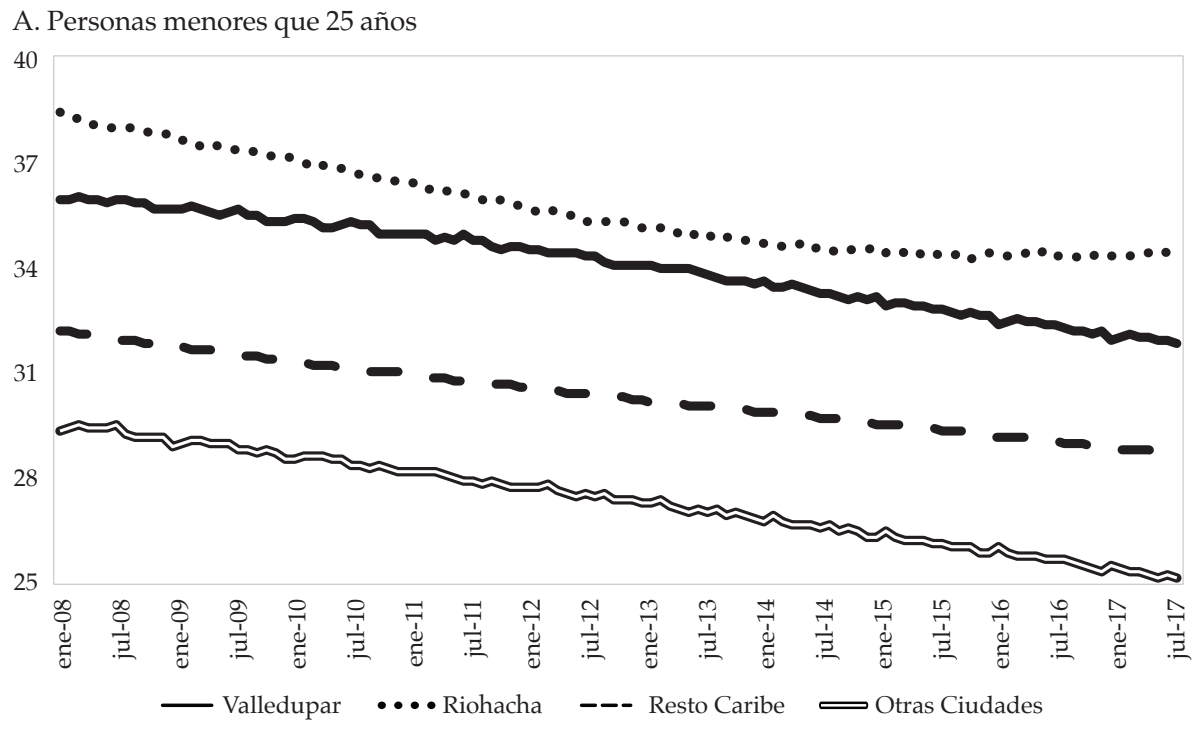

B. Personas entre 25-40 años

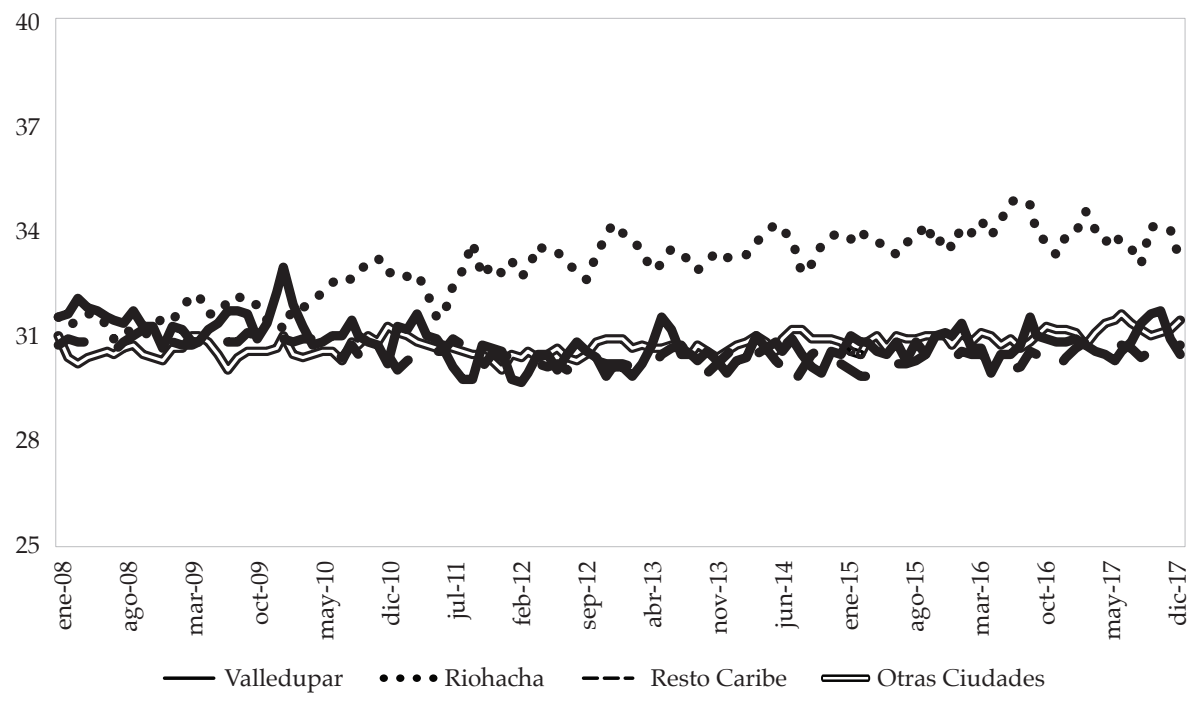




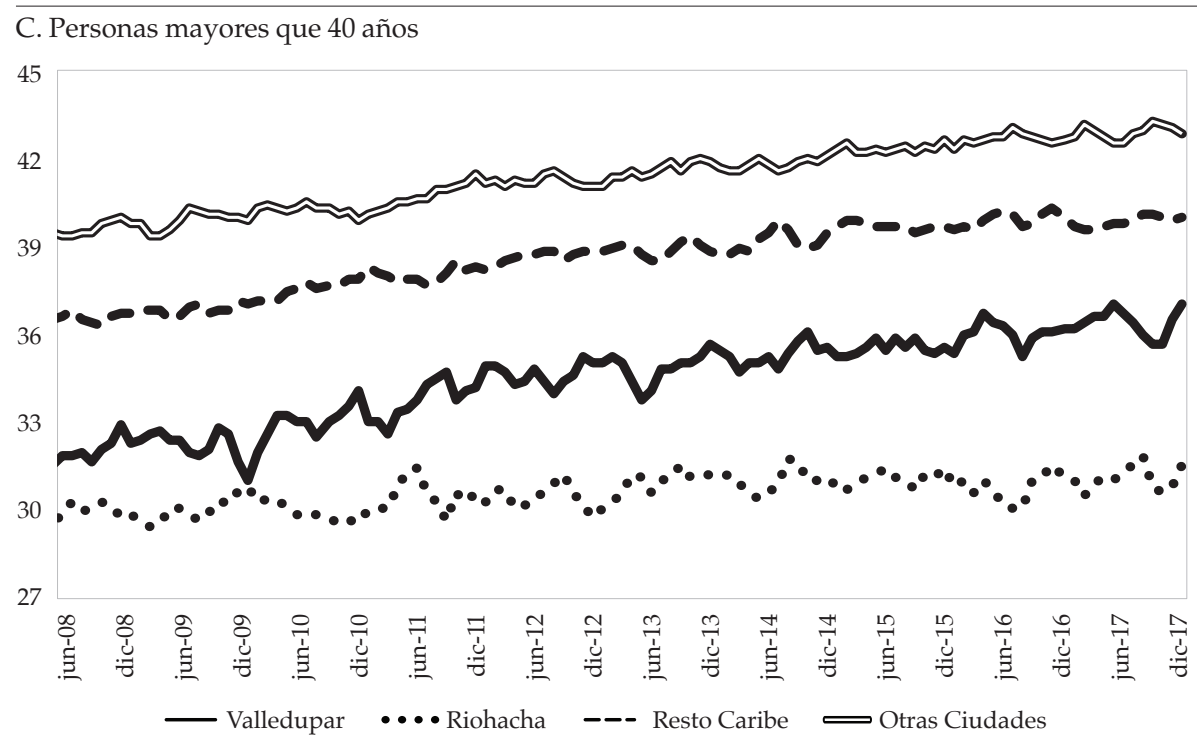

Figura 9. Composición de la PET por edades

Fuente: elaboración propia con datos del Departamento Administrativo Nacional de Estadística (DANE), Gran Encuesta Integrada de Hogares (GEIH).

Lo anterior indica que Valledupar y el resto de ciudades de la región Caribe son ciudades jóvenes, donde la proporción de fuerza laboral entre 25-40 es similar al resto del país con excepción de Riohacha. Esta composición de la fuerza laboral contribuye a que las ciudades de la región Caribe tengan una participación laboral mucho más baja, pues los jóvenes tienen una mayor probabilidad de dedicarse al estudio y depender económicamente de otros miembros del hogar.

\subsection{Determinantes de la participación laboral}

Teóricamente, la decisión de participar de las personas en el mercado laboral (estar ocupado o buscando una ocupación) depende de la comparación que hacen entre el salario esperado y el salario de reserva: si el primero es mayor que el segundo, la persona participará en el mercado laboral; ${ }^{7}$ en caso con-

7 El salario esperado se refiere al salario que una persona estima encontrar en el mercado de trabajo mientras que el salario de reserva es aquel que hace indiferente a una persona entre trabajar y no trabajar (el salario más bajo al cual aceptaría una oferta de trabajo). 
trario, no lo hará. ${ }^{8}$ Empíricamente, se plantea un modelo donde un miembro del hogar, perteneciente a la PET, toma la decisión de hacer o no parte de la fuerza laboral (PEA) basándose en criterios de participación que dependen de características individuales como escolaridad, edad, sexo y estado civil, al igual que de características del hogar, como la riqueza y la cantidad de niños en primera infancia.

A continuación, se estima un modelo de la probabilidad de participar con el propósito de explicar el porqué de las diferencias entre Valledupar y los tres grupos de ciudades restantes. Este ejercicio se realiza sobre la población en edad de trabajar entre los 12 y los 65 años de edad, ${ }^{9}$ y utiliza como fuente de información la GEIH para el periodo $2009-2016 .{ }^{10}$ Dada la importancia del carbón en la economía del Cesar y La Guajira, la versión empírica del modelo incluye los precios internacionales del carbón y el precio del petróleo ${ }^{11}$ (West Texas Intermediate, WTI) bajo el supuesto de que estos afectan no solo los salarios de mercado sino también los de reserva.

La ecuación (1) presenta la estimación empírica de la probabilidad de participación en el mercado laboral:

$$
P_{i, t}=\alpha_{0}+\alpha_{E} E_{i, t}+\alpha_{E 2} E_{i, t}^{2}+\alpha_{e d u} e d u_{i, t}+\alpha_{X} X_{i, t}+\sum_{i=0}^{k} \alpha_{p c, j} p c_{t-j}+\omega_{i, t}
$$

donde $P_{i, t}$ es una variable dicótoma que toma el valor de 1 si el individuo pertenece a la PEA y 0 en caso contrario. La variable $E$ representa la edad, edu el número de años de educación aprobados, y pc, las variaciones anuales de los precios internacionales del carbón y las variaciones del precio WTI. ${ }^{12}$ El vector $X$ incluye otras variables observables, como el nivel educativo del individuo

8 El modelo teórico se puede encontrar en Ehrenberg y Smith (2009), entre muchos otros.

9 Se limita la edad de la población en edad de trabajar (PET) porque se considera a los mayores de 65 años como una población en edad potencialmente dependiente o menos productiva.

10 Las regresiones utilizan información del periodo 2009-2016 para el cual los datos de ingresos imputados e IPC para cada una de las 23 ciudades estaban disponibles en el Dane.

11 El petróleo es el principal producto de exportación de Colombia. Además, constituye una importante fuente de ingresos en el presupuesto nacional. Representa alrededor de $70 \%$ del valor agregado de la rama de actividad explotación de minas y canteras.

12 Las series mensuales de estos commodities se obtuvieron de la página web del Banco mundial http:/ / www.worldbank.org/en/research/commodity-markets. Se calcularon las variaciones anuales como la diferencia entre el logaritmo natural del precio del carbón/ WTI en el periodo $t$ frente al periodo $t-12$ 
(tec y uni son variables dummy que representan el grado de educación: tec es igual a 1 si el individuo culminó sus estudios técnicos o tecnológicos y uni toma el valor de 1 si finalizó estudios universitarios o de postgrado); men corresponde al número de menores de seis años en el hogar; y riq es una variable dummy relacionada con la riqueza del hogar que excluye los ingresos laborales del individuo. Esta variable, utilizada antes por Posada y Arango (2003), se define como una variable dicótoma que toma el valor de 1 si se cumple por lo menos una de las siguientes condiciones: si la vivienda del hogar es propia o si el nivel de ingresos del hogar es mayor que $\$ 2.000 .000$ constantes de 1998; en caso contrario, toma el valor de $0 .{ }^{13}$ También se incluyen eciv una dummy que toma el valor de 1 si el individuo está casado o vive en pareja y 0 en otro caso; y mujer es una dummy que toma el valor de 1 si el individuo es mujer. Esta variable se interactuó con la de menores en el hogar. También se incluyen efectos fijos de tiempo (mes-año) y efectos fijos de ciudad para el caso de las ecuaciones del resto de ciudades de la costa Caribe y de las otras 16 ciudades.

El Cuadro A del Anexo presenta las estadísticas descriptivas de las variables utilizadas en la estimación. Como se puede observar, en promedio, Valledupar y Riohacha tienen una población más joven, con menor experiencia, que las 16 ciudades. Los años de educación promedio en los cuatro grupos está alrededor de 10 años, siendo un poco mayor este promedio para las mujeres; en todos los casos, la diferencia frente a los hombres es estadísticamente significativa. De otro lado, las mujeres en edad de trabajar y los menores de cinco años o menos son más numerosos en Valledupar respecto a otras ciudades del Caribe y al resto del país. El porcentaje de individuos casados o en unión libre es mayor en las ciudades de la costa Caribe frente a las 16 ciudades. Finalmente, la variable riqueza es menor en Riohacha, una de las ciudades más pobres del país (Meisel \& Ricciulli, 2018).

La tabla 2 presenta los efectos marginales de las variables en la probabilidad de participar en el mercado laboral usando un modelo probit. Las columnas 1, 2, 3 y 4 corresponden, respectivamente, a Valledupar, Riohacha, otras ciudades del Caribe y las 16 ciudades del resto del país consideradas por el DANE. Como se observa, el efecto de los precios del carbón sobre la probabilidad de participar es positivo, es decir, los altos precios del carbón afectan al alza los salarios de los trabajadores vinculados directa e indirectamente con el sector, especialmente asentado en la Jagua de Ibirico-La Loma y El Cerrejón; dicho efecto positivo sobre el salario esperado domina el efecto sobre el

13 Tanto las variables de ingresos del hogar como la de vivienda propia son proxys de los otros ingresos no laborales del hogar que potencialmente pueden afectar la decisión de participar. 
salario de reserva. En tal sentido, una caída (incremento) de los precios del carbón reduce (aumenta) la probabilidad de participar en el mercado laboral.

El caso de los precios del petróleo es diferente, ya que el efecto es negativo en todos los dominios, contribuyendo menos a explicar la heterogeneidad del mercado laboral que los precios del carbón. Este resultado estaría sugiriendo un efecto de los precios del petróleo vía regalías, aumentando el salario de reserva de los hogares y, por ende, provocando una menor participación laboral; es decir, las regalías que llegan al Departamento del Cesar y a la ciudad de Valledupar y contribuyen a disminuir la pobreza reduciendo los incentivos a participar en el mercado laboral. Para el caso de la capital del Cesar, el efecto de la variación de los precios del carbón es mayor que el efecto del precio de WTI especialmente en el horizonte de tres meses. ${ }^{14}$

Por lo demás, se observa que, en todos los dominios geográficos analizados, las variables tienen el signo esperado y son estadísticamente significativas. Así, la participación aumenta con la edad, la escolaridad y el nivel educativo de las personas. De otro lado, ser mujer, estar casado o en unión libre, y vivir en un hogar con mayor riqueza, reducen la probabilidad de participar en el mercado laboral. El número de niños menores de cinco años o menos tiene un efecto positivo en la participación, pero, cuando se examina solo para las mujeres, el efecto es negativo y estadísticamente significativo para las ciudades de la región Caribe, excluyendo Riohacha y Valledupar.

Al analizar la participación laboral en los diferentes dominios geográficos se encuentra que la probabilidad promedio estimada de participar en Valledupar y las otras ciudades de la costa Caribe es alrededor de $61 \%$, menor que la estimada para Riohacha y para las otras 16 ciudades $(65 \%$ y $71 \%$, respectivamente). En toda la región Caribe (Valledupar, Riohacha y otras capitales de la Costa) sobresale el efecto marginal de ser mujer en la participación laboral, el cual es negativo e inferior, en promedio, en más de $20 \%$ frente a los resultados obtenidos por los hombres. Adicionalmente, en estas ciudades, el efecto marginal en la participación por cada año de educación adicional es menor (entre $0,41 \%$ y $0,58 \%$ ) frente al promedio de las 16 ciudades (0,74\%). A pesar de que el efecto marginal en la probabilidad de participar de las personas con título universitario frente a aquellas sin educación superior es mayor en las ciudades de la región Caribe, la probabilidad promedio de participación de un universitario en estas ciudades, excepto Riohacha, sigue siendo menor

14 Estos resultados se mantienen cuando en la regresión se incluyen solamente los precios internacionales del carbón. 
frente a las 16 ciudades (Valledupar, 80,6\%; Riohacha, 83,5\%; otras ciudades del Caribe, 80,7\%; y otras 16 ciudades, 83,9\%).

Tabla 2. Determinantes de la participación laboral (efectos marginales)

\begin{tabular}{|c|c|c|c|c|}
\hline \multirow{2}{*}{ Variables } & Valledupar & Riohacha & Caribe $\sin (1)$ y (2) & 16 ciudades \\
\hline & (1) & (2) & (3) & (4) \\
\hline \multirow{2}{*}{ Edad } & $0,0158^{* * *}$ & $0,0169^{* * *}$ & $0,0132^{* * *}$ & $0,0106^{* * *}$ \\
\hline & $(0,0000)$ & $(0,0000)$ & $(0,0000)$ & $(0,0000)$ \\
\hline \multirow{2}{*}{ Mujer } & $-0,2157^{* * *}$ & $-0,1909^{* * *}$ & $-0,2167^{* * *}$ & $-0,1571^{* * *}$ \\
\hline & $(0,0002)$ & $(0,0002)$ & $(0,0000)$ & $(0,0000)$ \\
\hline \multirow{2}{*}{ Años de educación } & $0,0048^{* * *}$ & $0,0041^{* * *}$ & $0,0058^{* * *}$ & $0,0074^{* * *}$ \\
\hline & $(0,0000)$ & $(0,0000)$ & $(0,0000)$ & $(0,0000)$ \\
\hline \multirow{2}{*}{ Educación técnica y tecnológica } & $0,1275^{* * *}$ & $0,0896^{* * *}$ & $0,1193^{* * *}$ & $0,0887^{* * *}$ \\
\hline & $(0,0003)$ & $(0,0004)$ & $(0,0001)$ & $(0,0000)$ \\
\hline \multirow{2}{*}{ Universitario y posgrado } & $0,1641^{* * *}$ & $0,1637^{* * *}$ & $0,1518^{* * *}$ & $0,0847^{* * *}$ \\
\hline & $(0,0004)$ & $(0,0005)$ & $(0,0001)$ & $(0,0001)$ \\
\hline \multirow{2}{*}{ Estado civil } & $-0,0394^{* * *}$ & $-0,0243^{* * *}$ & $-0,0296^{* * *}$ & $-0,0298^{* * *}$ \\
\hline & $(0,0002)$ & $(0,0003)$ & $(0,0001)$ & $(0,0000)$ \\
\hline \multirow{2}{*}{ Riqueza } & $-0,0456^{* * *}$ & $-0,0397^{* * *}$ & $-0,0304^{* * *}$ & $-0,0519^{* * *}$ \\
\hline & $(0,0002)$ & $(0,0002)$ & $(0,0001)$ & $(0,0000)$ \\
\hline \multirow{2}{*}{ Menores } & $0,0234^{* * *}$ & $0,0201^{* * *}$ & $0,0224^{* * *}$ & $0,0193^{* * *}$ \\
\hline & $(0,0001)$ & $(0,0001)$ & $(0,0000)$ & $(0,0000)$ \\
\hline \multirow{2}{*}{ Mujer $\times$ menores de 5 años } & $-0,0001$ & $-0,0001$ & $-0,0043^{* * *}$ & $-0,00003$ \\
\hline & $(0,0001)$ & $(0,0001)$ & $(0,0000)$ & $(0,0000)$ \\
\hline \multicolumn{5}{|l|}{ Variación del precio del carbón ${ }^{15}$} \\
\hline \multirow{2}{*}{ Acumulado 3 meses } & $0,0517^{* * *}$ & $0,0367^{* * *}$ & $0,0256^{* * *}$ & $0,0030^{* * *}$ \\
\hline & $(0,0014)$ & $(0,0019)$ & $(0,0004)$ & $(0,0002)$ \\
\hline \multirow{2}{*}{ Acumulado 6 meses } & $0,0064^{* * *}$ & $0,0023^{* *}$ & $-0,0022^{* * *}$ & $-0,0013^{* * *}$ \\
\hline & $(0,0007)$ & $(0,0010)$ & $(0,0002)$ & $(0,0001)$ \\
\hline
\end{tabular}

15 En el modelo probit se incluyen los primeros 6 rezagos de las variaciones de precio de los bienes primarios. En la tabla 2 se muestra el efecto marginal del acumulado de los primeros 3 rezagos y de los primeros 6 . Estos se calculan como combinaciones no lineales de los parámetros estimados de los rezagos. El error estándar se calcula mediante el método delta. 


\begin{tabular}{lcccc}
\hline \multirow{2}{*}{ Variables } & Valledupar & Riohacha & Caribe sin (1) y (2) & 16 ciudades \\
\cline { 2 - 5 } & $(1)$ & $(2)$ & $(3)$ & $(4)$ \\
\hline Variación del precio del WTI & $-0,0137^{* * *}$ & $-0,0082^{* * *}$ & $-0,0063^{* * *}$ & $-0,0064^{* * *}$ \\
Acumulado 3 meses & $(0,0010)$ & $(0,0014)$ & $(0,0003)$ & $(0,0001)$ \\
& $-0,0060^{* * *}$ & $-0,0187^{* * *}$ & $-0,0137^{* * *}$ & $-0,0046^{* * *}$ \\
Acumulado 6 meses & $(0,0009)$ & $(0,0012)$ & $(0,0003)$ & $(0,0001)$ \\
N de observaciones & 159.966 & 148.873 & 826.139 & 2.357 .115 \\
p-seudo R del probit & 0,3178 & 0,3099 & 0,3280 & 0,3045 \\
Área bajo la curva ROC & 0,8543 & 0,8531 & 0,8585 & 0,8497 \\
\hline
\end{tabular}

Nota: errores estándar en paréntesis. Nivel de significancia: ${ }^{* *} \mathrm{p}<0.01,{ }^{* *} \mathrm{p}<0.05,{ }^{*} \mathrm{p}<0,1$. Incluye controles de años y meses.

Fuente: elaboración propia con datos del Departamento Administrativo Nacional de Estadística (Dane), Gran Encuesta Integrada de Hogares (GEIH).

La brecha de participación es aún más grande cuando comparamos la diferencia entre la probabilidad de participar por años de educación en el mercado laboral de hombres y mujeres (figura 10). Por ejemplo, una mujer con 11 años de educación participa 20 pp menos que un hombre con el mismo nivel educativo en Valledupar, mientras en las 16 ciudades esta diferencia es de $15 \mathrm{pp}$. A pesar de que esta brecha se reduce con el aumento de los años de educación, siempre es negativa en favor de los hombres, en todos los dominios analizados (figura 10).

La composición etaria de la fuerza laboral en las ciudades de la costa también explica parte de la menor participación. Como se mencionó en la sección anterior, estas ciudades están caracterizadas por tener una PET joven frente al promedio de las 16 ciudades. La probabilidad de participar de una persona con 20 años de edad es alrededor de $44 \%$ en Valledupar y en el resto de ciudades de la costa Caribe, frente al $56 \%$ de las otras 16 ciudades (figura 11). Esta probabilidad converge a medida que la población envejece. 


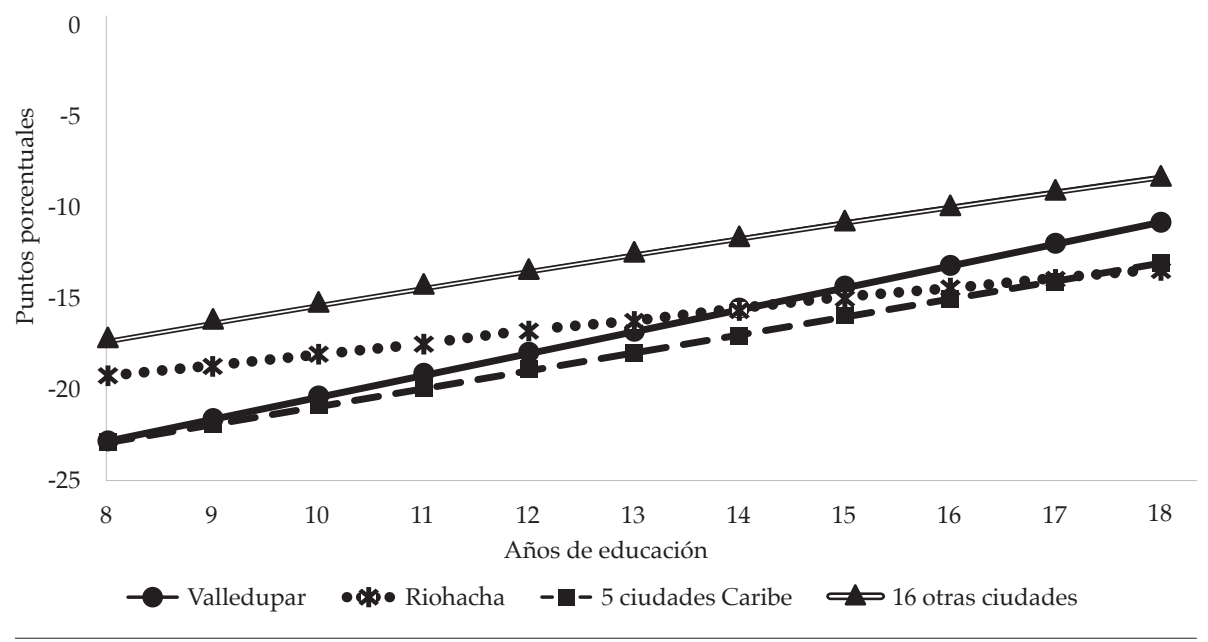

Figura 10. Diferencia en la probabilidad promedio de participar entre mujeres y hombres por años de educación (entre 8 y 18 años de educación)

Fuente: elaboración propia con datos del Departamento Administrativo Nacional de Estadística (DANE), Gran Encuesta Integrada de Hogares (GEIH).

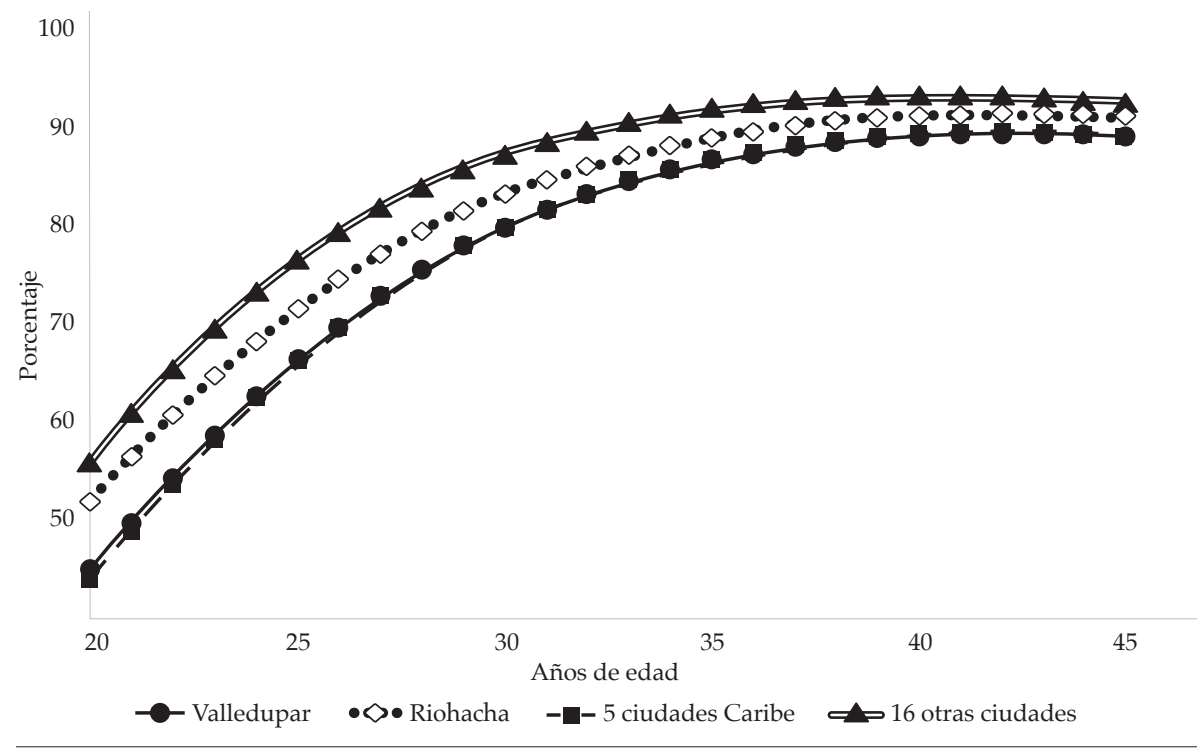

Figura 11. Probabilidad promedio de participar por edad (entre 20 y 45 años)

Fuente: elaboración propia con datos del Departamento Administrativo Nacional de Estadística (DANE), Gran Encuesta Integrada de Hogares (GEIH).

En resumen, existen características comunes que explican una menor participación en las ciudades de la región Caribe. Sin embargo, Valledupar 
exhibe ciertas particularidades que explican la menor participación laboral. En primer lugar, la PET es mucho más joven y, en segundo lugar, tiene una proporción de mujeres ligeramente mayor que el promedio de la costa Caribe o resto de 16 ciudades. Finalmente, un tercer elemento que explica las diferencias en participación, especialmente en Valledupar y Riohacha, son los precios internacionales del carbón dada la alta dependencia de la producción de este bien primario, convirtiéndolas en ciudades de alta exposición al riesgo de choques exógenos.

\section{Demanda de trabajo}

En esta sección se analiza el comportamiento de la demanda laboral. Como proxy de esta se utiliza la tasa de ocupación (TO), la cual mide el porcentaje de las personas en edad de trabajar que se encuentran ocupadas. La TO de Valledupar y Riohacha tuvieron un crecimiento entre 2009 y 2010, en línea con la senda de crecimiento económico que experimentaron en esos años los departamentos del Cesar y La Guajira (figura 12). Este buen dinamismo de la TO comenzó a deteriorarse desde mediados de 2014, afectando en mayor medida a Valledupar y más recientemente a Riohacha; aunque se observa una etapa de recuperación reciente en la demanda laboral sobre todo en Valledupar.

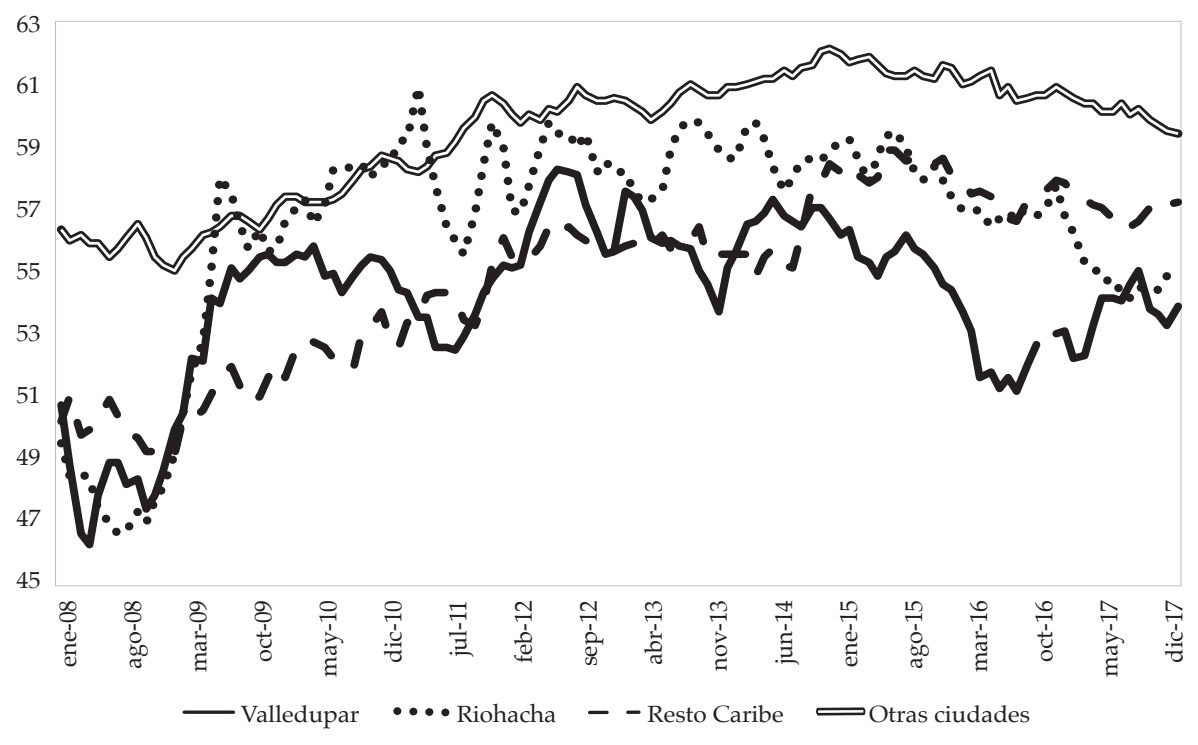

Figura 12. Tasa de ocupación

Fuente: elaboración propia con datos del Departamento Administrativo Nacional de Estadística (DANE), Gran Encuesta Integrada de Hogares (GEIH). 
A pesar de lo anterior, la diferencia en la demanda laboral de Valledupar y Riohacha se estaría ampliando, no solo con el resto de 16 ciudades, sino también con las cinco ciudades de la región Caribe.

La figura 13 presenta la TO por nivel educativo. En Valledupar, desde 2015, se observa una caída de la demanda de la mano de obra calificada y no calificada. Sin embargo, al comparar el promedio de la TO en 2015, frente a los niveles observados en 2017, se observa una caída más pronunciada en las personas más educadas (2,8 pp) frente a 1,3 pp de las menos educadas
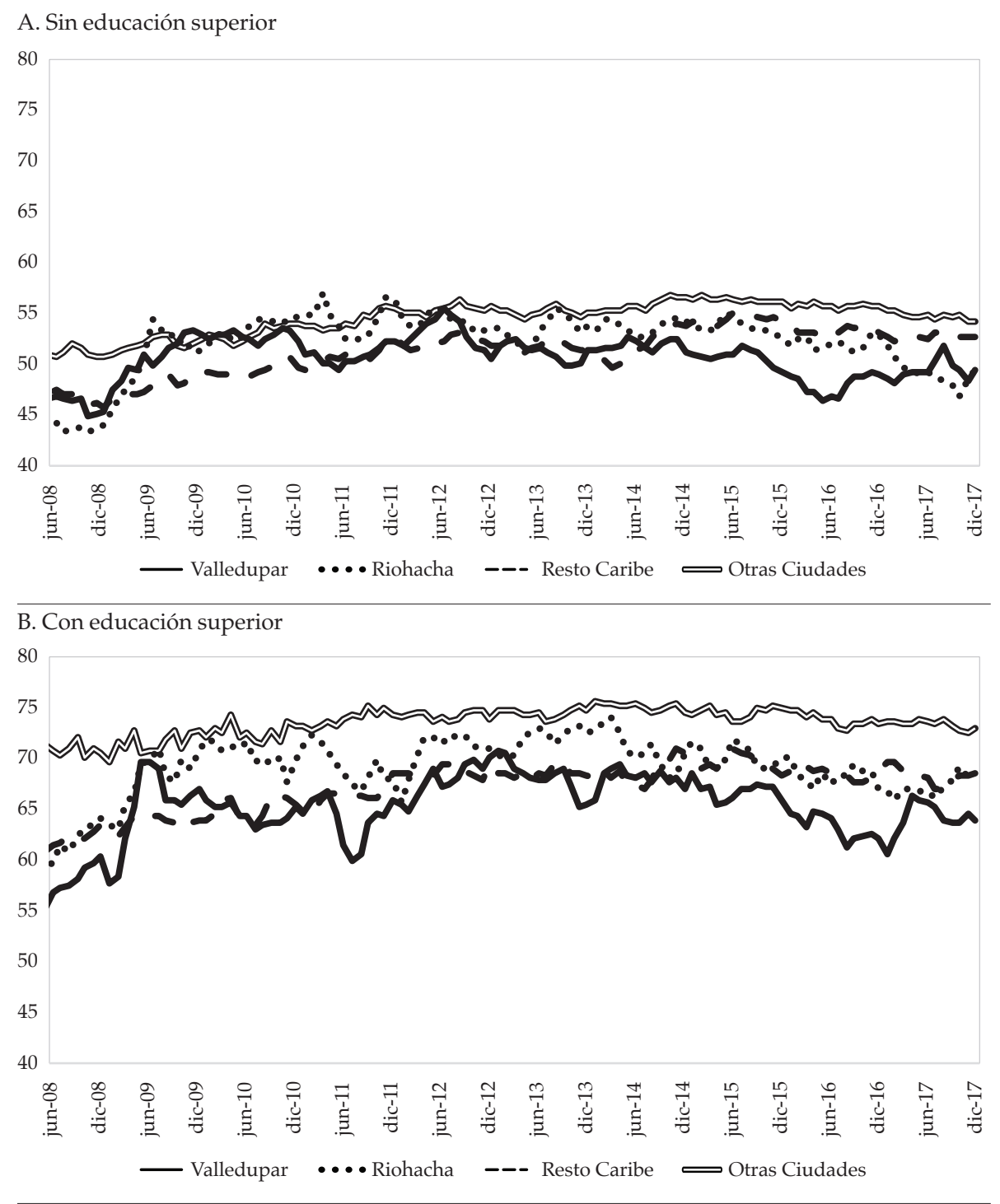

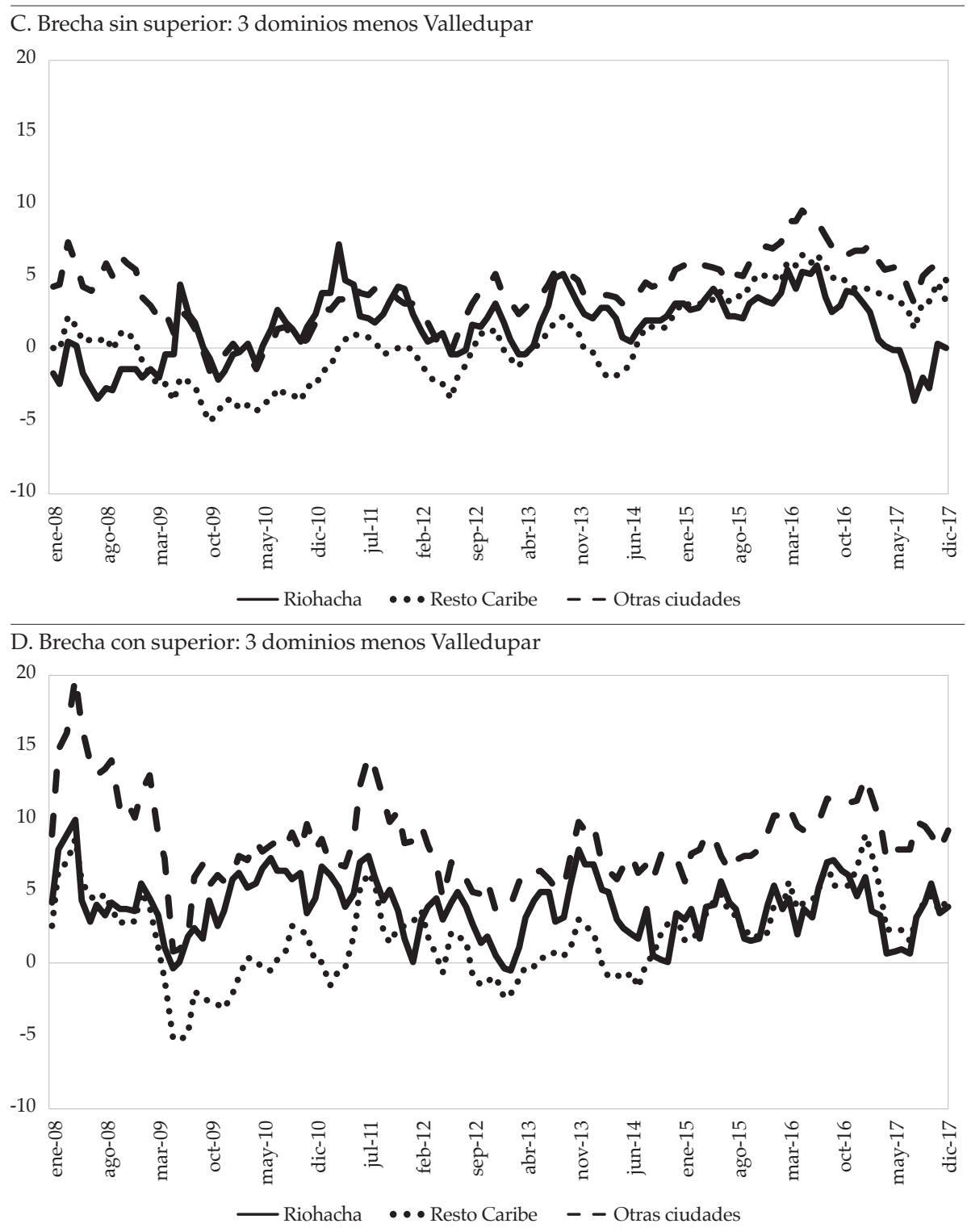

Figura 13 .Tasa de ocupación por nivel educativo

Fuente: elaboración propia con datos del Departamento Administrativo Nacional de Estadística (DANE), Gran Encuesta Integrada de Hogares (GEIH).

(panel A y B). En el caso de Riohacha también se observa una caída importante en la mano de obra menos calificada, especialmente durante 2017.

La demanda de trabajadores de ambos sexos ha registrado una caída notoria desde 2015 en Valledupar (figura 14); por su parte, en Riohacha se 
observó una caída importante en la demanda laboral de los hombres en 2017. Lo anterior ha llevado a un aumento reciente en la brecha de la demanda laboral, tanto de hombres como de mujeres en Valledupar frente al resto de 16 ciudades, siendo la brecha de las mujeres mucho más pronunciada (panel D).
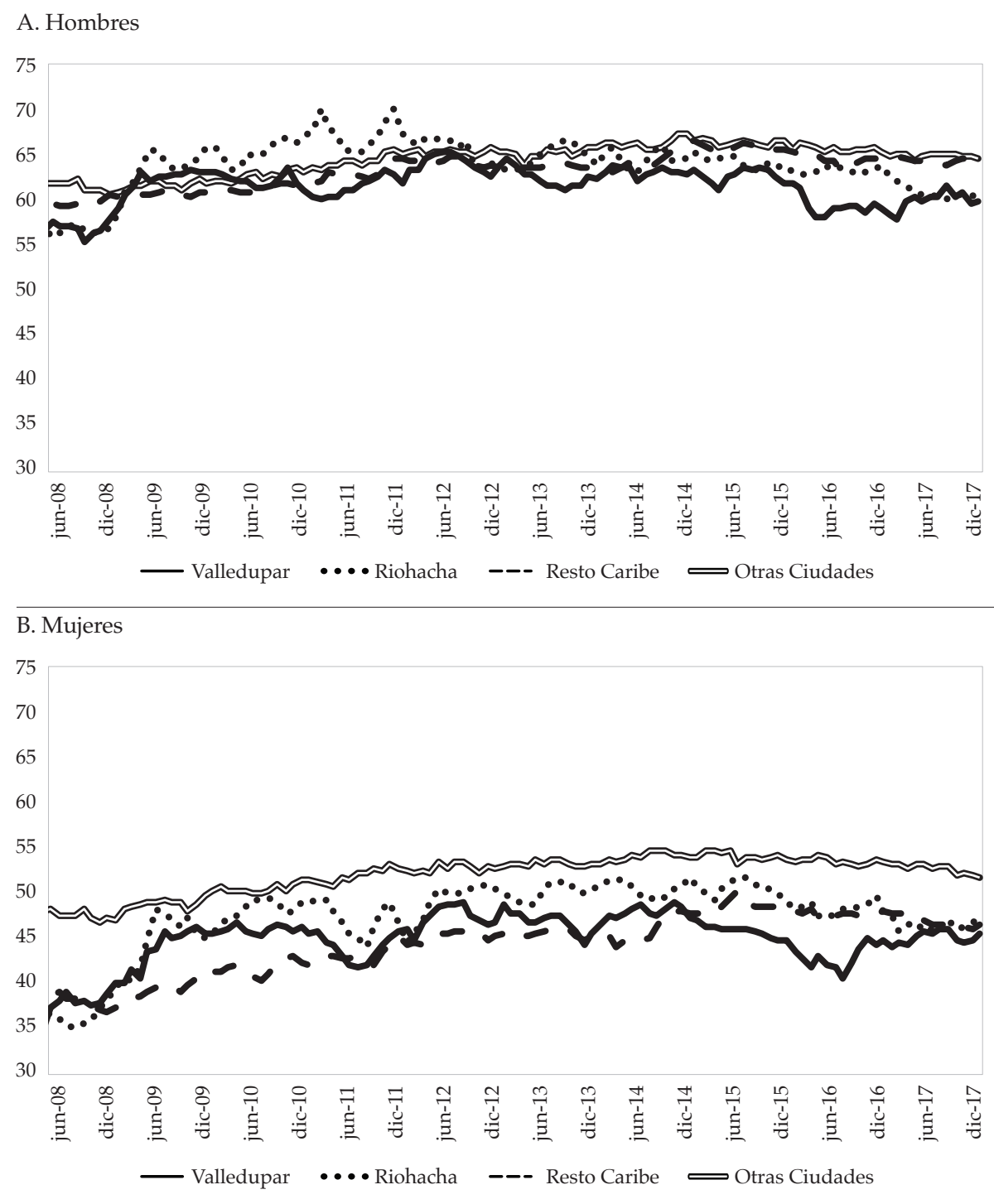


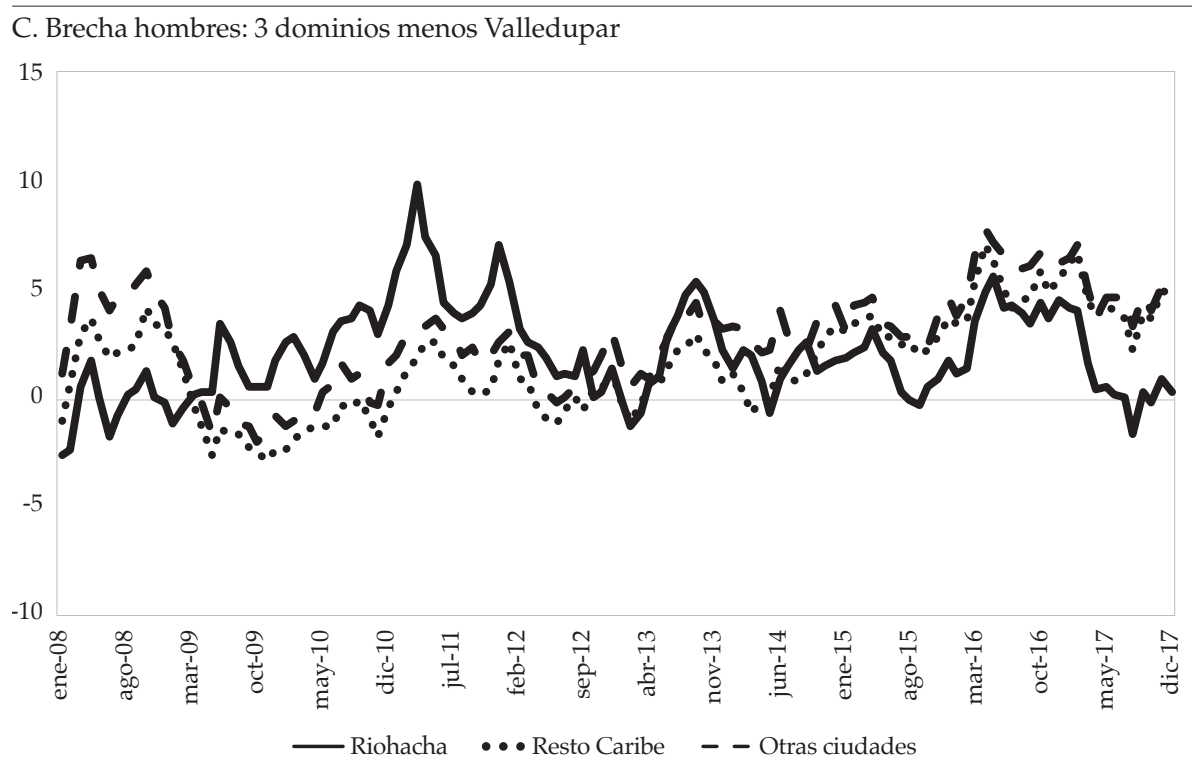

Panel D. Brecha mujeres: 3 dominios menos Valledupar 15

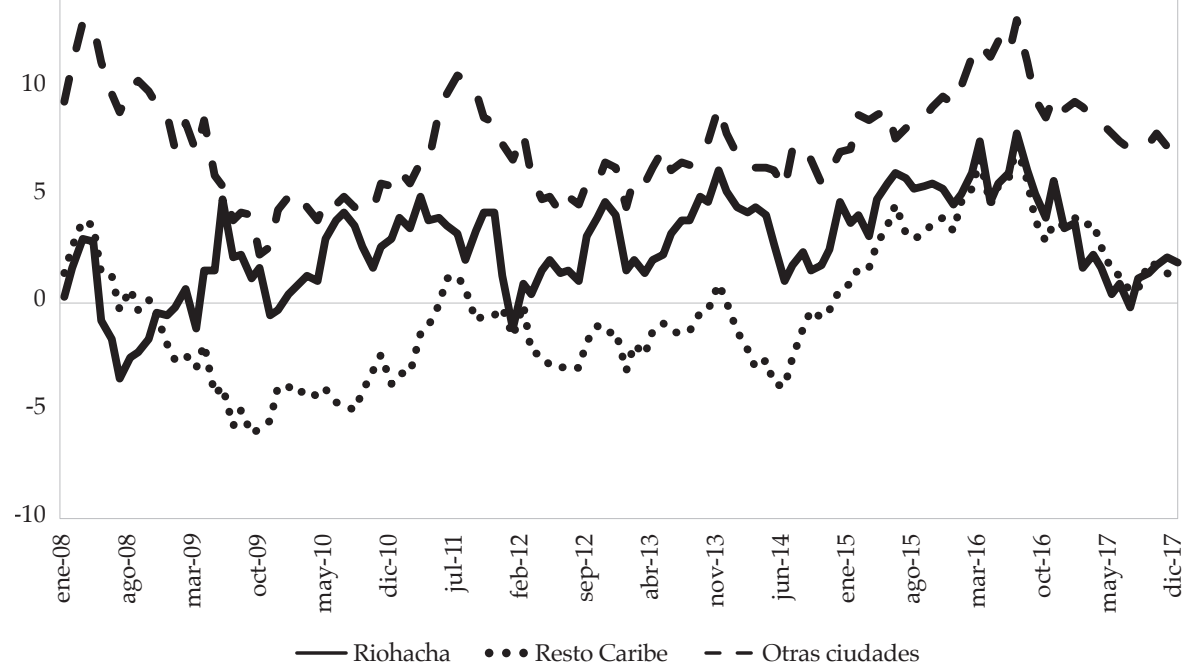

Figura 14. Tasa de ocupación por género

Fuente: elaboración propia con datos del Departamento Administrativo Nacional de Estadística (DANE), Gran Encuesta Integrada de Hogares (GEIH).

La figura 15 muestra la TO por edades. Como se puede observar, para los mayores de 25 años, la demanda laboral es muy similar en Valledupar y el resto de ciudades, excluyendo Riohacha. Sin embargo, la diferencia 
importante se observa en la TO de los menores de 25 años, especialmente en Valledupar, la cual presenta una caída desde 2012 y, aunque corrige algo durante 2017, sigue estando muy por debajo del promedio de 16 ciudades, lo que ha implicado una brecha creciente frente a la demanda observada para el promedio de 16 ciudades (panel D).

A. Mayores que 25 años

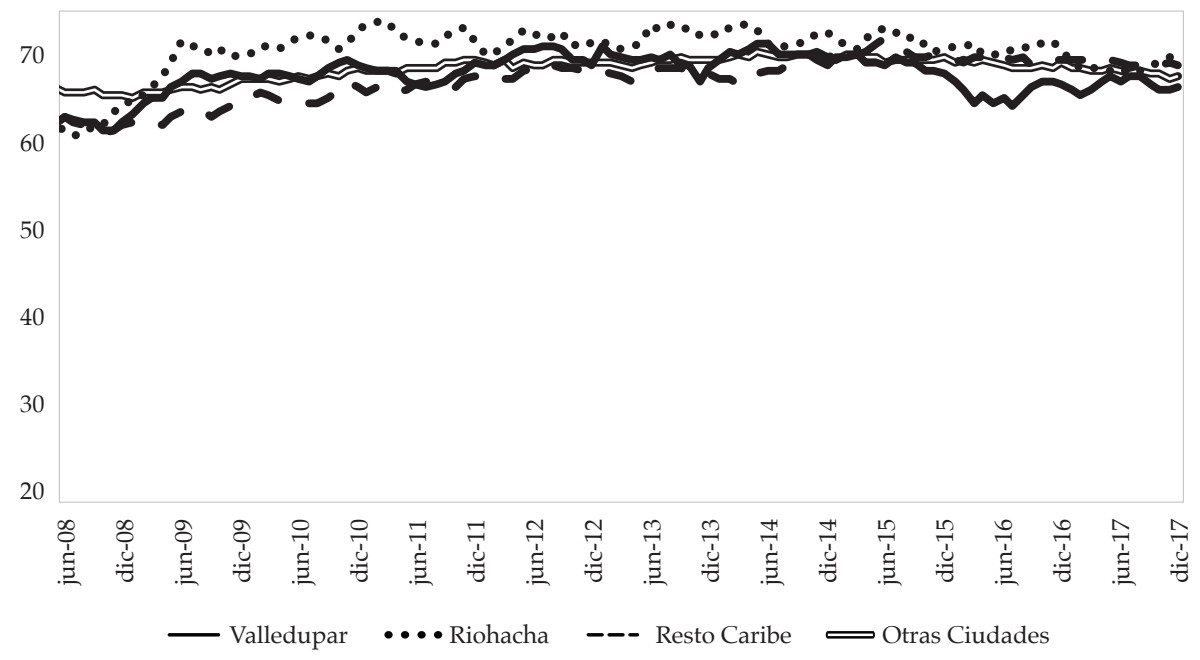

B. Menores o igual que 25 años

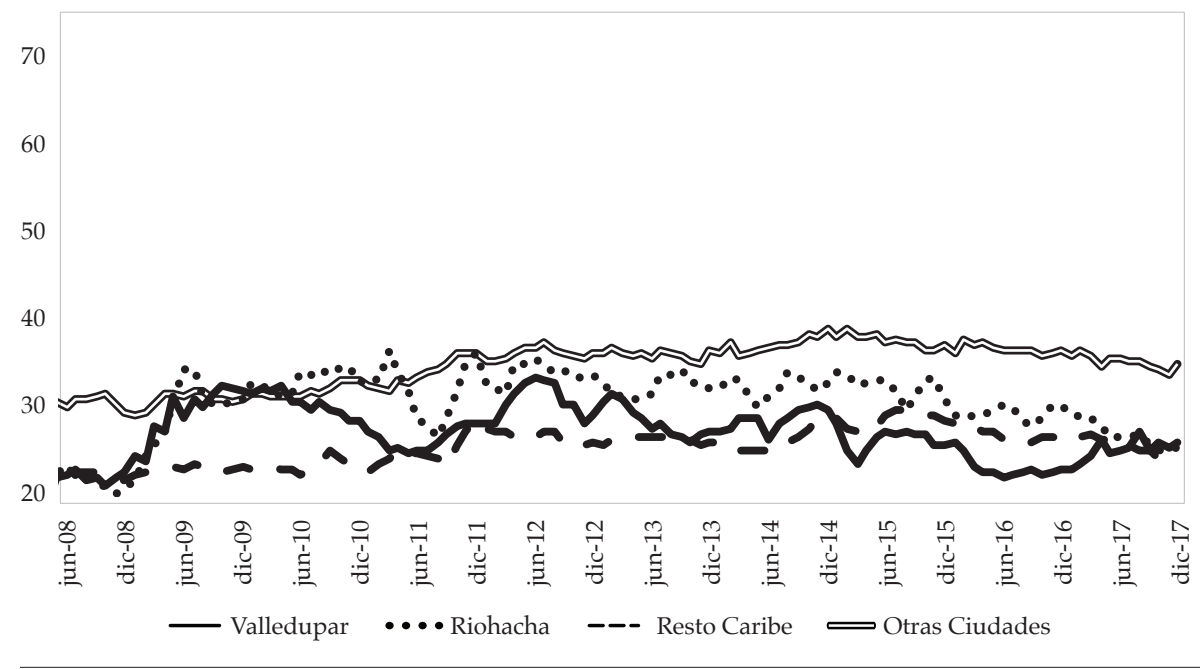


C. Brecha menores e iguales que 25 años: 3 dominios menos Valledupar

20

15

10

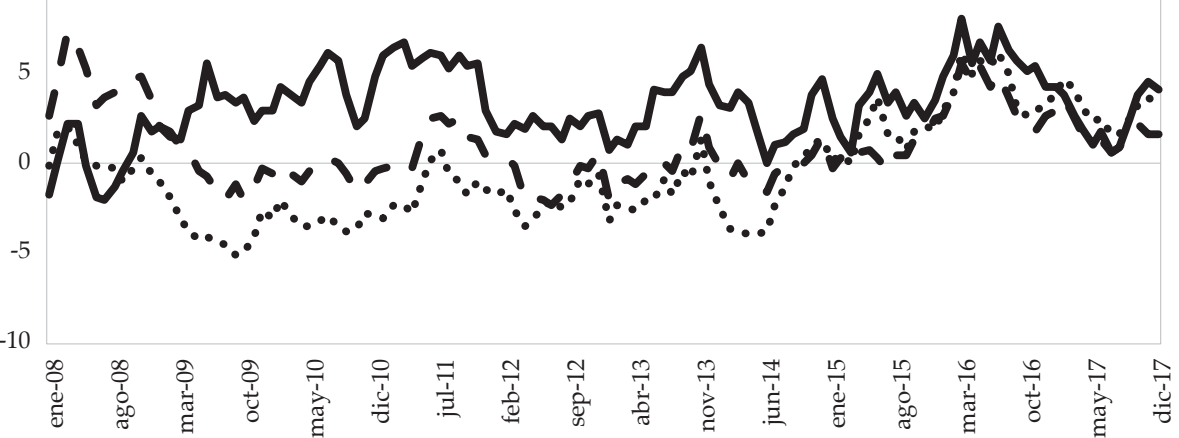

- Riohacha $\quad$-.. Resto Caribe _ - Otras ciudades

D. Brecha mayores 25 años: 3 dominios menos Valledupar

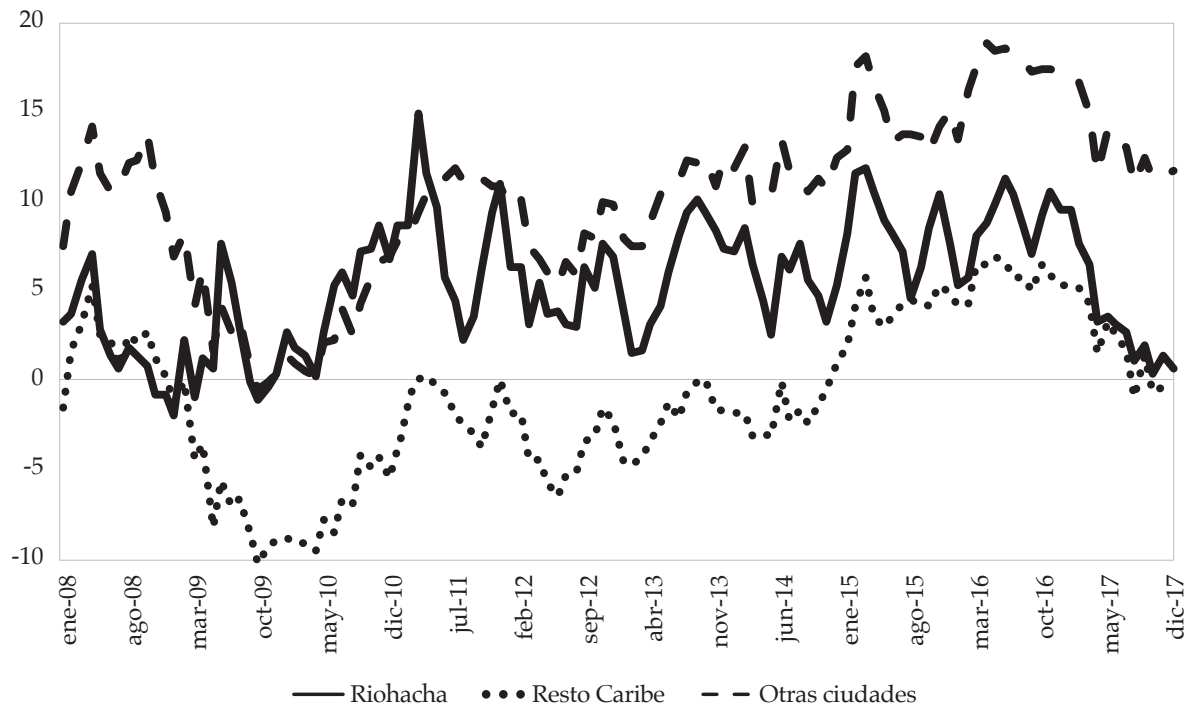

Figura 15. Tasa de ocupación por edades

Fuente: elaboración propia con datos del Departamento Administrativo Nacional de Estadística (Dane), Gran Encuesta Integrada de Hogares (GEIH). 
La figura 16 muestra la proporción de ocupados asalariados y no asalariados. ${ }^{16}$ El empleo asalariado está asociado con aquellos que cuentan con un

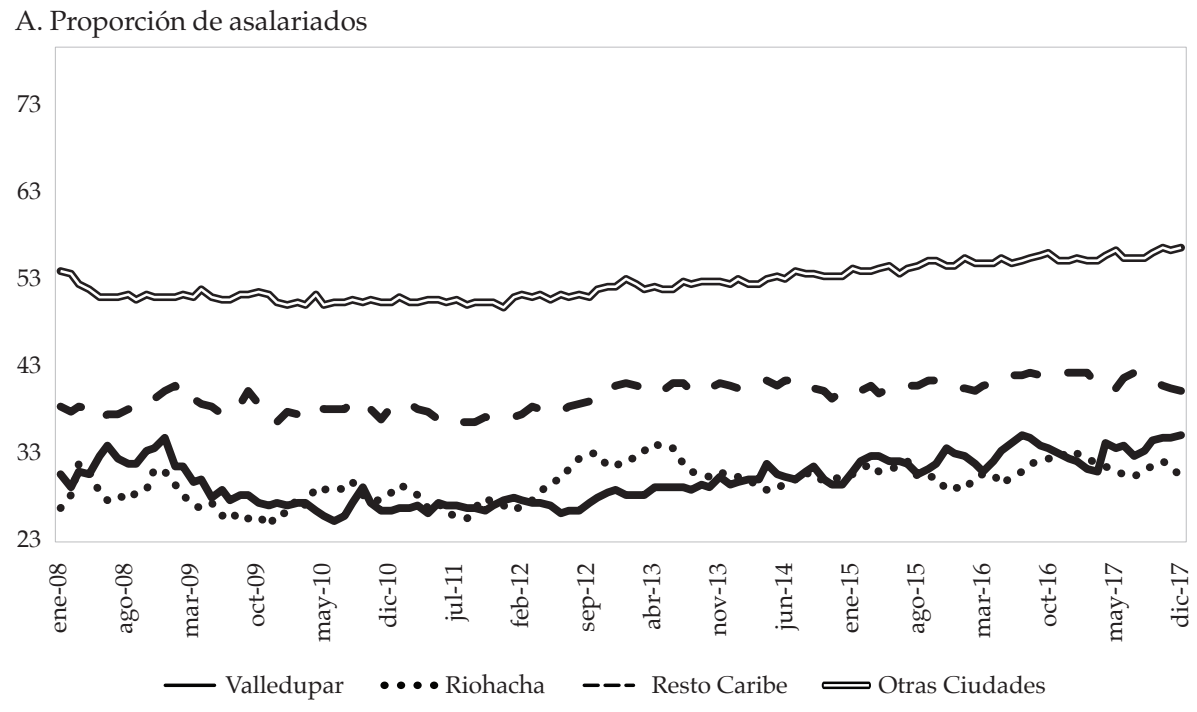

B. Proporción de no asalariados

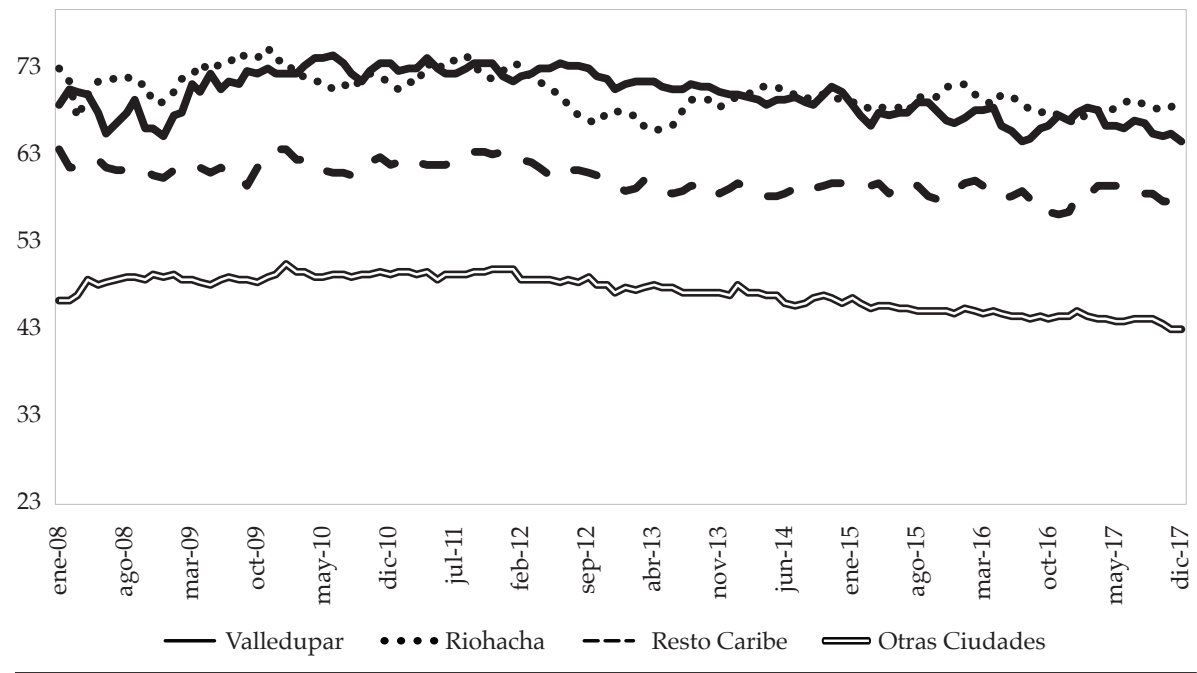

Figura 16. Proporción de ocupación asalariada y no asalariada

Fuente: elaboración propia con datos del Departamento Administrativo Nacional de Estadística (DANE), Gran Encuesta Integrada de Hogares (GEIH).

16 Esta proporción corresponde a la relación de trabajadores asalariados y no asalariados con respecto al total de ocupados. Los trabajadores asalariados son empleados y obreros de empresas particulares o del Gobierno. 
trabajo generalmente de mejor calidad; Mora y Ulloa (2011) encuentran que en Colombia los trabajadores asalariados tienen empleos con mejores características que los independientes, ya que devengan ingresos mayores; además, una mayor proporción está afiliada a salud y pensión y cuenta con un contrato laboral. Como se observa, en el caso de Valledupar, el empleo asalariado representó en promedio el 34\% del empleo total en 2017, mientras que el empleo no asalariado fue cerca del $66 \%$. En Riohacha, se observa una situación similar. La proporción de ocupados asalariados en estas dos ciudades se encuentra levemente por debajo de lo observado en las otras cinco ciudades de la costa Caribe, pero bastante lejos del promedio de las 16 ciudades restantes. A pesar de lo anterior, sobresale la moderada tendencia ascendente en la proporción de ocupados asalariados especialmente desde 2012, que sería en parte el resultado de la política de formalización laboral implementada por el Gobierno nacional mediante la reforma laboral de 2012. ${ }^{17}$ Varios estudios muestran que esta tuvo un efecto positivo pero moderado en el empleo formal (Morales \& Medina, 2016; Eslava et al., 2017; Fernández \& Villar, 2016; \& Osorio, 2016), que también pudo presentarse en el mercado laboral de Valledupar. En este sentido, a pesar de la menor demanda laboral observada en Valledupar, hay una mejora en la calidad del empleo, debido a la menor creación de empleo no asalariado; sin embargo, el nivel del empleo asalariado aún se encuentra muy por debajo de los niveles deseados.

\section{Desempleo y salarios}

En esta sección analizamos el comportamiento de la tasa de desempleo como resultado de la interacción de oferta y demanda de trabajo (figura 1). Como se mencionó anteriormente, la oferta laboral ha venido cayendo, lo cual contribuye con la reducción del desempleo; sin embargo, si la reducción de la demanda laboral es mayor que la reducción de la oferta, se tendrá un aumento en la tasa de desempleo (TD). En la coyuntura reciente, sobresale el aumento de la TD de Valledupar seguido del de Riohacha.

La figura 17 presenta la tasa de desempleo de personas con y sin educación superior. Se observa que, tanto en Valledupar como en Riohacha, se viene presentando un aumento persistente de la TD de las personas sin educación superior, ubicándose por encima de los observados para el promedio de ciudades de la costa Caribe. Por su parte, la TD de las personas educadas en Valledupar, durante la mayor parte del periodo de análisis, estuvo por

17 Esta reforma laboral redujo los costos no salariales en 13,5 pp. 
encima del promedio de 16 ciudades y del resto de ciudades de la costa Caribe. Otro hecho notable es la diferencia en los niveles de las TD de educados y no educados en Valledupar y Riohacha; allí se observa que la TD de las personas con al menos un año de educación superior es mayor que la de las personas sin educación superior, diferente a lo que sucede en las 16 ciudades restantes, donde estos dos grupos han tenido TD relativamente similares. El panel D de la figura 17 muestra cómo la TD de las personas más educadas en Valledupar se ubica 6 pp por encima de la observada en la costa Caribe y promedio de 16 ciudades.
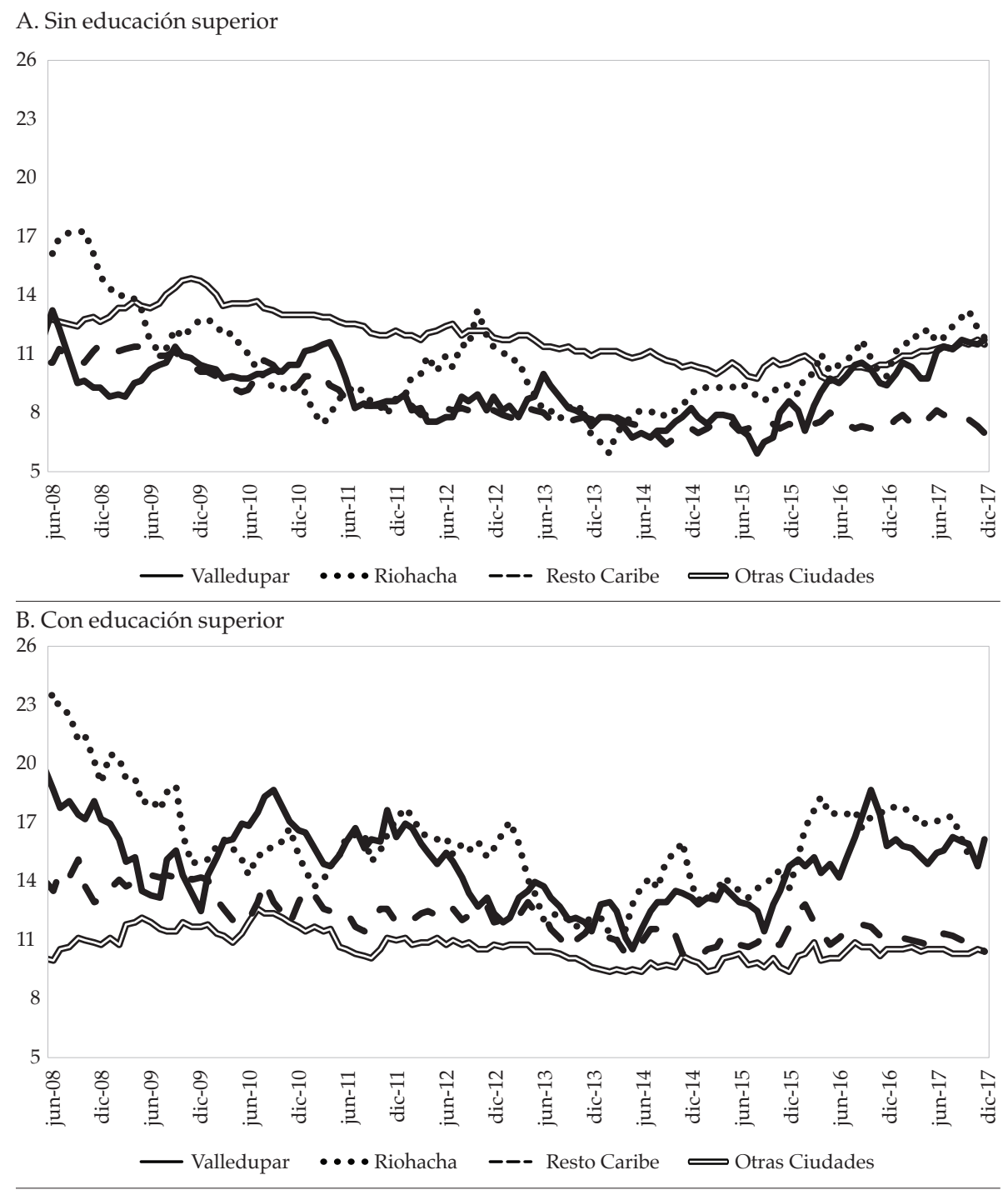


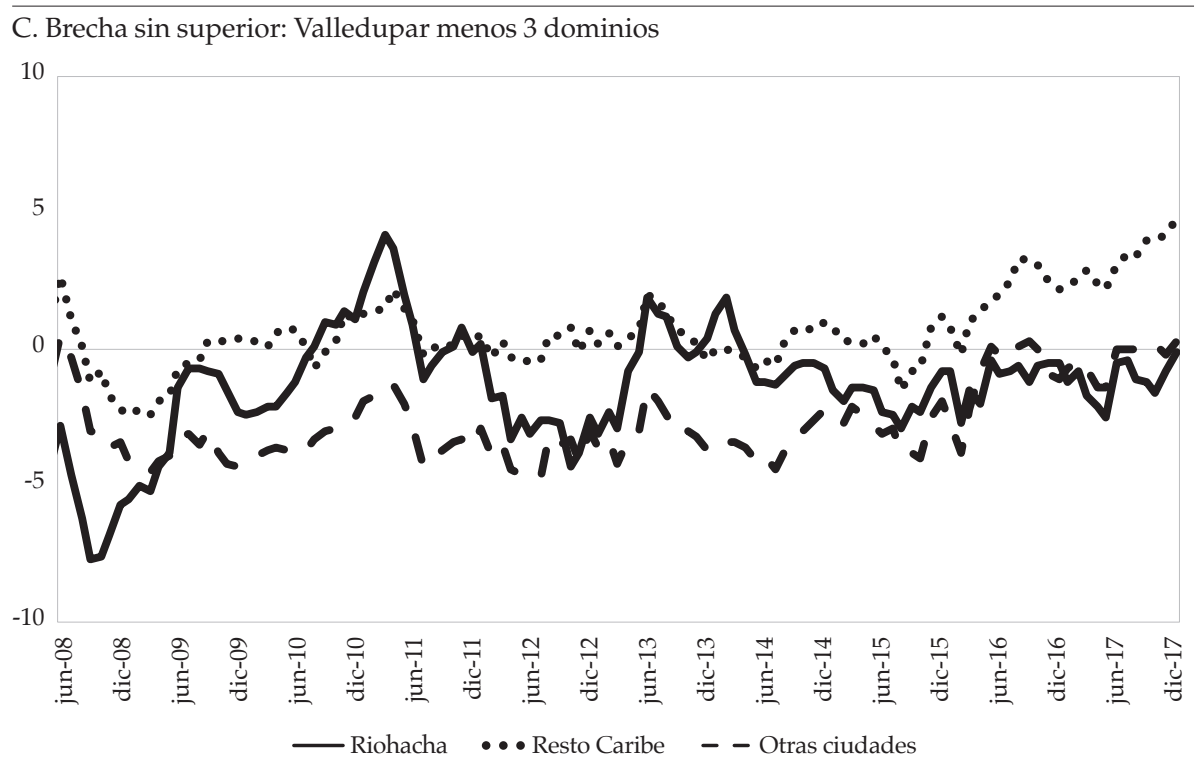

D. Brecha con superior: Valledupar menos 3 dominios

10

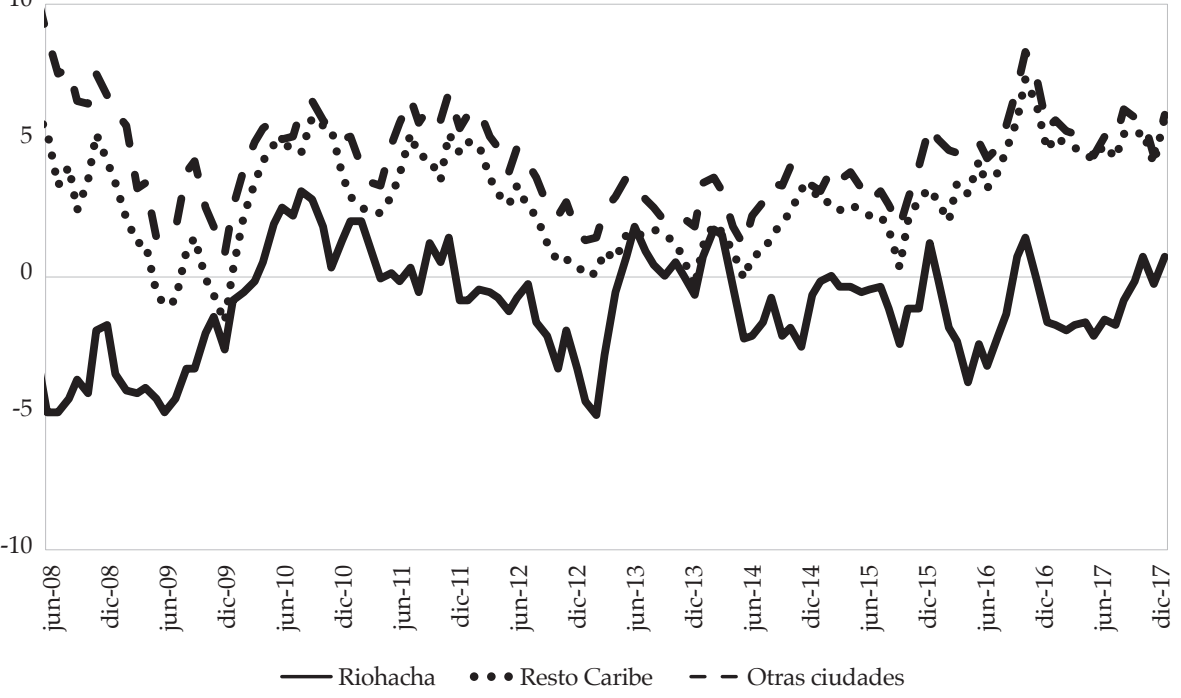

Figura 17. Tasa de desempleo por nivel educativo

Fuente: elaboración propia con datos del Departamento Administrativo Nacional de Estadística (DANE), Gran Encuesta Integrada de Hogares (GEIH).

La figura 18 muestra la TD de hombres y mujeres. Como ya se ha reportado para Colombia, la TD de las mujeres es mucho mayor que la de los hombres (Arango, Castellani \& Lora, 2017). Además, desde finales de 2015 
se observa un incremento importante de la TD tanto de los hombres como de las mujeres en Valledupar y en Riohacha; sin embargo, para el caso de las mujeres, la TD de Valledupar está 5 pp por encima de la observada en el promedio de 16 ciudades (panel D). Es interesante observar que antes de dicho periodo, la TD de los hombres, en Valledupar y Riohacha, estaba por debajo del promedio de 16 ciudades, mientras que para el caso de las mujeres esta se ubicaba alrededor de dicho promedio. El caso del resto de ciudades de la costa Caribe sobresale por una baja TD de los hombres.
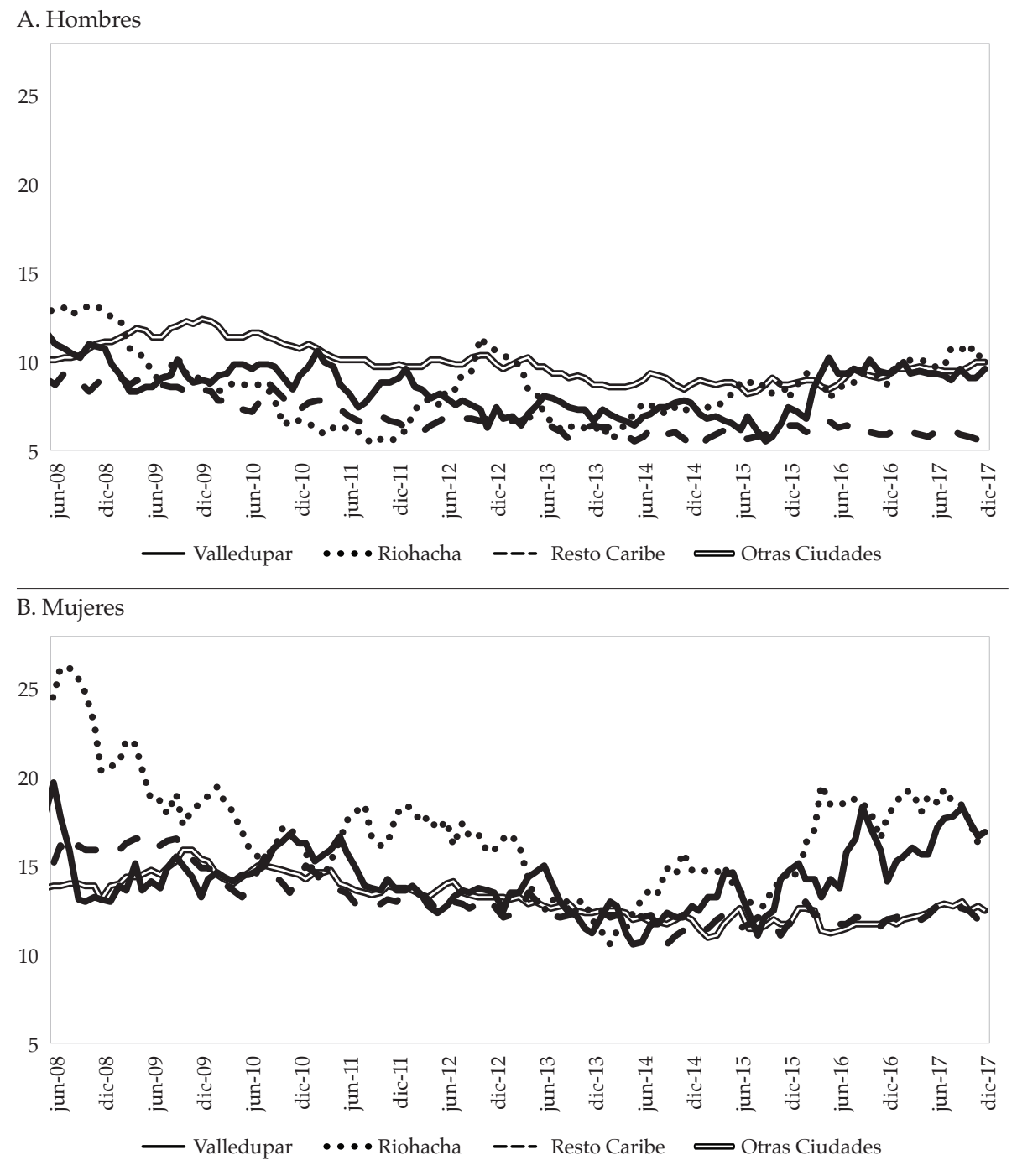


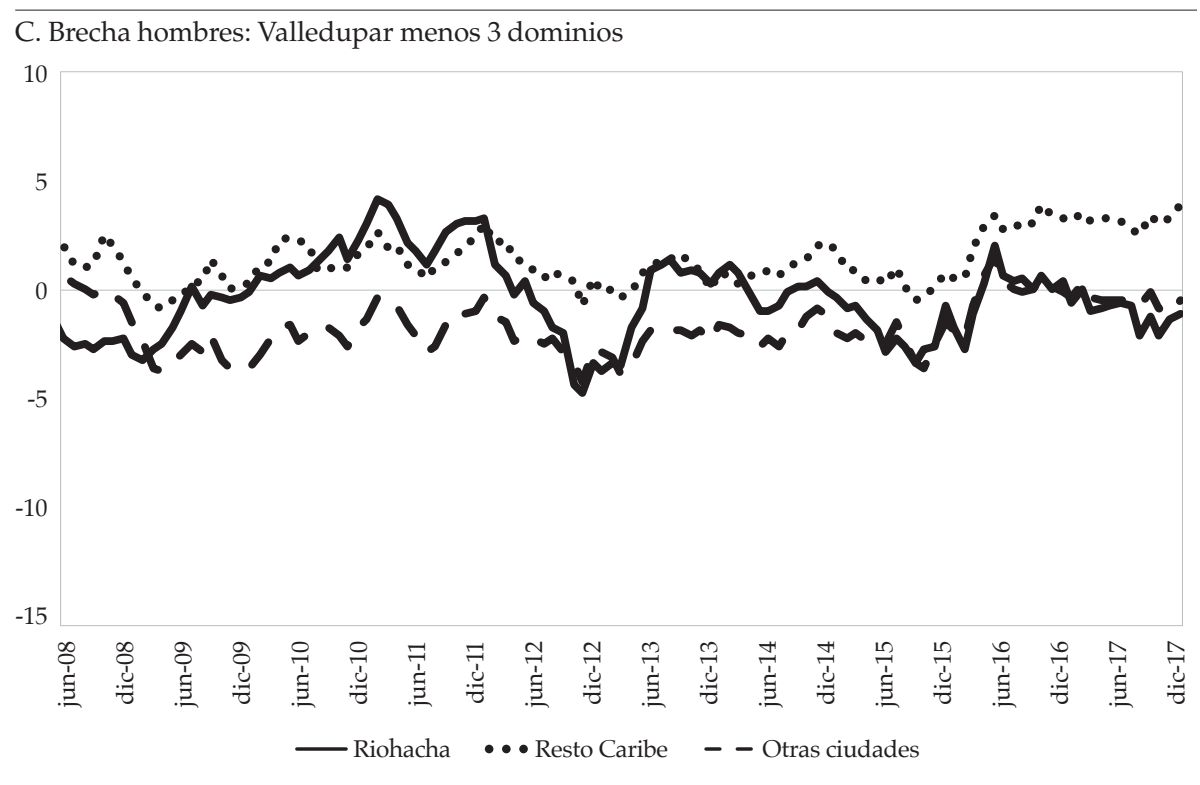

D. Brecha mujeres: Valledupar menos 3 dominios

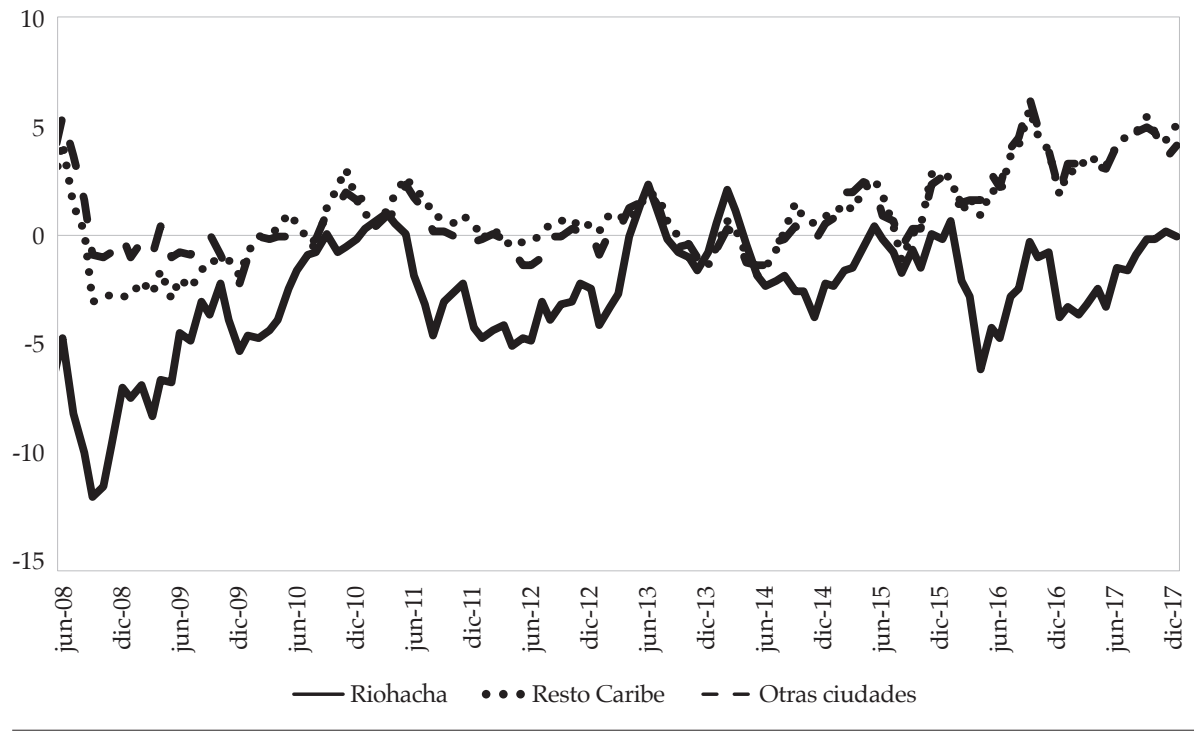

Figura 18. Tasa de desempleo por género

Fuente: elaboración propia con datos del Departamento Administrativo Nacional de Estadística (DANE), Gran Encuesta Integrada de Hogares (GEIH). 
La figura 19 presenta la evolución de la TD por edades. Desde 2015 se observa un aumento importante de la TD de Valledupar y Riohacha tanto de los menores como de los mayores de 25 años. Antes de ese período, sobresalen las bajas TD de los mayores de 25 años en Valledupar, frente al promedio de las 16 ciudades.

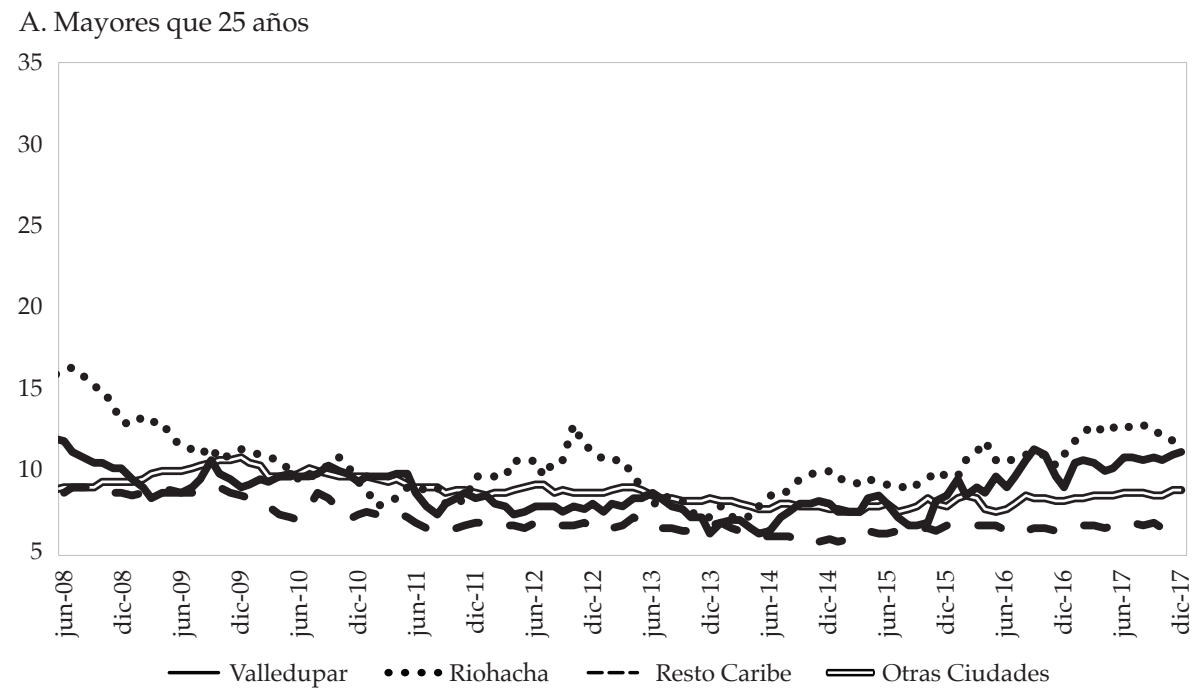

B. Menores e iguales que 25 años

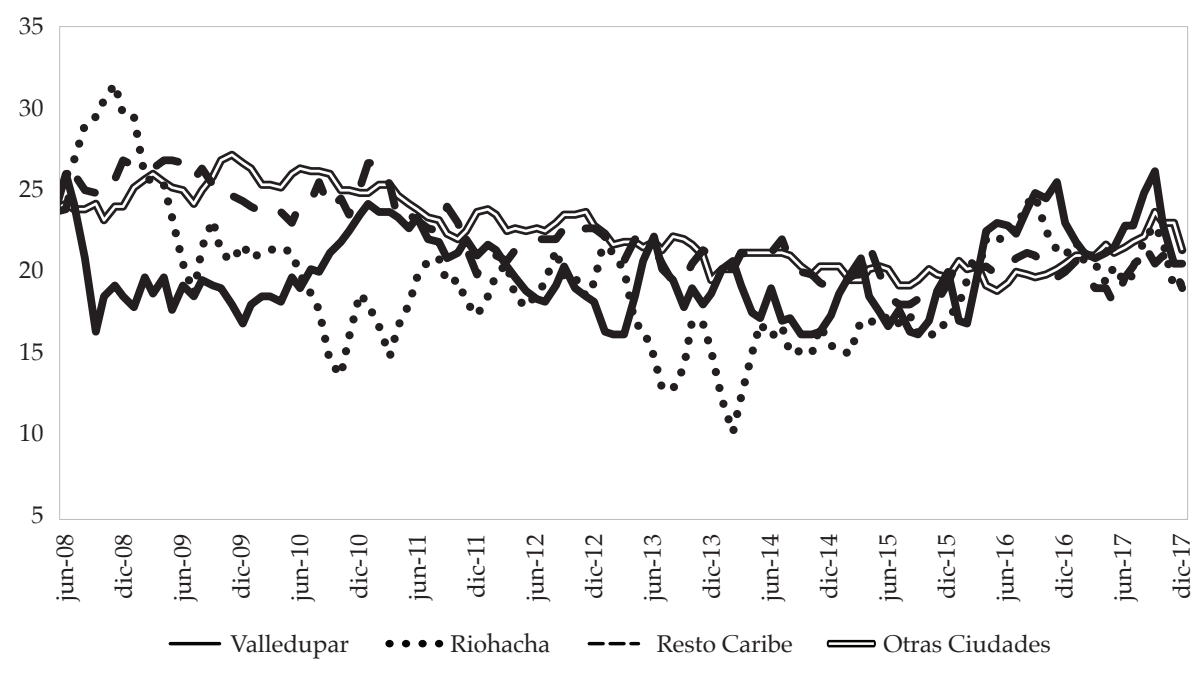


C. Brecha mayores que 25 años: Valledupar menos 3 dominios

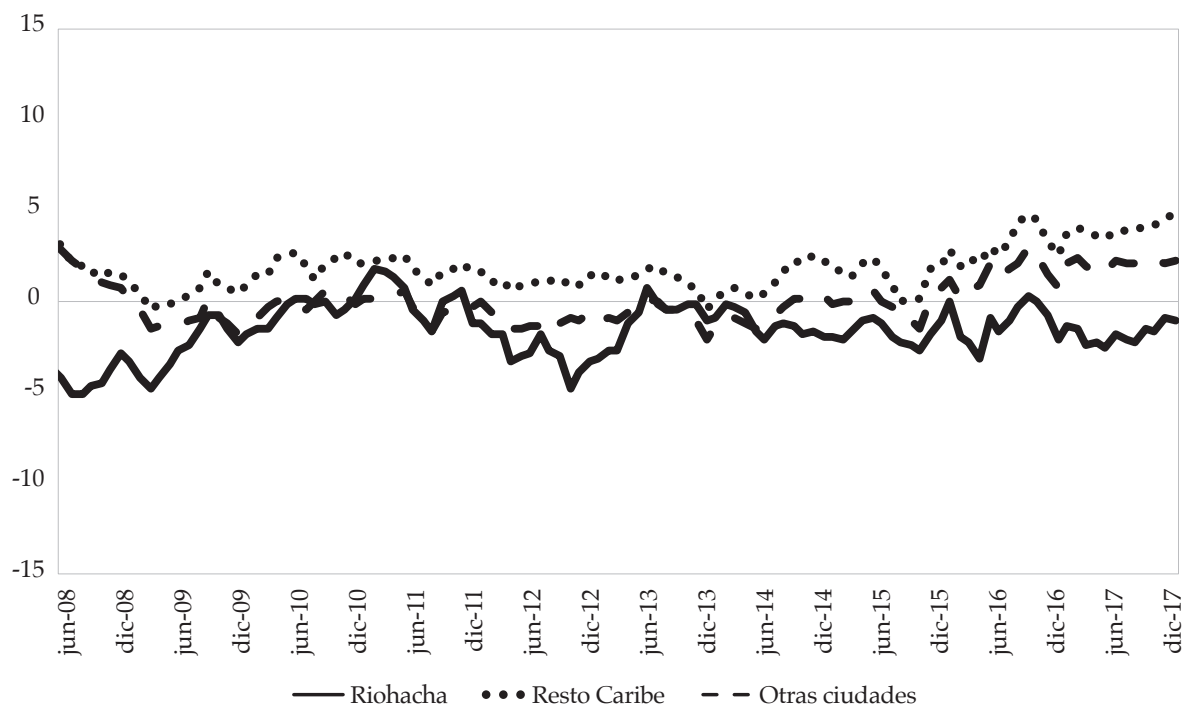

D. Brecha menores e iguales que 25 años: Valledupar menos 3 dominios

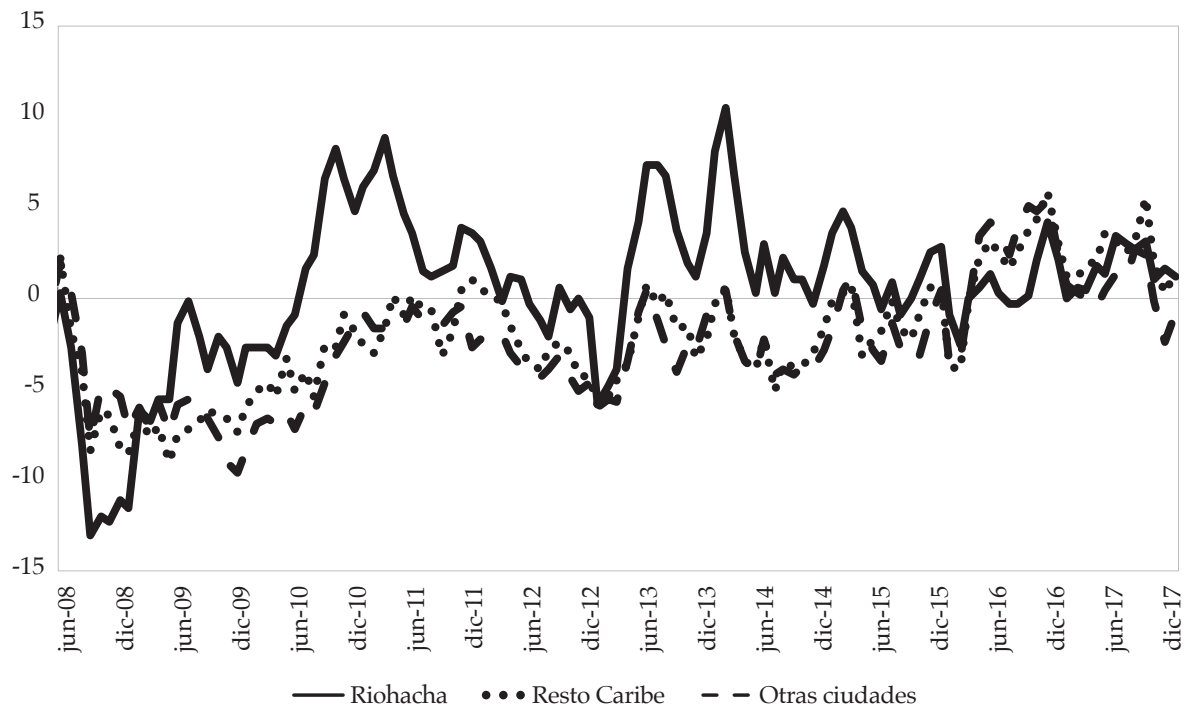

Gráfico 19. Tasa de desempleo por edades

Fuente: elaboración propia con datos del Departamento Administrativo Nacional de Estadística (DANE), Gran Encuesta Integrada de Hogares (GEIH). 
La figura 20 muestra el comportamiento reciente de los ingresos de las personas asalariadas y no asalariadas. Como se observa, existe una amplia divergencia en los salarios reales ${ }^{18}$ observados en las diferentes ciudades analizadas. Por ejemplo, para el caso de los asalariados, sobresalen los altos salarios reales observados en Riohacha, mientras Valledupar y el resto de ciudades de la costa Caribe presentan salarios reales por debajo del promedio de las 16 ciudades restantes. Adicionalmente, solo en Valledupar se observa una caída de los salarios reales desde mediados de 2016. Riohacha, por el contrario, ha mostrado salarios reales por encima del promedio de 16 ciudades durante todo el periodo analizado, con incrementos durante la coyuntura reciente (panel A). En contraste, en el caso de los no asalariados sobresalen los bajos ingresos observados en la mayoría de ciudades de la región Caribe frente al promedio de 16 ciudades, siendo Riohacha la ciudad con ingresos inferiores. Por su parte, Valledupar y el resto de ciudades de la costa Caribe presentan un comportamiento similar de los ingresos laborales (panel C).

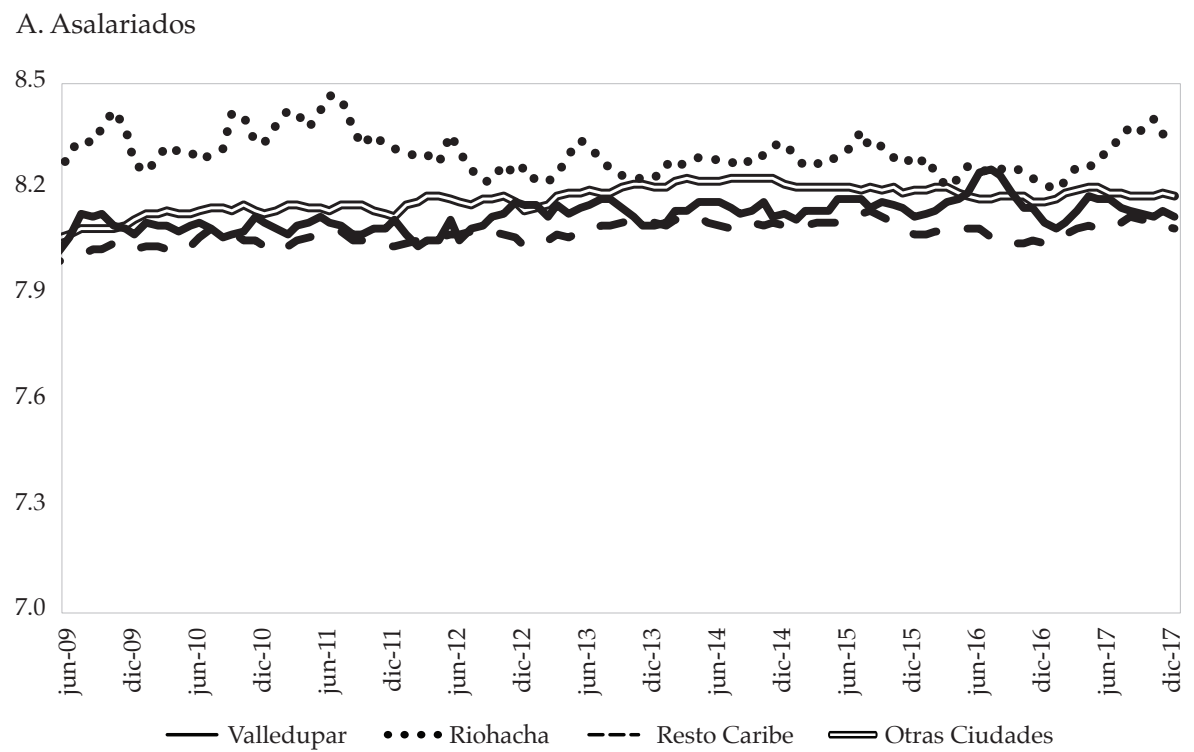

18 El ingreso laboral mediano de cada ciudad se deflactó con el IPC respectivo. En el caso de los dominios geográficos de las otras ciudades de la costa Caribe y las otras 16 ciudades, el ingreso laboral mediano real por hora corresponde a un promedio del ingreso laboral mediano de cada ciudad, ponderado por el total de ocupados de las ciudades que componen cada dominio geográfico. 


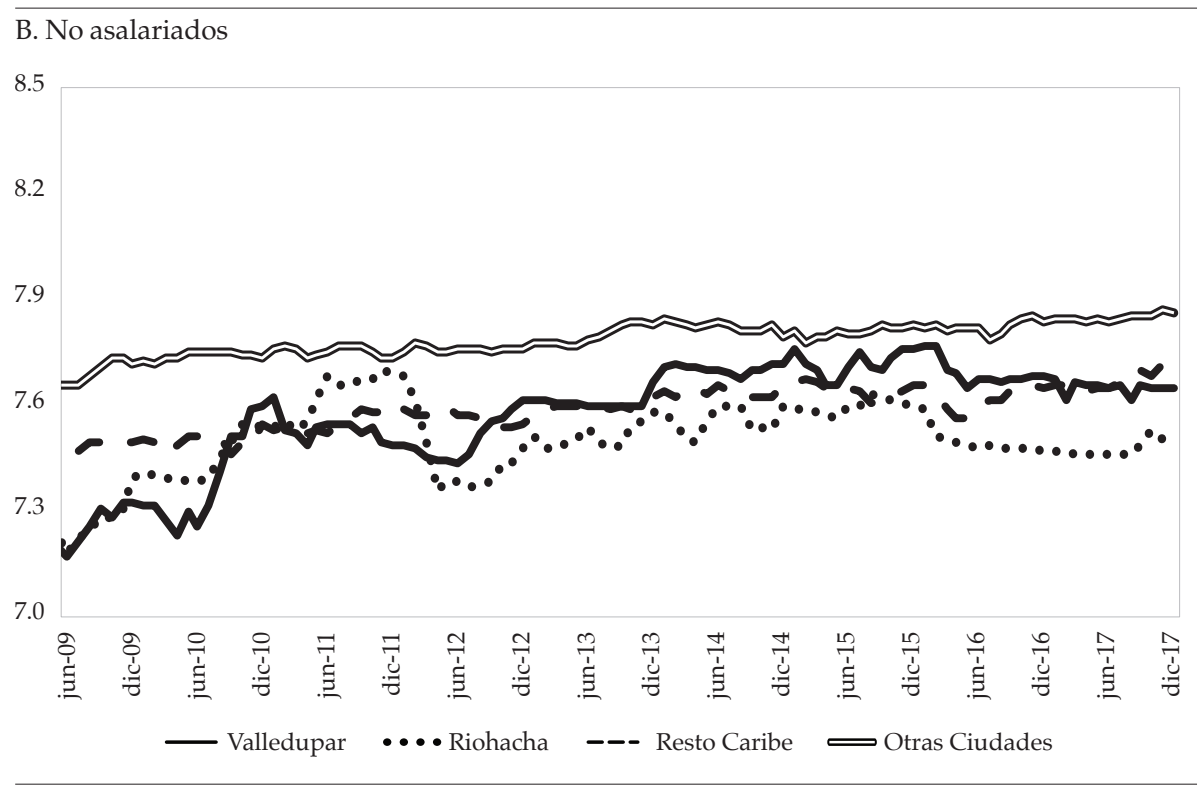

Figura 20. Ingresos laborales medianos reales (logaritmos) por hora Fuente: Departamento Administrativo Nacional de Estadística (DANE), Gran Encuesta Integrada de Hogares (GEIH).

Esta heterogeneidad también se encuentra al comparar los salarios reales por nivel educativo (figura 21). Para el caso de las personas más educadas, sobresalen los menores salarios observados en las ciudades de Valledupar y el resto de ciudades de la costa Caribe frente al promedio de 16 ciudades. En el caso de las personas sin educación superior los salarios de Valledupar, Riohacha y el resto de ciudades de la costa Caribe están levemente por debajo de los observados en el resto del promedio de 16 ciudades.

Estas divergencias de los salarios, especialmente de las personas con educación superior, derivan una de las preguntas que abordamos en este documento: ¿sigue siendo el precio de los bienes primarios determinante en la formación de los salarios en Valledupar? ¿Reflejan las distancias salariales entre grupos geográficos las diferencias en la vocación productiva de las ciudades? En la siguiente sección se exploran estas preguntas. 

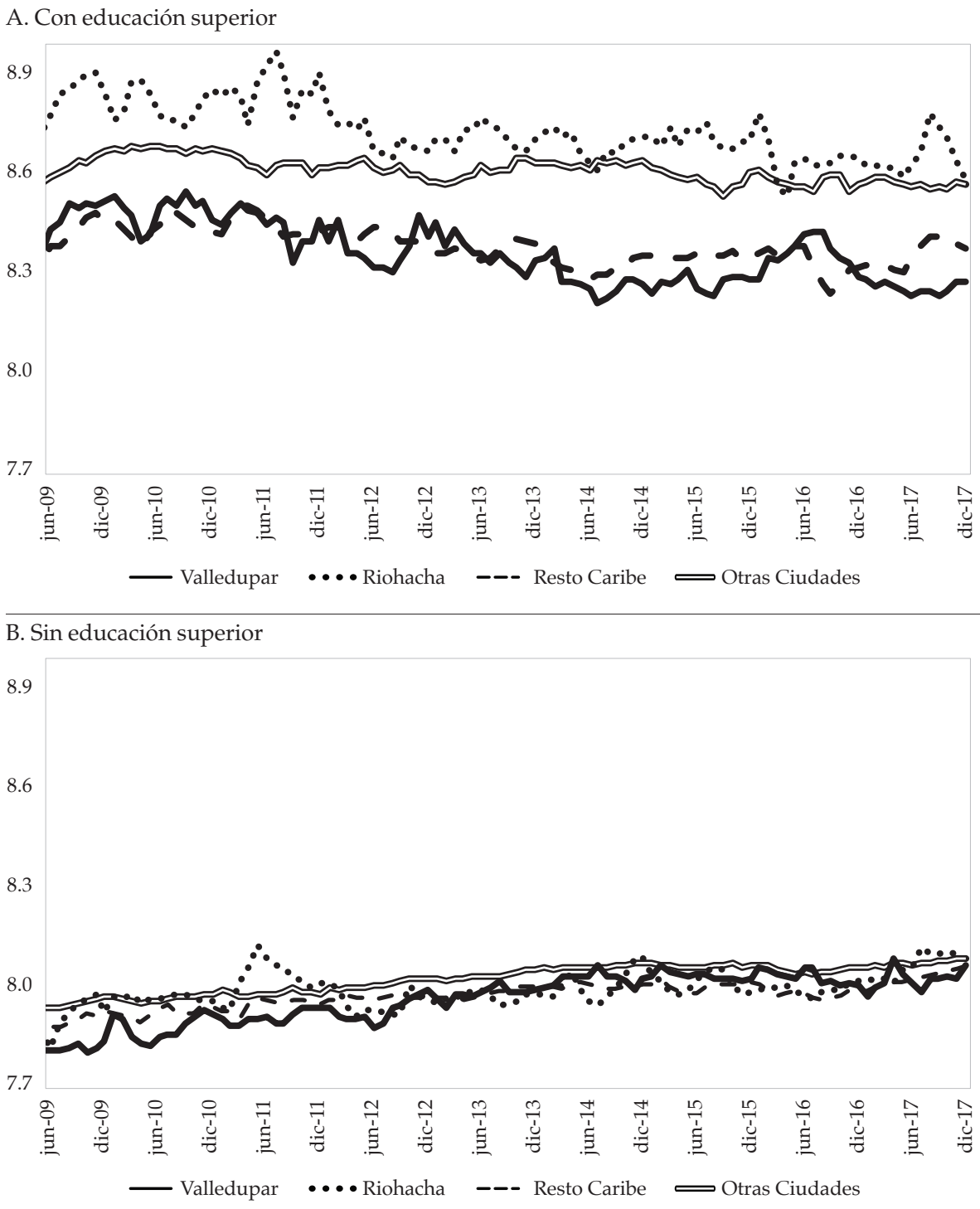

Figura 21. Salarios medianos reales (logaritmos) por nivel educativo

Fuente: elaboración propia con datos del Departamento Administrativo Nacional de Estadística (DANE), Gran Encuesta Integrada de Hogares (GEIH).

\subsection{Determinantes de los salarios}

En esta sección se realizan algunas estimaciones de los determinantes de los salarios en Valledupar, Riohacha, las otras cinco ciudades de la costa Caribe y las 16 ciudades del resto del país. Los ejercicios econométricos utilizan la 
información de los individuos entre 12 y 65 años residentes en las 23 áreas de la GEIH para el periodo 2009-2016.

El enfoque teórico utiliza una función de producción Cobb-Douglas cuyo único factor es trabajo:

$$
y=\theta N^{\alpha}
$$

siendo $N$ el número de trabajadores y $\theta$ el factor de escala. Del proceso de maximización usual se obtiene:

$$
w=\alpha \theta N^{\alpha-1}
$$

Partiendo de la ecuación (3), el enfoque empírico consiste en estimar la ecuación de ingresos:

$$
W_{i, t}=\beta_{i, t}+\beta_{e d u} e d u_{i, t}+\beta_{\exp } \exp _{i, t}+\beta_{\exp ^{2}} \exp _{i, t}^{2}+\beta_{m u j} m u j e r_{i, t}+\beta_{X} X_{i, t}+\sum_{j=0}^{k} \beta_{p c, j} p c_{t-j}+\varepsilon_{i, t}
$$

En este artículo se realiza una estimación de la ecuación de Mincer siguiendo la ecuación (4) para los asalariados ${ }^{19}$ usando la GEIH entre 2009:1 y 2016:12. Así, se modela el logaritmo del salario real por hora del individuo $i$, $W_{i, t}$, como una función del nivel de educación ${ }^{20}$ y la experiencia ${ }^{21}$ en el mercado laboral de cada individuo, y se incluye el sexo como otra característica. Como en el ejercicio realizado para la oferta, considerando la importancia del carbón en la economía del Cesar y La Guajira, se toman en cuenta las variaciones anuales de los precios internacionales del carbón y el precio del petróleo (WTI) que estarían reflejando indirectamente el ciclo económico en estas regiones. Además, se incluyen las interacciones de las dummies de nivel educativo con la variable mujer y las variaciones en los precios de las commodities. Por otra parte, para controlar por diferencias salariales entre sectores económicos se utiliza una dummy para cada uno de estos.

19 Asalariados incluyen a los empleados y obreros del sector privado y del sector público.

$20 \mathrm{Al}$ igual que en el ejercicio de oferta, se incluyen las variables años de educación y las dummies tec y uni que reflejan el nivel educativo del individuo.

21 Con base en Prada (2006) la experiencia se calcula como min \{edad - 16, edad - años de educación - 6\}. 
De igual manera, se incluye la adaptación del índice de cambios de demanda laboral de Katz y Murphy (1992) realizada por Moretti (2004). El índice captura cambios exógenos en la demanda relativa de diferentes grupos educativos, de acuerdo con la estructura económica de cada mercado laboral o ciudad. Moretti (2004) anota que si el empleo de los más educados en una industria específica aumenta a nivel nacional, las ciudades donde esa industria emplea una importante proporción de la fuerza laboral experimentará un choque positivo de la demanda de trabajadores educados. En este caso el índice de Katz y Murphy (1992) se construye como:

$$
\text { Choque }_{j c t}=\sum_{s} \eta_{s c t-1} \Delta E_{j s t}
$$

Donde choque ${ }_{j c}$ representa el cambio predicho en el empleo de los trabajadores que pertenecen al grupo educativo $j$ en la ciudad $c, \eta_{\text {sct-1 }}$ la proporción de horas trabajadas en el sector económico $s^{22}$ de la ciudad $c$ frente al total de horas trabajadas en la ciudad $c$, para el periodo $t-1$, y $\Delta E_{j s t}$, el cambio del logaritmo natural del total de horas trabajadas a nivel nacional en cada sector económico s para los trabajadores que pertenecen al grupo de educación $j$. Se definen 2 grupos de educación: sin educación superior y con al menos un año de educación superior. ${ }^{23}$

Los determinantes de los salarios se estiman por medio del método de máxima verosimilitud, corrigiendo el sesgo de selección mediante el método de Heckman (1979) y controlando los choques de demanda laboral sugerido por Moretti (2004); esta ecuación se estima solamente para los asalariados. ${ }^{24} \mathrm{La}$ tabla 3 muestra los resultados de la ecuación de Mincer (4) con y sin corrección de Heckman. La primera etapa de los resultados del modelo con corrección de selección son los presentados en la sección anterior, donde se analizó el modelo de participación laboral. Las variables usadas en la selección son el número de niños menores de seis años, el estado civil del individuo y la riqueza del hogar, las cuales estarían relacionadas con la decisión de participar, pero no con el salario. Las columnas 1, 3, 5 y 7 contienen los coeficientes sin corrección de Heckman y las columnas 2, 4, 6 y 8 con dicha corrección. Los

22 Se utilizaron las ramas económicas de manufactura, comercio, transporte, construcción, servicios comunales, servicios financieros, inmobiliarios y empresariales.

23 Este indicador se construye utilizando la información de la GEIH; para cada mes se calcula el promedio móvil semestral.

24 Se excluyeron a los individuos que reportaron salarios iguales a cero y se omitió las personas con ingresos en el $1 \%$ más bajo y $1 \%$ más alto de la distribución. 
resultados sugieren que, frente a otros dominios geográficos, en Valledupar los retornos a la educación superior son bajos tanto para tecnólogos y técnicos como para universitarios; incluso comparado con Riohacha, las diferencias son significativas, especialmente para técnicos y tecnólogos. Igualmente, las mujeres presentan menores salarios que los hombres principalmente en Valledupar y Riohacha. Estas diferencias persisten con la corrección de Heckman. En adelante se hará referencia a estos resultados.

Los coeficientes de educación y experiencia tienen los signos esperados y son estadísticamente significativos. El retorno de un año adicional de educación es cerca de 8 \% sin importar la ubicación geográfica del individuo. Sin embargo, al analizar la prima por nivel educativo se encuentran diferencias importantes. En Valledupar y las otras ciudades del Caribe, alcanzar un título como técnico o tecnólogo aumenta el retorno de educación en un $20 \%$ frente a una persona sin educación superior (columnas 2 y 6). En Riohacha este retorno es mucho mayor (34\%) según se observa en la columna 4 . Cuando el título alcanzado es universitario o de posgrado, el retorno en Valledupar aumenta en $52 \%$, siendo inferior en cerca de $18 \mathrm{pp}$ frente al promedio de 16 ciudades (columna 8). Estos resultados corroboran la hipótesis planteada en la sección anterior, donde a pesar de que las ciudades analizadas tienen una tendencia similar en la composición de la PET, los retornos de la educación de las personas más educadas difieren de manera significativa, especialmente en Valledupar.

En promedio, en los cuatro dominios geográficos analizados, las mujeres tienen un menor salario que los hombres. En Valledupar y Riohacha esta diferencia es mayor que $36 \%$, mientras que en las otras capitales de la costa Caribe y en las demás ciudades la diferencia es de $27 \%$ y $21 \%$, respectivamente.

Sin embargo, es importante señalar, que las mujeres universitarias tienen un mayor salario respecto de los individuos que no tienen educación superior, ${ }^{25}$ siendo el retorno más alto en Valledupar y Riohacha (21 \% y $23 \%$ respectivamente), aunque inferior al retorno marginal de un universitario promedio en cada dominio geográfico (por encima del $50 \%$ ). ${ }^{26}$

25 Incluso al estimar la ecuación de ingresos solamente para personas con educación universitaria, el coeficiente de la variable de género (mujer) es positivo y significativo en los cuatro dominios geográficos.

26 Lo anterior indicaría que la menor participación laboral de las mujeres podría también estar relacionada con los menores retornos. 


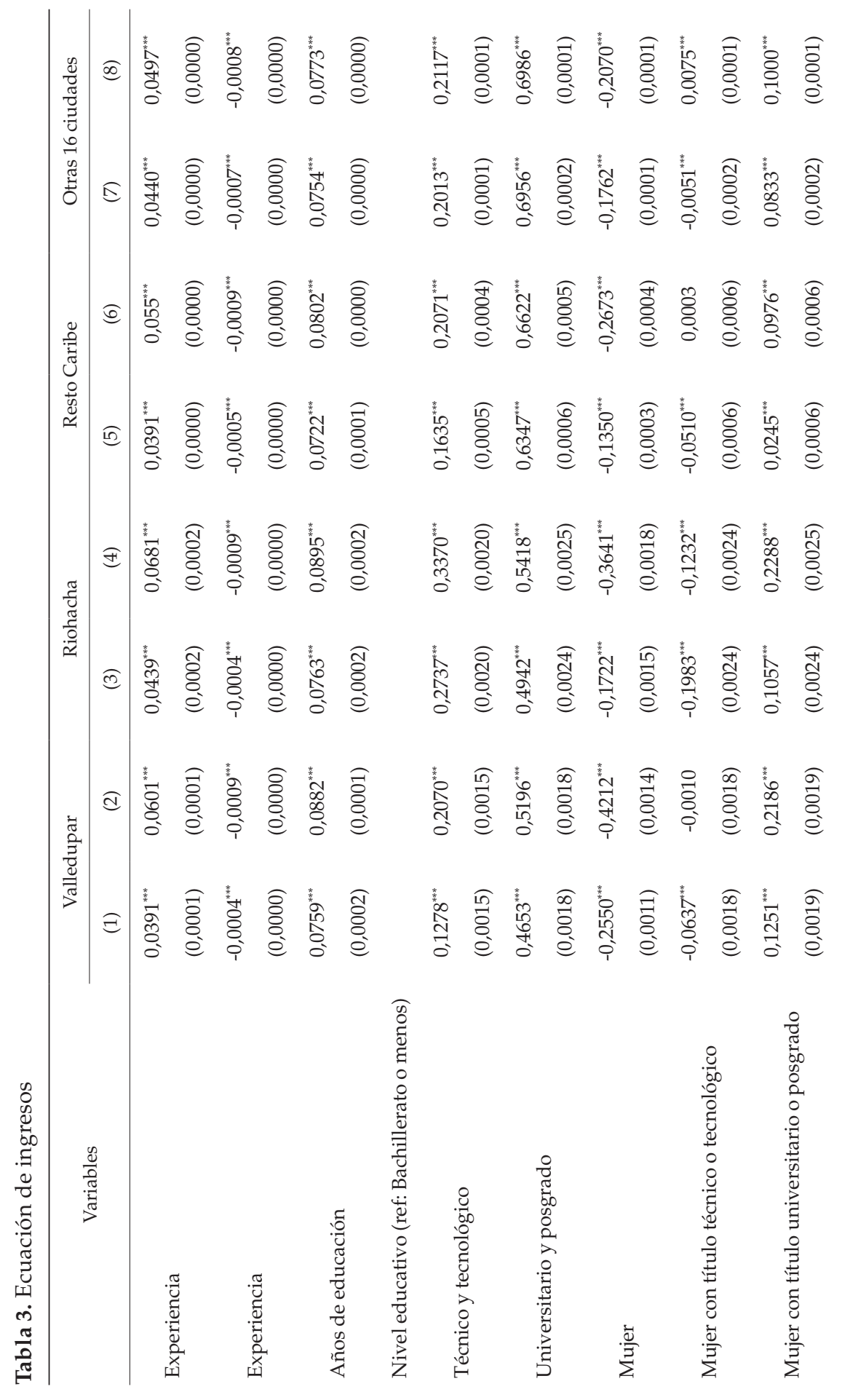




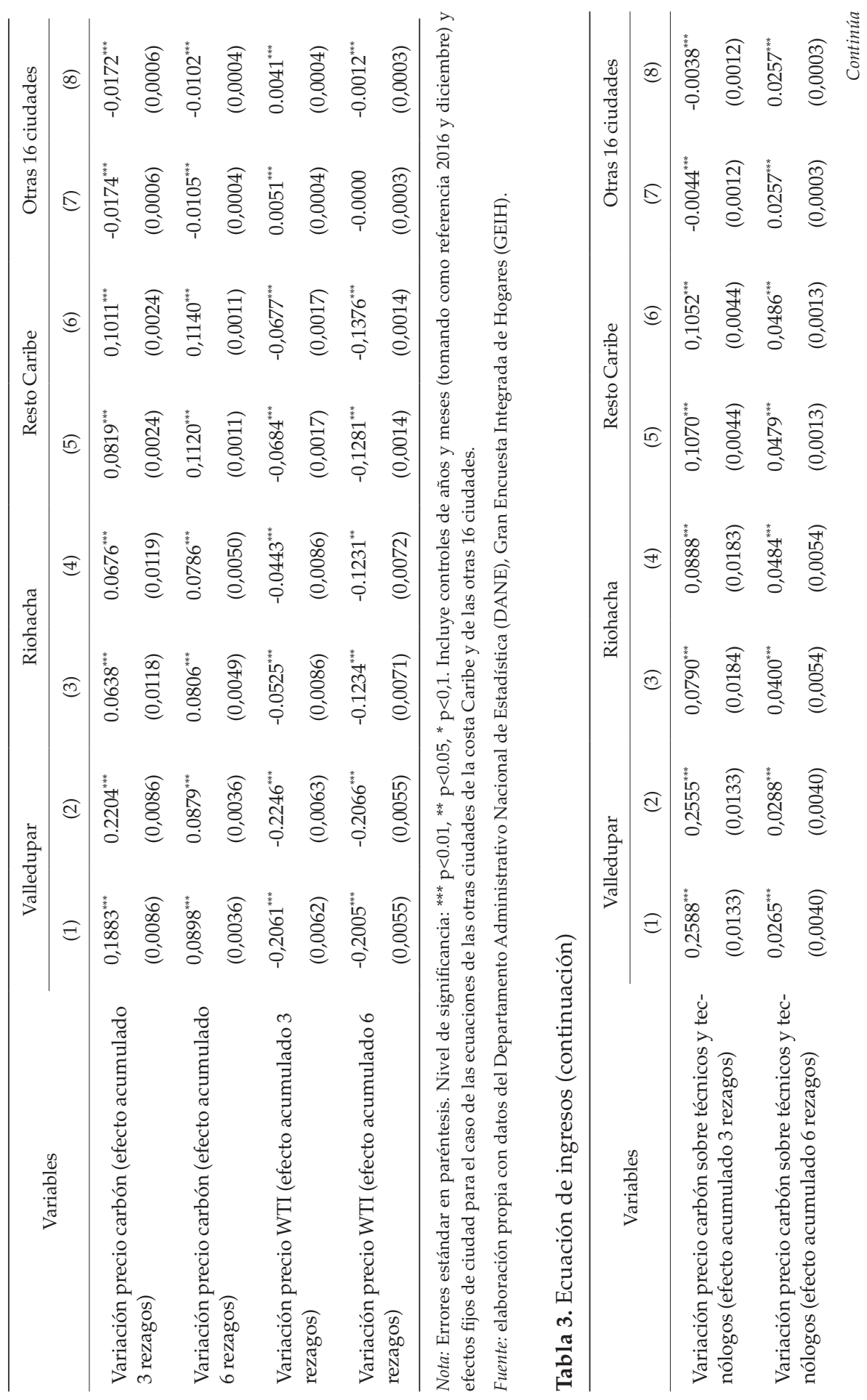




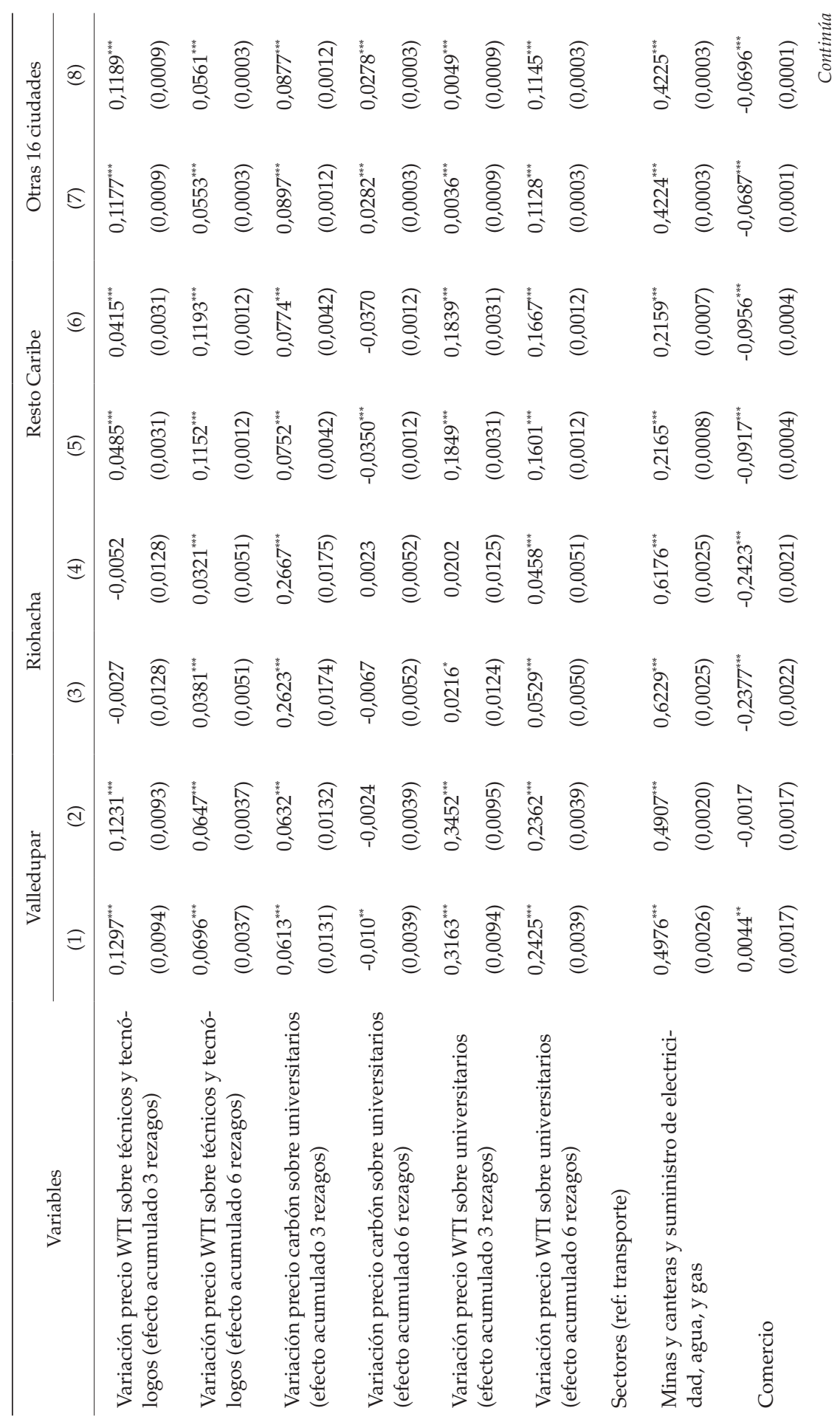




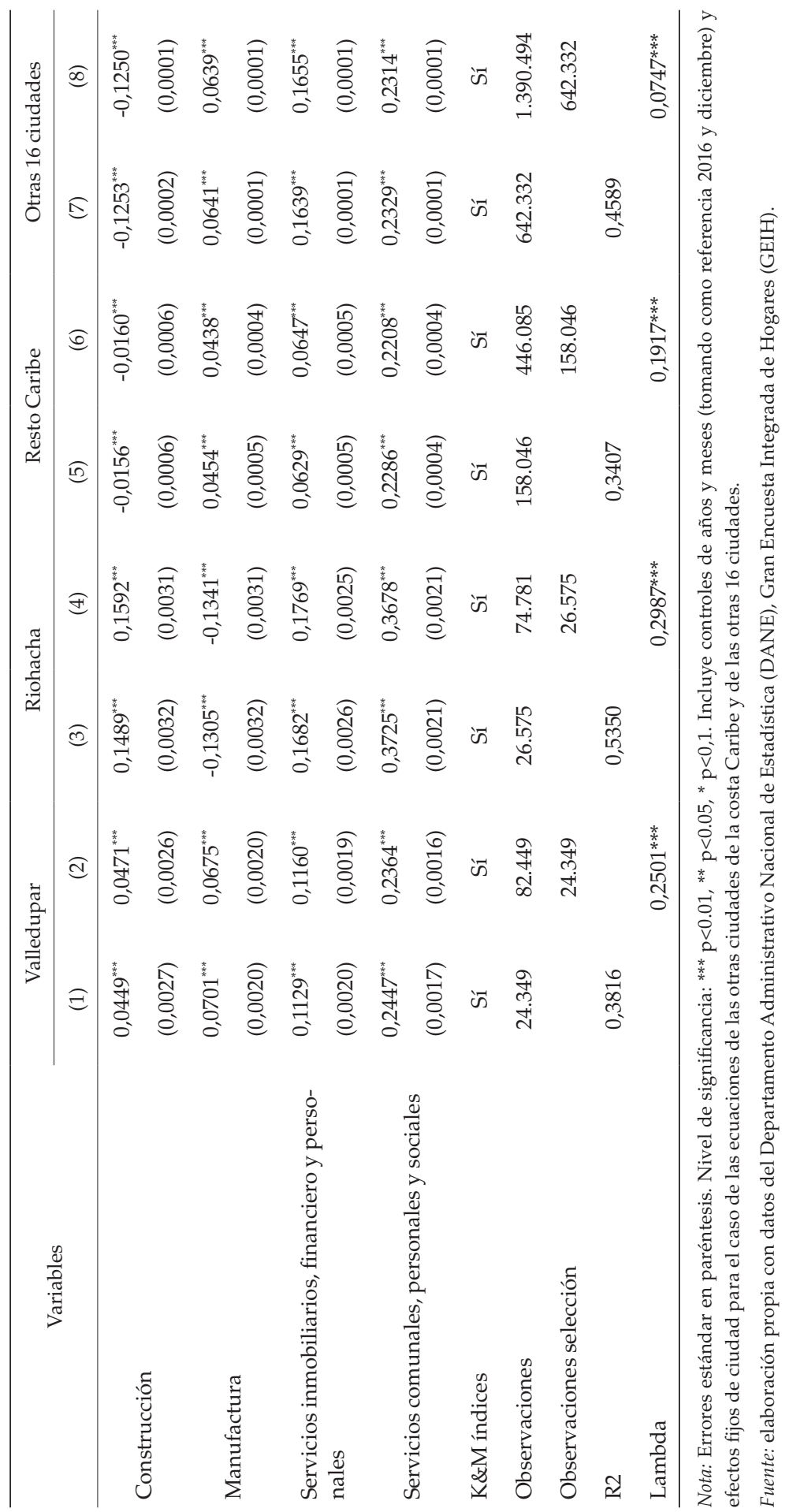


Estos resultados corroboran los encontrados por Galvis (2010) para las 13 principales ciudades, ${ }^{27}$ quien encuentra una amplia heterogeneidad de las brechas salariales en favor de los hombres. Por ejemplo, Bogotá, Cali, Medellín, Manizales y Pereira muestran las menores desigualdades salariales por género, mientras Bucaramanga, Ibagué, Pasto, Cúcuta, y tres de las ciudades de la costa Caribe (Barranquilla, Montería y Cartagena) muestran las mayores brechas. Adicionalmente, el autor resalta que estas brechas salariales parecen tener mayor importancia en la población de ingresos bajos, especialmente en las ciudades más distantes al centro del país.

En cuanto a los precios de los commodities, un aumento del precio del carbón tiene un efecto positivo en los salarios de las ciudades de la costa Caribe, especialmente en Valledupar y Riohacha, ciudades ubicadas en una región donde el carbón es motor de la actividad económica. Sin embargo, el impacto de los mayores precios del carbón sobre los salarios es diferencial dependiendo del nivel educativo de los individuos. En Valledupar, los más beneficiados son los técnicos y tecnólogos, con respecto a los bachilleres y personas de menor educación, quienes registran mayores salarios con aumentos de precios en un horizonte acumulado de tres meses. Por lo tanto, la caída reciente de los precios del carbón es compatible con el comportamiento de los salarios observados en la figura 21 , donde las mayores reducciones corresponden a las personas más educadas.

En relación con los precios del petróleo, los menos beneficiados con sus aumentos son las personas de menor educación ${ }^{28}$ en toda la región Caribe, especialmente en Valledupar. Estos registran efectos acumulados negativos en horizontes de tres y seis meses. Los técnicos y tecnólogos también presentan caídas acumuladas en sus salarios, aunque menores que las observadas para los menos educados. En esta región (con excepción de Riohacha) y especialmente en Valledupar, los únicos que presentan un efecto positivo del precio del petróleo en su salario son los universitarios; por su parte, en las 16 ciudades el efecto del precio de petróleo es positivo, tanto para los técnicos y tecnólogos como para los universitarios.

27 Barranquilla, Bogotá, Bucaramanga, Cali, Cartagena, Cúcuta, Ibagué, Manizales, Medellín, Montería, Pasto, Pereira y Villavicencio.

28 Sin hacer, énfasis en esta zona del país, el efecto diferencial de los choques en los precios del WTI en los salarios de los menos educados ya había sido argumentado antes por Perilla (2010), quien sostiene que se podía observar un encarecimiento de los precios domésticos de combustibles, aumentando los costos de las empresas y generando presiones a la baja de los salarios de los trabajadores, especialmente de los menos capacitados, mientras la demanda de los más capacitados aumenta. 
En la tabla 3 también se presentan las diferencias salariales por sectores. Se encuentra que, en los cuatro dominios geográficos, tomando como referencia el sector transporte, los salarios de los sectores de minas y canteras y suministro de electricidad, gas y agua tienen los salarios más altos, seguido por el sector de servicios comunales, personales y sociales, el cual está asociado con las actividades de gobierno. Pese a que durante el período de análisis hay alguna respuesta en los salarios de un sector transable como es el manufacturero, en relación con el de transporte, la misma es mucho menor que en los salarios del sector de minas y canteras, lo cual se ajusta a la predicción del modelo competitivo. Los sectores de servicios también registran salarios más altos que los de transporte.

\section{Conclusiones y recomendaciones de política}

Este artículo estudia el mercado laboral de Valledupar en el periodo 2007-2017. Dado que el referente es Riohacha, también se derivan lecciones del mercado de trabajo para esta ciudad. El artículo contribuye con la explicación de la heterogeneidad geográfica del mercado laboral en Colombia. En este caso particular, se verificó la importancia de los choques del precio del carbón y también del petróleo en los mercados internacionales, sobre la economía del Cesar, particularmente en su capital Valledupar.

Además, se encuentra una importante dependencia, tanto en la oferta como en la demanda laboral, de los precios del carbón, lo cual va en línea con la importancia de la actividad carbonífera en la economía del departamento. En tal sentido, la caída de la participación laboral entre 2014 y 2016 en Valledupar estuvo influenciada en gran parte por la caída de los precios del carbón en ese periodo. Dado el signo positivo de los coeficientes de los precios del carbón en la probabilidad de participar, la intuición sugiere que domina el efecto sobre el salario de mercado por encima del salario de reserva de las personas.

El efecto de los precios del carbón en la probabilidad de participar es mayor durante los primeros tres meses que al finalizar los primeros seis meses después del choque. Sin embargo, este siempre es más alto en Valledupar seguida de Riohacha. Las variaciones en los precios del petróleo (WTI) también afectan la decisión de participar, no solo en menor medida sino también con el signo contrario. Es probable que en este caso el canal de afectación esté más asociado con el salario de reserva -posiblemente vía regalías y otros efectos indirectos- que con el salario de mercado.

Además de los precios de los commodities, también se encontró evidencia de que, la menor participación laboral en Valledupar se explica por otros 
factores estructurales como la mayor proporción de jóvenes y mujeres en la PET, frente a otras ciudades del país.

Por el lado de la demanda, un choque positivo de los precios del carbón produce aumentos en los salarios, en la región Caribe, principalmente en Valledupar y Riohacha; sin embargo, el efecto de los mayores precios del carbón es diferencial dependiendo del nivel educativo. En Valledupar los técnicos y tecnólogos registran los mayores incrementos salariales frente a las personas de menor educación. Por su parte los universitarios presentan incrementos positivos similares a los observados en el resto del Caribe y las 16 capitales restantes, pero después de seis meses el efecto acumulado solo es significativo en este último dominio.

Las variaciones exógenas del precio del WTI reducen los salarios de las personas menos educadas en toda la región Caribe, especialmente en Valledupar; los universitarios son los únicos que presentan incrementos positivos en sus salarios. Por otro lado, en las 16 ciudades el efecto de los precios del petróleo es positivo tanto para técnicos y tecnólogos como para universitarios.

En Valledupar, alcanzar algún título de educación superior tiene un retorno menor que en los otros dominios analizados. Estos retornos diferenciales entre ciudades podrían estar indicando diferencias de productividad o de las estructuras de los mercados locales, especialmente en lo relacionado con la participación de las mujeres. Los resultados econométricos indican que, en general, las mujeres tienen un menor salario frente a los hombres, pero esta diferencia es mayor en Valledupar y Riohacha que en el resto de ciudades. Este resultado, que no es nuevo en la literatura, ${ }^{29}$ requiere de un examen profundo con el fin de adoptar medidas que permitan un tratamiento más igualitario y equitativo de las mujeres en estos mercados laborales locales.

Algunos estudios han resaltado los bajos retornos observados en la década reciente en algunos programas de estudios superiores. Por ejemplo, Camacho, et al. (2017) encuentra que detrás de estos retornos menores estaría la menor calidad de los estudiantes que escogen dichos programas y los bajos retornos de las áreas ofrecidas. Aunque en este documento no se evalúa la calidad de los programas en Valledupar, este podría ser el caso, donde las personas no solo se estarían capacitando más en áreas menos rentables, si no también menos pertinentes para el mercado laboral local. Los resultados anteriores podrían estar evidenciando la necesidad de enfocar los estudios superiores en áreas que realmente sean críticas en los mercados locales. Para

29 Galvis (2010) efectivamente encuentra que las brechas salariales de género son heterogéneas para las 13 principales ciudades y son de mayor magnitud en las ciudades de menores ingresos y más distantes del centro del país. 
ello se requiere una mayor comunicación entre el sector productivo y el sector educativo local siempre con visión futurista.

Por lo anterior, es importante diseñar políticas orientas a las necesidades específicas de cada ciudad o región, especialmente en economías como la de Valledupar, cuya dinámica está vinculada al precio del carbón y donde una caída en este afecta principalmente a las personas de menor educación. Dichas políticas podrían enfocarse en una capacitación o readiestramiento de la mano de obra de forma que, ante caídas de la demanda laboral de un sector específico, esta se pueda reubicar rápidamente ya sea en la misma ciudad o en cualquier otra ciudad del país. Desde luego que los programas de reentrenamiento deben estar financiados, al menos parcialmente, con recursos obtenidos durante los períodos de auge de precios, es decir, en la época de altos salarios. Por lo tanto, se debería pensar en programas de ahorro o líneas de aseguramiento que cumplan dicho propósito.

\section{Referencias}

Arango, L. E. (2013). Mercado de trabajo en Colombia: suma de partes heterogéneas. En L. E. Arango, \& F. Hamann (Ed.), El mercado de trabajo en Colombia: hechos, tendencias e instituciones (pp. 167-202). Bogotá: Banco de la República.

Arango, L.E., \& Flórez, L.A. (2018). Determinants of Structural Unemployment in Colombia. A Search Approach. Empirical Economics. Doi: https: / / doi. org/10.1007/s00181-018-1572-y.

Arango, L.E., \& Flórez, L.A. (2017). Informalidad laboral y elementos para un salario mínimo diferencial por regiones en Colombia. Borradores de Economía, 1023, Banco de la República.

Arango, L. E., Castellani, F., \& Lora, E. (2017). Desempleo femenino en Colombia. Bogotá: Banco de la República.

Bonet, J., \& Ayala, J. (2017). Las Finanzas públicas de Valledupar, 2005-2015. Documento de Trabajo sobre Economía Regional, 252, Banco de la República.

Banco de la República. (2017). Costa Caribe, II trimestre 2017, Boletín Económico Regional (BER). Banco de la República.

Camacho, A., Messina, J., \& Uribe Barrera, J. P. (2017). The Expansion of Higher Education in Colombia: Bad Students or Bad Programs? Documento CEDE, (2017-13). Universidad de los Andes.

Cárdenas, C., Hernández, M., \& Torres, J. (2015), A Statistical Analysis of Heterogeneity on Labour Markets and Unemployment Rates in Colombia. Desarollo \& Sociedad, (75), 153-196. 
CEPAL, N. (1998). Ciudades intermedias de América Latina y el Caribe: propuestas para la gestión urbana. Santiago de Chile: CEPAL.

DANE. (2016). Comunicado de Prensa, Recuperado de https:/ /www.dane. gov.co/files/investigaciones/.../CP_ctas_dptal_2011def_2013pre.pdf

Drummond. (2018). Página web principal de la empresa. Recuperado de http:/ / www.drummondco.com/nuestro-compromiso/empleados/?lang=es

Ehrenberg, R. G., \& Smith, R. S. (2009). Modern Labor Economics: Theory and Public Policy. Routledge.

El Heraldo (2017). Prodeco produjo 11,1 millones de toneladas de carbón en Calenturitas. El Heraldo. Recuperado de https://www.elheraldo.co/ economia/prodeco-produjo-111-millones-de-toneladas-de-carbon-encalenturitas-336392

Eslava, M., Bernal, R., Meléndez, M., \& Pinzón, A. (2017). Switching from Payroll Taxes to Corporate Income Taxes: Firms's Employment and Wages after the Colombian 2012 Tax Reform. Inter-American Development Bank. Technical Note, IDB-TN-1268.

Fernández, C., \& Villar, L. (2016). The Impact of Lowering the Payroll Tax on Informality in Colombia, Working Paper, No. 72, Fedesarrollo.

Galvis, L. A. (2010). Diferenciales salariales por género y región en Colombia: Una aproximación con regresión por cuantiles. Revista de Economía del Rosario, 13(2), 235-277.

Guzmán, K. (2013). La industria de lácteos en Valledupar: primera en la región Caribe. Documento de Trabajo sobre Economía Regional, No. 184, Banco de la República

Heckman, J. (1979), Sample Selection Bias as a Specification Error, Econometrica, 47 (1), 153-161.

Katz, L. F., \& Murphy, K. M. (1992). Changes in Relative Wages, 1963-1987: Supply and Demand Factors. The Quarterly Journal of Economics, 107(1), 35-78.

La República (2018). Acuerdo entre sindicato y Cerrejón evita huelga en mayor mina de carbón de Colombia. La República. Recuperado de https:/ / www.larepublica.co/economia/acuerdo-entre-sindicato-y-cerrejon-evitahuelga-en-mayor-mina-de-carbon-de-colombia-2597493

Meisel, A. (2007). La Guajira y el mito de las regalías redentoras. Banco de la Republica de Colombia. Documentos de trabajo sobre Economia Regional y Urbana No. 86.

Meisel A., \& Ricciulli, D. (2018). La pobreza en Santa Marta: Los Estragos del Bien. Banco de la República de Colombia, Documentos de trabajo sobre Economia Regional y Urbana No. 266. 
Mincer, J. (1974). Schooling, Experience, and Earnings. Human Behavior \& Social Institutions No. 2.

Mora, J. J., \& Ulloa, M. P. (2011). Calidad del Empleo en las Principales Ciudades Colombianas y Endogeneidad de la Educación. Revista de economía institucional, 3(25), 163-177.

Morales, L., \& Medina, C. (2016). Assessing the Effect of Payroll Taxes on Formal Employment: The Case of 2012 Tax Reform in Colombia, Borradores de Economía, 971. Banco de la República.

Moretti, E. (2004). Estimating the Social Return to Higher Education: Evidence from Longitudinal and Repeated Cross-Sectional Data. Journal of econometrics, 121(1-2), 175-212.

Osorio, L.M. (2016). Reforma tributaria e informalidad laboral en Colombia: Un análisis de equilibrio general dinámico y estocástico. Ensayos de Política Económica, 34 (80), 126-145.

Prada, C. F. (2006). ¿Es rentable la decisión de estudiar en Colombia? Ensayos sobre política económica, 24, 226-323.

Perilla, J. (2010). El impacto de los precios del petróleo sobre el crecimiento económico en Colombia. Revista de economía del Rosario, 13(1), 75-116.

Posada, C. E., y Arango, L. E. (2003). La participación laboral en Colombia. Coyuntura Social, No. 28, Fedesarrollo.

\section{Anexo}

Tabla A. Estadísticas descriptivas: medias muéstrales y desviaciones estándar

\begin{tabular}{|c|c|c|c|c|}
\hline \multirow[t]{2}{*}{ Variable } & Valledupar & Riohacha & $\begin{array}{c}\text { Caribe } \sin (1) \\
y(2)\end{array}$ & $\begin{array}{l}\text { Otras } 16 \\
\text { ciudades }\end{array}$ \\
\hline & (1) & (2) & (3) & (4) \\
\hline \multirow{2}{*}{ Edad } & 32,84 & 32,28 & 33,85 & 34,41 \\
\hline & $(14,57)$ & $(14,12)$ & $(14,70)$ & $(14,88)$ \\
\hline \multirow{2}{*}{ Años de educación } & 9,65 & 9,69 & 9,67 & 9,73 \\
\hline & $(4,21)$ & $(4,55)$ & $(4,10)$ & $(4,30)$ \\
\hline \multirow{2}{*}{ Experiencia } & 15,31 & 14,56 & 16,37 & 16,81 \\
\hline & $(14,52)$ & $(13,92)$ & $(14,67)$ & $(14,88)$ \\
\hline \multirow{2}{*}{$\begin{array}{l}\text { Número de niños de } 5 \text { años o menos en } \\
\text { el hogar }\end{array}$} & 0,50 & 0,57 & 0,47 & 0,34 \\
\hline & $(0,76)$ & $(0,81)$ & $(0,74)$ & $(0,61)$ \\
\hline $\begin{array}{l}\% \text { de hogares con presencia de menores } \\
\text { de } 6 \text { años en los que la mujer no participa }\end{array}$ & $20,53 \%$ & $19,97 \%$ & $19,48 \%$ & $12,41 \%$ \\
\hline
\end{tabular}




\begin{tabular}{|c|c|c|c|c|}
\hline \multirow{2}{*}{ Variable } & Valledupar & Riohacha & $\begin{array}{c}\text { Caribe } \sin (1) \\
\mathrm{y}(2)\end{array}$ & $\begin{array}{l}\text { Otras } 16 \\
\text { ciudades }\end{array}$ \\
\hline & (1) & (2) & (3) & (4) \\
\hline \multirow{2}{*}{ Tasa de desempleo } & $10,80 \%$ & $11,87 \%$ & $9,59 \%$ & $11,47 \%$ \\
\hline & $(1,22)$ & $(1,71)$ & $(1,12)$ & $(1,16)$ \\
\hline $\begin{array}{l}\text { \% personas con por lo menos un años de } \\
\text { educación superior / PET }\end{array}$ & $29,07 \%$ & $31,98 \%$ & $25,96 \%$ & $28,09 \%$ \\
\hline$\%$ mujeres $/$ PET & $55,25 \%$ & $54,65 \%$ & $53,59 \%$ & $54,44 \%$ \\
\hline \% casados o unión libre/ PET & $46,62 \%$ & $48,86 \%$ & $49,03 \%$ & $44,91 \%$ \\
\hline $\begin{array}{l}\text { \% personas con título Técnico o tecnoló- } \\
\text { gico / PET }\end{array}$ & $11,12 \%$ & $12,07 \%$ & $8,59 \%$ & $9,16 \%$ \\
\hline $\begin{array}{l}\% \text { personas con título Universitario y } \\
\text { superior / PET }\end{array}$ & $9,81 \%$ & $12,45 \%$ & $10,16 \%$ & $10,75 \%$ \\
\hline $\begin{array}{l}\% \text { población que cumple con condición } \\
\text { riqueza }=1\end{array}$ & $52,11 \%$ & $41,29 \%$ & $52,97 \%$ & $50,56 \%$ \\
\hline \multirow{2}{*}{$\begin{array}{l}\text { Número de niños de } 5 \text { años o menos en } \\
\text { hogares de mujeres }\end{array}$} & 0,53 & 0,60 & 0,50 & 0,36 \\
\hline & $(0,53)$ & $(0,83)$ & $(0,75)$ & $(0,63)$ \\
\hline \multirow{2}{*}{$\begin{array}{l}\text { Años de educación de hombres en la } \\
\text { PET }\end{array}$} & 9,42 & 9,35 & 9,56 & 9,65 \\
\hline & $(4,19)$ & $(4,44)$ & $(4,10)$ & $(4,29)$ \\
\hline \multirow{2}{*}{ Años de educación de mujeres en la PET } & 9,83 & 9,98 & 9,76 & 9,79 \\
\hline & $(4,23)$ & $(4,61)$ & $(4,09)$ & $(4,31)$ \\
\hline \multirow{2}{*}{$\begin{array}{l}\text { Años de educación de hombres universi- } \\
\text { tarios en la PET }\end{array}$} & 16,53 & 16,75 & 16,49 & 17,00 \\
\hline & $(0,01)$ & $(0,01)$ & $(0,01)$ & $(0,00)$ \\
\hline \multirow{2}{*}{$\begin{array}{l}\text { Años de educación de mujeres universi- } \\
\text { tarias en la PET }\end{array}$} & 16,38 & 16,56 & 16,35 & 16,77 \\
\hline & $(0,01)$ & $(0,01)$ & $(0,00)$ & $(0,00)$ \\
\hline \multirow{2}{*}{$\begin{array}{l}\text { Años de educación de menores de } 26 \\
\text { años en la PET }\end{array}$} & 9,53 & 8,90 & 9,50 & 9,65 \\
\hline & $(3,21)$ & $(3,45)$ & $(3,16)$ & $(3,20)$ \\
\hline \multirow{2}{*}{$\begin{array}{l}\text { Años de experiencia para menores de } 26 \\
\text { años en la PET }\end{array}$} & 1,26 & 1,27 & 1,36 & 1,38 \\
\hline & $(3,35)$ & $(3,44)$ & $(3,39)$ & $(3,33)$ \\
\hline
\end{tabular}

Nota: Para las variables no dicótomas se muestra la desviación estándar en paréntesis.

Fuente: elaboración propia con datos del Departamento Administrativo Nacional de Estadística (DANE), Gran Encuesta Integrada de Hogares (GEIH). 